European Alternatives:

Daphne Büllesbach,

Marta Cillero,

Lukas Stolz (eds.)

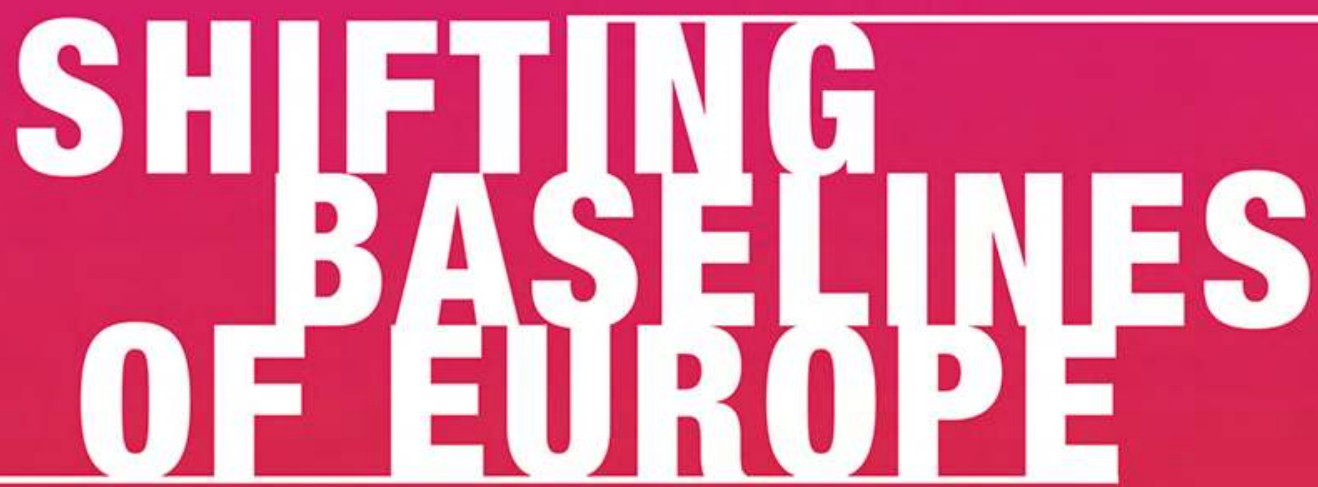

New Perspectives

beyond Neoliberalism

and Nationalism

[transcript] $x$ T E X T S 
European Alternatives: Daphne Büllesbach, Marta Cillero, Lukas Stolz (eds.) Shifting Baselines of Europe 


\section{T E X T S}

The supposed "end of history" long ago revealed itself to be much more an end to certainties. More than ever, we are not only faced with the question of "Generation X". Beyond this kind of popular figures, academia is also challenged to make a contribution to a sophisticated analysis of the time. The series X-TEXTS takes on this task, and provides a forum for thinking 'for and against time'. The essays gathered together here decipher our present moment, resisting simplifying formulas and oracles. They combine sensitive observations with incisive analysis, presenting both in a conveniently, readable form. 
European Alternatives:

Daphne Büllesbach, Marta Cillero, Lukas Stolz (eds.)

\section{Shifting Baselines of Europe}

New Perspectives beyond Neoliberalism and Nationalism

[transcript $]$ 
www.euroalter.com

European Alternatives works to promote democracy, equality and culture beyond the nation state
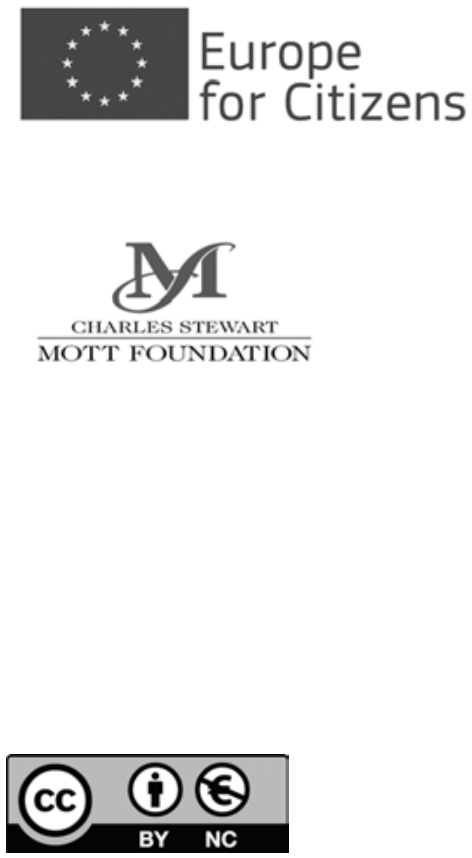

This work is licensed under

the Creative Commons Attribution-Non Commercial 3.0 (BY-NC) license,

which means that the text may be may be remixed, build upon and be distributed, provided credit is given to the author, but may not be used for commercial purposes. For details go to: http://creativecommons.org/licenses/by-nc/3.o/.

\section{Bibliographic information published by the Deutsche Nationalbibliothek}

The Deutsche Nationalbibliothek lists this publication in the Deutsche Nationalbibliografie; detailed bibliographic data are available in the Internet at http://dnb.d-nb.de

\section{() 2017 transcript Verlag, Bielefeld}

Cover layout: Kordula Röckenhaus, Bielefeld

Typeset by Mark-Sebastian Schneider, Bielefeld

Printed by Majuskel Medienproduktion $\mathrm{GmbH}$, Wetzlar

Print-ISBN 978-3-8376-3954-4

PDF-ISBN 978-3-8394-3954-8 


\section{Contents}

Note from the editors $\mid 9$

\section{INTRODUCTION}

\section{Shifting the baselines}

Daphne Büllesbach | 15

\section{Our European incapacity}

Etienne Balibar | 18

\section{Our European capacity}

Which Europe do we want? Rediscovering Hannah Arendt's concept of integral federalism

Ulrike Guérot | 26

\section{Shifting Cities}

Introduction | 35

The magnet and the container

A transnational space of expression for "Cities of change" through Europe

Giuseppe Caccia $\mid 37$ 
The cities want them in

For a revised common European refugee policy

to revive the European Union

Gesine Schwan $\mid 4^{2}$

\section{Rebel cities are not utopia}

Interview with Luigi de Magistris, Mayor of Naples | 45

\section{Institutions mean inertia}

Interview with Laia Forné, Barcelona en Comú| 49

\section{Moment of confluence on the Atlantic coast}

Interview with Claudia Delso, Marea Atlántica | 57

\section{This is how you win an election}

Stacco Troncoso in conversation with Victoria Anderica, head of

Transparency, and Miguel Arana, director of Citizen Participation,

City of Madrid | 62

\section{Forerunners of Italian municipalism}

Interview with Renato Accorinti, Mayor of Messina 170

\section{Don't let them d(r)own}

Interview with Dobrica Veselnovic and Ksenija Radovanović,

Ne da(vi)mo Beograd $\mid 74$

\section{Cities rejecting surveillance}

Renata Avila $\mid 78$

\section{Shifting Media}

Introduction | 85

\section{The populist Challenge $\mathbf{2 . 0}$}

How populism profits from social media Jan Rohgalf $\mid 87$ 
Contesting the shrinking media space in Slovakia

Alena Krempaska and Peter Weisenbacher | 97

Fluid media landscapes

Adam Ramsay | 101

Networked protest for a populist age

Jakub Dymek | 105

Journalism in spite of everything

Interview with Esther Alonso, eldiario.es | 109

We are the newcomers

Interview with Ramy Al-Asheq, Abwab | 113

Our digitally mediated society

Robin Mansell| 119

\section{Shifting Alliances}

Introduction | 131

A rigged economy in a rigged democracy

Lorenzo Marsili | 133

Breaking with the rules that ruin the Union

Lorenzo Marsili in conversation with Barbara Spinelli| 141

Social networks of influence in Europe - and beyond

Dieter Plehwe 147

Learning from Syriza

Andreas Karitzis | 158

The commons as unifying political vision

Sophie Bloemen | 167 
Instructions for building a pan-European movement

Interview with Pia Eberhardt, Corporate Europe Observatory $\mid 174$

Together means Razem

Interview with Marcelina Zawisza and Maciej Konieczny, Razem | 180

The birth of a new civic platform in Romania

Interview with Oana Băluță and Camil Pârvu, Demos $\mid 185$

The Rojava Revolution and the model of democracy without a state Sheruan Hassan and Jonas Staal $\mid 189$

Works by Democratic Self-Administration of Rojava and Studio Jonas Staal

New World Summit Rojava (2015-2017) | 193

A revolution of life

Jonas Staal in conversation with Salih Muslim | 200

\section{Annex}

List of organisations in order of appearance | 207

List of contributors $\mid 210$ 


\section{Note from the editors}

Since we started work on this book, a political earthquake has shaken the world. Coming from the other side of the Atlantic Ocean, the shockwaves have reached Europe as well. However we judge these events, they make the title of this book seem even more up-to-date than in the late summer of 2016 , when the idea to this publication first came up in the aftermath of European Alternatives' Campus "Shifting Baselines" ${ }^{1}$. Having gathered 80 activists, researchers and artists from across the continent to develop strategies for an open and democratic Europe, we felt something essential to any political undertaking: optimism. By meeting other engaged citizens from within and outside Europe and getting to know projects from Poland to Portugal, we could see that there are alternatives already changing Europe. Struck by the remarkable and resourceful strength of the actors and thinkers of our network, we wanted to make these ideas accessible to a wider audience. We hope this book can amplify the optimism we felt when we met them.

In our effort to shift Europe in a direction that we can define as forward, radically democratic, commons-based and catering to the needs

1 | The concept of shifting baselines has originally been developed in climate change research and later also adopted into social sciences analysis by the social psychologist Harald Welzer. The reference point is Daniel Pauly's study: Anecdotes and the shifting baseline syndrome of fisheries in Trends in Ecology and Evolution 10 (1995) about attitudes to climate change by fishermen. Pauly explains how humans tend to be unimpressed by environmental changes because they do not perceive long-term changes in their entirety but only in relation to conditions they themselves have witnessed. In his study some fishermen fail to identify the 'baseline' population size of fish in the ocean and hence operate from a shifted baseline. 
of all, we gave this book the title and the structure of the Campus (Cities, Media, Alliances) because we see in these thematics a strong need and potential for political leverage.

The phenomenon of shifting baselines means that the fundamental norms by which we judge what is acceptable are changing. ${ }^{2}$ They do so in a paradoxical way: on the one hand there is a lot of noise about the 'populist age', on the other hand, when it comes to the treatment of people fleeing war, to social security and solidarity, to what a good economic model is, what democracy and privacy mean, the shift is happening often gradually and going unnoticed. And in each of these areas there has been a shift, too often to the right, too often a race to the bottom. It would be fatal though, and also an incomplete analysis, to leave the picture like that. In the shadow of the big headlines, all over the continent, it is European citizens that every day keep the idea for a Europe for all alive through practicing it.

By taking already existing alternatives into consideration and combining them with contributions of distinguished and well-known authors, we try to present a positive and pragmatic transnational left position. The ideas here are largely born out of the practice and experience of activists from throughout the continent. We also think that policy recommendations can and should be drawn from the thoughts and projects presented here, against the general fatalism and political depression. This book shows that we do have alternatives and aims to reach not only researchers, activists and students already participating in politics, but also those that feel uncomfortable with the status quo but are not yet aware of the alternatives already under development. We want to open the often narrow discourse on the future of Europe and criticise the false dichotomy between nationalism on the one hand and a neoliberal version of Europe on the other. We still believe in a third option: A Europe made by and for its citizens. After all, "Shifting Baselines" leaves open in which direction the shift will happen.

2 | Also the concept of the 'Overton Window' could be evoked here as a helpful concept that refers to a framework of what ideas are seen as acceptable, in this case in a public policy context. See Nathan J. Russel (2006): An Introduction to the Overton Window of Political Possibilities, published at https://www.mackinac. org/7504. 


\section{Acknowledgments}

We would like to express our gratitude to Alison Waldie and Sally Hole for their editing work. For their support, we thank everyone in the team of European Alternatives. For their inspiration and initiatives, we thank all European Alternatives members, activists and the participants of the Campus of European Alternatives 2016. And of course a special thanks to the contributors of this book.

\section{Notes before reading}

We decided to use essays and interviews for the content of this book. The team of editors formulated the questions for a number of interviews, while others were carried out by external contributors. External interviews are presented as conversations between two or more people, whose names are indicated at the start of the article. There are some pieces that have been published before in other outlets and for different purposes. The reader can find a note at the beginning of these texts acknowledging this.

Daphne Büllesbach, Marta Cillero, Lukas Stolz 

Introduction 



\title{
Shifting the baselines
}

\author{
Daphne Büllesbach
}

If you know European Alternatives, you will know what is important to us is to engage and inspire people to act. Having launched just over ten years ago, our aim has been, from the start, to contribute to the writing of the next chapter of European integration. A chapter that looks significantly different to the status quo and that can only be written by all those citizens who feel trapped in the neoliberal dogma of today's European Union and whose voices too often go unheard. Our politics are based on the fact that it has become impossible to do progressive politics in only one country or only on a national basis, hence our motto of democracy, equality and culture beyond the nation state. We need a transnationally engaged civil society that understands itself as such and acts as such in itself and for itself. The wind is blowing ever stronger for those that do not want to give up the European project and retreat to nationalism, protectionism, walls and fences. But if we are unable to make a hegemonic shift in the direction of a progressive internationalism, we are not talking about the end of free movement, but the end of the European project itself.

We need to act now against the rise of authoritarianism in the guise of right wing populists. We need to act against the nationalism that threatens to destroy what we, the generations that have grown up with the fall of the Berlin wall, have taken for granted: freedom of movement for all people and, indeed, not only of us privileged European passport holders. And yet again, mere opposition is not enough, we cannot only engage in a politics of defense that is incapable of articulating something new, incapable of articulating the world we want to see.

For effective cooperation and transnational movement building, there is a need for better analysis and background on the context and realities in which actors operate. These are still very different across Europe and 
across political fields, and often rooted in national or regional contexts. But while we also do have transnational spaces and many live transnational lives, little do we yet challenge power effectively on a transnational level (of those that do, we show examples in this book, including the anti-TTIP campaign).

Electoral democracy is in a state of disrepair. Centre-left political parties have been hollowed out, social democracy has completed the shift towards market fundamentalism, leaving a potential vacuum. The banking crisis has brought no consequences and no government has stood up against the financial corporations. Movements for a fairer society and fairer economy flourish briefly, such as Occupy, Nuit Debout or the Refugees Welcome movement, that existed in the summer of 2015 across Europe. They shoot to international attention and capture people's imagination, yet little seems left of them a few months after ${ }^{1}$. There is an increasing realisation that we need to shelve the pure horizontality of the movements of the squares as it fails to effectively challenge the centres of power.

It is often the city, the space of social and cultural condensation, that provides the breeding ground for new ideas and formations, where many of these movements have started from. In Spain we have seen major cities being taken over by platforms emerging from the square occupations. Putting the citizen back into politics was the recipe to their success: what answers to the crisis of representation can we take from there? After just two years in power the civic platform government of Madrid has interesting perspectives to give on the question of whether their victory and the seizure of the institution has led to a politicisation of public life and whether they are able to go beyond the symbolism of that victory. This debate opens up the old question of whether the left should seize power or whether an institutionalised left is only busy negotiating the notorious contradictions between the 'inside' and the 'outside' of government.

As the proclamation of the 'post-factual era' has made us aware again, the power of emotions and the need for inspiration are key to counteracting the rise of nationalism and the narrative of austerity and neoliberalism.

1 Meanwhile it is arguable that without Occupy, we might not have had Bernie Sanders or without the Refugees Welcome movement, we might not have had Merkel's welcome policy. 
This book contributes to offering a vision and feeling of how alternatives could look like by creating visibility for such initiatives and narratives: from the municipal level to the level of transnational media, to how we work with technology and counter-surveillance, to a concrete proposal to revive the European refugee policy and the fundamental change of making society provided by the commons movement. Our motivation is to give people the desire to engage politically for an open, equal and democratic society.

The book is divided into three chapters that are each introduced in more depth separately. The following two texts are part of the introduction of this book as they set the tone, allowing us to understand the urgency in which we find ourselves in: a contribution by Etienne Balibar from 2011 and an answer today by Ulrike Guérot. They tackle the fundamental crisis underlying the European integration process, the missed opportunity to become a Union of Citizens by giving up on national sovereignty. Guérot suggests the path shown by Hannah Arendt's concept of integrated federalism could save the Union from disappearing into petty nationalisms. The mayor of Barcelona, Ada Colau, put it differently recently when she evoked the shifting baselines we are talking about here: "People call me a radical, but what is radical? We are living in strange times when defending democracy and human rights has become radical." It is up to us to not let this be the narrative of our time and define ourselves what is radical today. 


\title{
Our European incapacity
}

\author{
Etienne Balibar
}

To write about xenophobia in contemporary Europe - and especially to try and uncover the enigmatic path that would take us from the desolate shores of an 'intolerant Europe', whose tendencies appear increasingly self-destructive, to the more encouraging suggestions of a "new politics of hope" is not exactly an easy task in the current conjuncture.

This is not because we lack the necessary imagination or intellectual resolve, but because the more we think about it, the more we become aware that the path is intrinsically difficult to find: it could be effective only if we could bring together contradictory exigencies. This is more than utopian, since a 'utopia' is precisely what a 'politics of hope' is about and what it requires, in the sense of delineating the objectives and values, which "concerned citizens" are striving to promote. We may find this in the Open Letter to Europe of Ash Amin and his colleagues: "Living with Diversity" (which I completely endorse). This certainly does not prevent us from thinking about conditions, forces, material and cultural interests. The difficulty becomes infinitely greater, however, when we try and define a "politics of hope" in the very terms of the figures, tendencies, conflicts, movements of the situation that it should bring to an end. Because we are not even sure that we know or understand the realities that we want to transform, in spite of the fact that we are part of it. We rely on analogies, and these analogies are in fact highly problematic.

Let me take one example, which indeed I do not choose at random. Increasingly in Europe one hears it said (not only on the Left, or among intellectual militants) that the current situation is reminiscent of the great political and moral crisis of the 1930s. This is more than a way of adding pathos or dramatising the discourse: there must be an element

1 | This article was first published in openDemocracy on 16th May 2011. 
of intelligibility, or at least a question impossible to ignore in the fact that a major disruption of the financial and economic system, precipitating masses into joblessness and insecurity (albeit not equally across nations, even in the European space), is accompanied by the increasing disrepute of political institutions throughout Europe, and a growing influence of xenophobic ideas, feelings, and parties. Respectable political analysts argue for the heuristic function of this analogy, and they also, obviously, mean it as a serious warning not to underestimate the tragic evolution that would become possible if the genuine causes and dimensions of these phenomena (and their conjunction) were not taken into account. I agree, especially because I am alarmed by the naiveté of such mantras as "history does not repeat itself" or "Europe has learnt the lessons of its tragic past" (witness the construction of the European Union ...).

But I fear that the counterpart of this clarification is a blind spot covering the most enigmatic and embarrassing dimension of this political riddle, namely the contradictory reference both at the national and the transnational (or 'global') level, to democracy in a 'Europe' whose name now comprehends a totally different type of society.

Similar remarks apply to the use of the category 'populism', probably today the most widely invoked (both from inside and outside the nation) to name the xenophobic movements (most of the time strongly opposed to the "European supranational monster", and also islamophobic or hostile to minorities) which - one country after another: East and West, South and North, gain visibility and credibility on the public stage, while encouraging violent attitudes towards 'outsiders'. I hasten to add that I do not reject the term as such, especially because I am reminded of its long and ambivalent history as a political category inside and outside Europe, which it is especially worth studying in this moment.

Again, 'serious' political science seems at odds here with a contradiction impossible to resolve - possibly because it is itself part of the institutional system whose validity and durability is in fact challenged under the name 'populism'. We are asked not to draw a simple line of equivalence between such 'populism' and 'fascism' or 'neo-fascism' (in spite of the traditions and the men or women who transmitted a language, a culture, even an agenda from one to the other in some European countries). But we are also alerted to the fact that 'populism' (especially when adopted as a self-definition by political parties) is clearly a euphemistic name for racism, especially that kind of racism (by no means entirely new) that 
targets cultural difference and national origin as 'inassimilable' by the 'national community': was not this discourse precisely the main defining characteristic of fascism, which provided its discourse, its culture, in the end its mode of government with the 'interior enemy' against which it claimed to defend the nation?

In a mirror image, there is a divergence between those theorists and analysts for whom a 'populist' movement is essentially 'reactionary', in the etymological sense, inasmuch as it expresses frustrations and anger against the transformations of contemporary societies and against the new 'elites' who have appropriated positions of power; and those theorists for whom it brings back (even in a mystified, or destructive way) an element of popular contestation of power, and resistance to the 'de-democratisation' of neo-liberal 'democracies', a voice of the voiceless without which politics becomes reduced to the technocratic 'governance' of social tensions which are deemed both inevitable and inessential (since they do not involve historical alternatives).

But even the first theorists are led to explain that it would be selfdefeating for liberal democracies to ignore the element of truth and legitimacy involved in the 'populist' attacks against the corruption and the unlimited greed of the political-economic elites, or the mystification of the political life which resides in the fact that 'left' and 'right' governments basically implement the same policies. And the second are embarrassed to explain why a 'popular' reaction against the progressive neutralisation of every conflict with a meaningful social or cultural content, which has become the golden rule of 'governmentality' penetrating the (anti) political culture of the ruling elites in our countries, should coincide with an obsession with the decomposition of the national tissue, or the 'loss' of the cultural heritage of the nationals involved. Unless you implicitly admit a 'Schmittian' notion of political conflictuality as inextricable from the absolute primacy of the nation-State. Or also, even more problematically, you admit that the 'popular classes' are by their very nature, their social condition, etc., more inclined to enter into the conspiracy theories of the political, in which 'elites' and 'rulers' essentially aim to import outsiders, migrant workers, asylum seekers, and more generally foreigners, in order, first to provoke xenophobic and racist feelings in the masses, and second to exploit them as an instrument to undermine every revolutionary, or even progressive agenda ... 
I do not believe that we can easily disentangle the political dilemmas involved in these oscillations (and I especially do not want to 'resolve' them by resorting to some pre-established 'class analysis'). But I would like to offer some complementary hypotheses to start reflecting on the specific set of contradictions that seem to crystallise in the current crisis, even extending the complexity of its antitheses into the political projects through which we hope to overcome it. They are expressed both in terms which pointedly refer to Europe and at the same time to the obstacles to European construction. This is not meant to suggest that further steps in that construction - changing nothing in its dominant representation would form a solution per se (on the contrary, I tend to believe that Europe, as it stands, has become 'part of the problem'). It is also not a way to suggest that similar questions are not raised in other parts of the world (on the contrary I believe that these contradictions express global tendencies, but at the same time cannot be separated from specific historical and institutional conditions). So what I want to suggest is that we should do more to analyse 'xenophobia in Europe' as a European problem in the strongest sense: one that Europe creates, but also one that only Europe can resolve - perhaps at the cost (and the risk) of recreating itself on different bases. In this regard we already see a difference within the analogy with the situation of the 1930s (and the rise of fascism), and with other 'populist moments' in world-history.

My first hypothesis will be, simply, that there is again a 'national question' in Europe today, which has been completely underestimated, if not repressed, in the debates on the conditions, the modalities and effects of European construction; whereas in fact understanding it and joining together to address it should have been a primary concern for the 'architects' of Europe. Some of the main causes of this suppression clearly lie in the fact that the ruling classes of the European nations (and especially the 'leading' nations) believed in the irresistible power of economic integration to 'homogenise' (on individualistic and consumerist bases) the societies which Europe was bringing into its common territory 'without internal borders', while at the same time fiercely resisting every idea to build channels of communication and processes of mutual recognition (through education, but also social struggles and political campaigns) which would allow the peoples to confront their histories and merge their interests. For this would also have challenged the monopoly of representation of these 
ruling classes, both internally and at the supranational level (and thus their remaining the inevitable intercessors of 'their' peoples with regard to the European institutions).

In a sense this is exactly what 'populism' says: that Europe creates a problem for the nations (or even "destroys" them). Except that we must see the situation from an entirely opposite point of view: Europe reveals the incapacity of the nations, in the current historical moment, to resolve their problems (be they cultural or economic) in a 'sovereign' manner, while depriving them of every substantial possibility to resolve them at a different, common or interactive, level - thus becoming themselves 'postnations', or, better still, 'post-sovereign nations', which is not at all the same thing as no nations, or radically de-nationalised societies. In other terms, Europe has not really conceived (in spite of many lengthy and beautiful discourses) and even less constructed its own pluralism or "diversity", a failure, which has produced a completely 'fetishised' representation of collective identities, enclosing them in the stereotypes of 'invented traditions'.

It would be necessary here, of course, to go into some details about the crucial moments of this history of missed encounters and opportunities, by insisting particularly on the dramas of decolonisation (which totally displaced the reality and the image of the "stranger" in Europe), and the fall of the Cold War division (which was perceived on one side as an opportunity to resurrect historic nations crushed by totalitarian socialism, and on the other side as either the opening of a new empire, or a threat of new competitors). But I want simply to jump to a possible conclusion: xenophobias in Europe are multiple, never reducible to a single pattern (and never acting anywhere in exactly the same manner), but they completely over determine each other (and perhaps with this "crisis" we have reached precisely the moment when this overdetermination generates cumulative effects). By which I mean in particular that feelings of hatred towards the 'common Other' like islamophobia (and a fortiori the fear of "migrants") do nothing to unite Europeans, contrary to the fantasies à la Huntington of the advocates of "Christian Europe" (or, conversely, "secular Europe"): but they add to the distrust between Europeans themselves, or sometimes they displace it and express it in the manner of a Freudian symptom. There is an element of "hope" here: it means that to work against this hostility among Europeans (rarely admitted, but running very deep) is also to create some of the conditions for hospitality with respect to the non-European stranger 
(supposing that there is a fixed boundary between the "European" and the "non-European", which is not the case, not even juridical). Different types of "multiculturalism" are mutually interdependent.

My second hypothesis is a continuation of the first, taking into account a crucial element concerning the function of the state (and the nationstates) in the construction of the relationship of 'affiliation' between individuals and nations in the European framework, and the 'material constitution' which allows the 'citizens' of the same nation-state to mediate their conflicts of interest, particularly their economic interests - which is certainly not the same thing as reaching a consensus on the same values, sharing the same ideology, or thinking unanimously. In a sense it is just the opposite, which is the reason why, for several decades, politics has not been abolished by the development of social policies, but has remained active as its permanent condition of possibility.

Contrary to their own myth 'nations' are not eternal substances or entities, which subsist by inertia. They are fragile constructions, which must be permanently recreated through the achievement of institutional equilibria, therefore the setting of new relations of forces between their 'classes', or 'organic parties'. And they are also periodically threatened with losing this condition of possibility, either from inside or from outside, through wars and civil wars in the broadest sense. Now my hypothesis would be the following: inasmuch as European construction has essentially become an instrument of neo-liberal globalisation, in which financial imperatives of short-term profitability have the upper hand, and as a consequence, increasingly using its own framework as a field of competition among territories and populations - the State has shifted from a protective function to a function of destruction of its own civil society: not in the 'totalitarian' form, but in the 'utilitarian' form, which is hardly less violent. I am tempted to call this in Derridian terms a shift to "auto-immunity2". Pushed to an extreme, this would mean that the State increasingly works within society not as a set of institutions representing and mediating (even in a coercive or inegalitarian manner) communications and processes of recognition among citizens, but as a 'foreign body' which destroys the social bonds that it is supposed to protect - something which at a fantastic level at least must not be without

2 | "The Uses of Philosophy" July 8, 2003 (http://www.villagevoice.com/200307-08/books/the-uses-of-philosophy/) 
its relationship to the obsession with an invasion by 'foreign bodies' that riddles the current ideologies of the nation.

The state function of protection is indeed never an absolute guarantee. Furthermore it is never without its coercive, normative, and exclusionary aspects, since it is performed by what, in other places, I have called a national-social state, where 'social citizenship' and 'social rights' are collectively conquered, but also bureaucratically administered and riddled with all sorts of discrimination. But still, there is a dramatic contrast between such a bureaucratic administration of citizenship and a situation in which - while still pretending to be the protector of its citizens in the old sense that legitimised its sovereignty, but also claiming that this protection is transferred to the European Union itself, or to even more global and transnational instances of 'governance' - the nation state works to privatise public services, or subject them to the rules of management and accountability which hold for capitalist corporations, or actively contributes to dismantling the educational system by imposing market imperatives on learning and transferring the cultural missions of schools and colleges to massively commercialised television networks - a process which again cannot be entirely divorced from the development of populism and xenophobia, since the cultivation of ethnic stereotypes is a central orientation of these networks, together with the injection of standardised products of commercial entertainment.

I am aware that this description, if it is one, is in itself extremely brutal. The reality is one of conflicts between opposite tendencies unequally developed in different countries, but with an increasing disadvantage for the institutions of solidarity facing the forces of utilitarianism, which can count on the double support of the market and the state, or become pushed toward privatisation from within the public sphere itself. There is an extremely perverse game at work here, for which Europe appears as a justification and an objective, which, for many Europeans, seems to leave them with only one choice: either call for the suppression or the exclusion of every foreigner, every 'body' that is 'foreign' or alien, or different, in order to compensate imaginarily for the cruelty of the protector, or idealise the protector's function in the hope of exclusively benefiting from the inclusiveness of its restored services.

This "hope", it seems to me, is indeed a despair. I would therefore agree that we need a politics of hope, in a more authentic, less self-destructive sense - based on a conjunction of forces within and across borders. But 
such a politics must construct its forces, its goals, its language, entirely anew - taking as a negative criterion the reality of the contradictions which are revealed by the coexistence of an antidemocratic Europe, and an antiEuropean exploitation of fears and frustrations, which are largely two sides of the same culture. It must therefore reconstruct Europe as a federation of original and diverse nations, leaving aside the myth of their Statesovereignty, but mutually enhancing their power to create and collaborate. I say "it", in an impersonal manner: but this is our responsibility, before it becomes "hopefully" our capacity. 


\title{
Our European capacity
}

\author{
Which Europe do we want? Rediscovering Hannah Arendt's \\ concept of integral federalism
}

\section{Ulrike Guérot ${ }^{1}$}

In Our European incapacity, written already in 2011, Etienne Balibar lucidly describes why Europe did not become the democratic and social Europe aspired to in the Treaty of Maastricht - which envisioned a Union of Citizens based on coherence and economic convergence - but rather became technocratic and dominated by sovereign nation states that are not delivering good policies for many European citizens. A fact that is now triggering a wave of populist movements all across the Union, to the embarrassment of national elites.

Balibar offers as explanation that, as much as national elites were willing to Europeanise the market and currency, they were unwilling to do the same in the political arena, as it would have undermined their own power basis in the nation state. As such they administered their national democracies through largely neutralised grand coalition schemes lacking political contours, leading to a perfect erosion of state functions on the national level. It basically suited them to cling to fictive national power while accepting economic governance on the European level,

"Fiercely resisting every idea to build channels of communication and processes of mutual recognition (through education, but also social struggles and political campaigns) which would allow the peoples to confront their histories and merge their interests. For this would also have challenged the monopoly of representation of these ruling classes, both internally and at the supranational level and thus

1 | Guérot's response to Balibar's text was written in November 2016. 
their remaining the inevitable intercessors of 'their' peoples with regard to the European institutions." (Balibar 2011)

In other words: the famous, transnational 'politicisation' of European citizens, where the arbitrage of political decision-making could have been organised beyond national state sovereignty, never took place.

With the European Council becoming ever more important in decision-making in recent years, the primacy of the nation-state in a Schmittian notion of political conflictuality was kept within the EU's institutional structures, to the detriment of European citizens who could have benefitted from transnational European policy solutions, for example a European unemployment scheme. As Pierre Rosanvallon puts it, the EU was built on a lie and the lie is that the EU is equally a union of states and a union of citizens, as promised in the Treaty of Maastricht. The union of citizens does not exist. Actually, quite the opposite; European citizens are often the hostages of European Council decisions, opposition to which is not possible.

Should there be astonishment or embarrassment about a popular reaction to this violence of democracy at the national level, while not reconstituting it on the European level? Rather not. In the absence of any meaningful political content, policies were said to be without an alternative - which is the opposite of the political itself. The problem is not anti-elitism, but the fact that European populism is framed as a national movement.

Today's setting of anti-elitist movements across the union arguing against the national and European political class is the consequence of the fact that one market and one currency have never been turned into one democracy. Before digging further into today's populist problem in Europe, it should be reminded that anti-elitism is a priori a good thing, and by no means 'populist' per se.

Being against the establishment was also the main feature of the 68ers, hardly a right wing movement. One of their most extravagant slogans was "Who sleeps twice with the same person, belongs to the establishment". If any criticism of the system is called populism and shut down, democracies end up change resistant and lose the very capacity of a democratic system - in contra-point to authoritarian systems - which is precisely to integrate legitimate critics and to make things better. This is exactly what happened 
to the EU, which, falling short of the capacity for reform ended up with a monolithic inertia, triggering popular protest.

The anti-establishment claim thus does not yet make the right-wingers 'populists'. The problem is the anti-pluralistic spin, with fragmented groups pretending to represent the people, for example the German Pegida militants who shout "We are the people." Yet, who is the We? The German nation that they represent?

In fact, populism rather splits nations than uniting them. Brexit is the best example. If Theresa May has one problem today, it is to find the unity of the British nation. Whereas the very idea of Brexit was to defend the British identity against the European continent, the country is today deeply divided from Scotland to youth, to the City and the North of England, to Wales and Northern Ireland. The re-nationalisation discourse only distorts or hides a struggle about economic concepts, upon which the losers and winners of globalisation have different preferences - and needs. De facto, regional conflict about appropriate national economic policies is today's substitute for the former class conflict. In other words: what suits the City of London economically is not necessarily good for the deindustrialised regions in Northern England. Austria and France will be next to experience the way populism splits the nations it pretends to unitethe discourse of national pride only hides a conflict between citizens. Even more: with populism breaking up nations, the long-expected politicisation of Europe, which the 'United States of Europe' could never produce, is finally happening.

What we are really experiencing is not the renationalisation of Europe as most of the national press tries to make us believe. What is really shaping at the horizon is the latency of a European civil war between the protagonists of an agenda of opening and those defending an agenda of closing and this civil war is transnational on both sides. It is a fight among European civil society - progressives and conservatives, if not reactionary forces - about the future European social and political contract and the values underpinning it. On the one hand, there is a liberal to progressive civil society across Europe standing in the tradition of European humanism and the heritage of the French revolution; liberty, equality and solidarity. On the other side, there is naturalism, if not proto-fascist communitarian thinking based on ethnic grouping, scarifying liberal society in favour of a closed community. 
The European identitarian movement recently organised a huge conference in Linz, Austria, under the title "Defending Europe", gathering people from FIDES, UKIP, AfD, FPÖ and the Front National. In a way, we are experiencing the cosmopolitism of identitarian movements as contradictio in adjecto. One could even argue that the populists are the real Europeans, as they, for the time being, do a better job of organising transnationally than the scattered left or liberal parties on the European continent. The irony of history might produce the first truly transnational party formation by today's European right-wingers, realising what the socialist international failed to achieve a hundred years ago.

The expression of European civil war comes from the Austrian painter Franz Marc, who coined it in the midst of World War I to describe the struggle between the European spirit, as he called it, in defence of European humanisms and the cultural heritage of the French revolution on the one hand; and the Ungeist, leading to renationalisation, militarisation and finally fascism. Yet, the fight is not between countries, that is the point. Neither is it a fight between countries today.

"We must therefore reconstruct Europe as a federation of original and diverse nations, leaving aside the myth of their State-sovereignty, but mutually enhancing their power to create and collaborate." (Balibar, 2011)

This comes very close to what Hannah Arendt describes as 'integral federalism' in her political grammar of founding. Putting aside the myth of state sovereignty could indeed pave the way for the next European project, a project beyond nation states - as the founding fathers of the EU also aspired. "Nous ne coalisons pas des Etats, mais nous unissons des hommes", wrote Jean Monnet, as his vision of a radically de-nationalised European society. The shift from a Union of States to a Union of Citizens would go beyond the classical concepts of statehood-ness and sovereignty as brought to us by Hobbes or Rousseau. Hannah Arendt is in search of the hidden tradition of freedom, in favour of spontaneous forms of political organisation, among citizens, or towns or small entities, which form republican bodies.

Doing so, Arendt clearly distinguishes between sovereignty and freedom, because sovereignty contradicts the principle of plurality, if sovereignty is the absolute right of self-determination and the right of non-interference. Yet, nobody is sovereign, as (wo)man is not alone on 
earth. Sovereignty is only a (weak) concept to deal with plurality, all too often through arbitrary rules placed over others. Freedom, however, is the existence of plurality and intersubjectivity.

"The famous sovereignty of political bodies has always been an illusion, which, moreover, can be maintained only by the instrument of violence, that is, with essentially nonpolitical means ... If men wish to be free, it is precisely sovereignty they must renounce." (Arendt 2006: 163)

State sovereignty is a reductive concept; Hannah Arendt thinks about the organisation of political power without (state) sovereignty.

This is how she designs her concept of integral federalism, in line with the writing and thinking of Denis de Rougement, Franz Marc or even Albert Camus, who in the 5os, at the moment when the last European projects was taking shape in the form of the Rome treaty, advocated strongly against a state based, intergovernmental federalism, which ended up, as Hannah Arendt predicted, in the hollowing out of European democracy. What Jürgen Habermas has called "executive federalism", leading to the usurpation of people's freedom by nation states.

The notion of the nation state always mixes fatherland, state, nation and language. Yet, a federal structure, writes Denis de Rougement (de Rougement 1994: 223) cannot be based on one political feature - the nation state - alone, as the nation state amalgamates at least four different layers: patriotism, ideology, administration and culture. History, geography, language, tradition or economy are not embedded in one nation state, but can only be federated though spaces of citizen participation, through small communities, which do not request absolute sovereignty.

The Europe that we want is thus more the one of Franz Marc, Hannah Arendt and Denis de Rougement, which is the concept of a social federalism of civil society, or integral federalism, rather than the one of De Gaulle, Adenauer, De Gasperi or Paul Henri Spaak, who finally did not dare to deconstruct the nation and ended up in a concept of intergovernmental federalism.

The Europe we want frees people from power structures embedded in a nation state; it brings together regions and towns in autonomous political decision-making procedures; it frees the notion of democracy from the notions of territory, state and people; and frees the concept of 
Europe from the idea of integrating states so as to unite people; providing real freedom to European citizens.

\section{Bibliography}

Arendt, H. (2006): What is freedom? In: Between Past and Future. Eight Exercises in Political Thought, New York, pp. 163.

Balibar, E. (2001): Our European Incapacity. In: OpenDemocracy 16 May 2011 (https://www.opendemocracy.net/etienne-balibar/our-europeanincapacity)

Rougement, D. de (1994): Rede auf dem Kongress der Union des Fédéralistes Européens. In: Ecrits sur l'Europe, Bd. 1, Paris, pp. 223. 

Shifting Cities 



\section{Introduction}

What would happen if the international institutions opened spaces and mechanisms where cities could play an effective role in decision-making processes? What would happen if we could implement methods for sharing best practices to solve major local problems that have a global impact? What are the structures, resources and projects behind the "shelter cities"? In an era where the global can only exist with a connected local, cities are mobilising and proving to be the space where democratic renewal is happening.

Europe is witnessing the evolution of innovative cities where the relation between active citizenship, social movements and local administration is leading to a new way of doing politics. Cities are showing that alternatives exist and can be implemented; cities are putting the commons in the centre of their policies, where activists are taking control of the administration and increasing political pressure on national governments and European institutions.

This chapter depicts those parts of Europe, which are developing new relationships and methods between citizens and the institutions. Experiences, dynamics and programmes that are searching for creative paths and methods to face the struggles that directly connect the local with the global, that directly affect the welfare of the citizens. A new political agenda for the cities, projects for welcoming migrants, tools for engaging citizens in public participatory life or inclusion of the commons in the policy making process - these are some of the key challenges that this chapter presents.

City-makers, commoners, urban social movements, mayors, councillors, and activists that are helping to create, promote and develop new urban experiences come together in this chapter. "Cities could be places of radical innovation in politics, spaces of actual reinvention of democracy", 
argues Giuseppe Caccia, scholar in History of Political thought, in his essay opening the chapter. Similarly, Gesine Schwan, Professor of Political Science, proposes to start from the cities, or more precisely those cities in Europe that are welcoming refugees as places for building bottom-up alternatives and presents a revised common European refugee policy. Following this, five interviews with the mayors of Messina and Naples and city councillors from Barcelona, Madrid and A Coruña, portray practical cases and experiences on municipalism, the commons, policies for refugees and citizen participation in the institutions at the local level. In contrast, the activist collective 'Don't let Belgrade d(r)own', is not holding institutional power. They offer ideas and practices of urban resistance and mobilisation against the corrupt city officials. The chapter closes with Renata Avila, human rights lawyer and digital advocate, making the case against pan-optic surveillance in urban planning and why basic human rights in the digital era need to be defended also at the city level. 


\title{
The magnet and the container
}

\author{
A transnational space of expression for "Cities of change" \\ through Europe
}

Giuseppe Caccia

Permanence and nomadism, settlement and flows, have always characterised the very nature of the city. With extraordinary effectiveness, to describe the role of urban areas in the Mediterranean of the 16th century, Fernand Braudel writes: "The cities, motionless points in the maps, are actually fed by movement." And you can retrieve this long durée, this historical continuity, in the deep changes that have marked the European cities in recent decades. In fact, since late Middle Ages, cities in Europe have played a crucial role as places of recovery in production, craft, artistic and cultural creation, as nodes of extensive trade networks, as spaces of individual and collective liberation from previous constraints of servitude. Urban development has, since then, accompanied historical progresses in our continent. And the cities were, at the same time, the stage and the main actor in any process of economic, cultural and societal transformation.

In recent decades, the end of Fordistic production model, the new forms of work organisation - diffuse, immaterial and reticular -, the increasing financialisation of the economy, have again profoundly altered the nature, role and functions of European cities. They appear, simultaneously, as the context of a restructuring, on a metropolitan scale, of social production and reproduction, as hubs of global networks of communication and exchange, subject to financial investments on real estate, infrastructure and resulting speculative revenue.

The combination of these processes has generated new contradictions, dramatic imbalances and growing inequalities. Problems that have been exacerbated by the crisis management of the last eight years and by the 
consequences of austerity policies, with cuts in money transfers to local budgets reducing the room for territorial self-government, and which have often run down the very fabric of urban social cohesion. But, at the same time, cities have been and are the scene of resistance and innovation, often in terms of spontaneous ruptures and eruptions: the place where social protests burst and mutual cooperation unfolds, where street mobilisations and processes of artistic and cultural creation and productive innovation emerge.

The European Commission itself has recently stressed the leading role of cities and metropolitan areas in the construction of Union's choices and the need for a stronger coordination and exchange between them. A few pieces of data illustrate the importance of the issue: more than 70 per cent of Europeans live in urban areas, so there are focused mobility, production, trade, economic and social relations. In metropolitan areas 75 per cent of all energy consumption and 80 per cent of all emissions is concentrated, placing urban contexts to the core of the contemporary climate and environmental crisis. But urban areas are also the place where innovative policies could produce significant results in sustainable development and an even more radical social and ecological transformation. Consistent European policies can therefore set goals and promote strategies that are also the result of verification and dissemination of innovative experiences already achieved in some areas.

Such considerations make it even more worth facing the crisis of consensus and legitimacy of the EU's supranational institutions, and the role crisis of nation-states, reduced to a mere executioner of decisions taken elsewhere, paradoxically just as we are seeing a "re-nationalisation" of political discourse (from the Eurozone crisis to the "refugee crisis" and the collapse of the Schengen space). Precisely in such a critical context, the cities - as it was in crucial moments of transition in European history can play again a leading role. Not only for the reasons already mentioned, could they be places of radical innovation in politics, spaces of actual reinvention of democracy. And in this way they could provide answers to the major challenges of our contemporary world.

A long "municipalist" tradition of thought and practice, oriented in this direction, is waiting to be rediscovered, from medieval towns to its recovery in the 1990 s. This tradition seems today to live again in the experiences of government "for change." Everybody knows the "Plataformas ciudadanas" 
- civic platforms born from the movements that filled the squares of the Iberian Peninsula from 15M in 2011 - who won elections in May 2015 in some of the most important cities in Spain, starting from the election of Ada Colau as mayor of Barcelona, Manuela Carmena in Madrid and others in Valencia, La Coruña, Zaragoza and many smaller towns. In this first year and half of government they have already introduced important innovations in local policies, in particular by investing in "citizens' protagonism" - full transparency of the administration and direct participation of citizens in government decisions.

They chose to assign more resources in new welfare policies, suitable to counter the advance of mass impoverishment generated by the crisis. They intervened in urban planning, initiating housing policies more favourable to low-income residents and starting to hit the speculative interests of banks and financial holding companies. They have set up programmes supporting a more fair and inclusive social economy, by changing the rules of local tenders and procurement and by developing cooperative platforms instead of extractivist ones. They are trying to "remunicipalise" essential local public services, such as water and energy supplies, and even funeral services, which had been privatised in recent years. They decided, even in contrast to national and European policies, to devote themselves to the welcome of refugees and migrants, offering city spaces and resources and creating the possibility of direct "humanitarian channels".

Certainly what is happening in the Iberian Peninsula is the spearhead, both from a symbolic and a material point of view, of a "new municipalism" trying to reinvent democratic practices from the local dimension. But it is equally true that the whole map of Europe is dotted with cases of already established or embryonic initiatives, which are testing new possible relationships between citizenship and local institutions, in search for creative answers to the challenges of urban development and coexistence. In this spirit, European Alternatives launched over the last year a first-mapping on a European scale of the "cities of change", i.e. those cases where the initiative from the bottom of active citizenship (that is movements, associations, independent social and cultural projects) meets with original experiences of local governments, highly oriented to innovation. The first results of this work are amazing. In the North as well as in the South. In the East as well as in the West. Here we can mention only a few examples: the cities of Birmingham and Bristol in the 
UK; the State of Thuringia in Germany; a Mediterranean metropolis like Naples and a city at the foot of the Alps like Grenoble; many municipal governments and two regional administrations, those of Attica and the Ionian Islands, in Greece; in Poland towns such as Wadowice and Slupsk. And these results were for the first time discussed and elaborated in the Campus of European Alternatives.

But we cannot stop at a simple, although necessary, photographic reconnaissance of existing initiatives. The experience of the last year has also highlighted the limits and contradictions of these alternative realities. The life of every country is crossed by economic and financial flows that are elusive to the communities' control and removed from local democratic decision-making. On the city-level the same relations between active citizenship and local governments often prove to be problematic. As well, legal and institutional constraints by higher levels of government: the nation-state and the European, severely limit the range of concrete action of even the most innovative municipal or regional administration.

To prevent these problems from translating into the impossibility of any real change, it became clear that two parallel paths need to be crossed and intertwined.

First of all, there is the need to organise a permanent exchange between these experiences as a mutual learning ground: the transfer of knowledge on single projects, or single civic participation models experienced by this or that city, can help to address and to resolve problems that emerge in another urban context and can help adapt and improve practices already in place.

Second, it is urgent - particularly in the current situation, where there is the risk of the "disintegration" of Europe - to construct and develop a transnational space of political expression among "cities for change". It could be a decisive actor in increasing the potential of intervention and pressure on national governments and European institutions to affirm a real protagonism of the communities and local governments in political decisions that affect them. And it could contribute - along with so many others initiatives for social equality, rights and democracy in Europe to the reversal of the current dominant power relationships and to the identification of truly alternative solutions.

Sharing the thought of Lewis Mumford on the city: "the magnet comes before the container." (Mumford 1968: p.9) The cities' destinies are the same as that of Europe, of which they are original and constitutive 
elements. And in these turbulent times we need, desperately and hopefully, the attractiveness and connectiveness of many different magnets, capable of being the propellers of change.

\section{BIBLIOGRAPHY}

Mumford, L. (1968), “The City in History: Its Origins, Its Transformations, and Its Prospects", Harcourt, Brace \& World, New York, p.9 


\title{
The cities want them in
}

\author{
For a revised common European refugee policy to revive \\ the European Union
}

\section{Gesine Schwan}

The European Union desperately needs a realistic, and human rightsoriented, border and migration policy. The present situation puts the EU in a dangerous position of dependency on the Turkish President Erdogan, presumes African countries to be safe when they clearly are not, and considers North African countries as possible migration-policy partners, when they are neither coherent States, nor safe or observing minimal human rights standards.

The general political objectives of (1) overcoming the causes of migration; (2) supporting countries close to migration origins in hosting refugees; and (3) realising the Europeanisation of the border regime, are all necessary steps. But alone, they are insufficient. The idea of "outsourcing" migration control to countries outside the EU is not realistic in the longrun. It also undermines the fundamental values of the EU. The EU's current border and migration policy, which implicitly and inevitably leads to a "Fortress" Europe scenario, is already undermining the openness of our society and, indeed, will create new internal borders.

The urgent need for a sustainable, value-oriented approach to migration - which in the long-run needs to be combined with a European immigration policy - has been aggravated by the inability of the EU to find a concrete solution for the integration of refugees in Europe as a whole. For many reasons, a top-down distribution is condemned to fail. Therefore, we need a bottom-up alternative, led by municipalities and cities that have an interest in voluntarily integrating refugees, for both humanitarian reasons and for their own gains. 
A number of cities and municipalities all over Europe have already declared their readiness to welcome refugees, including cities in Central Europe, be it for demographic or other reasons. What these cities need are financing options for the costs of integration and related issues. In order to stimulate as many hosts for refugees as possible, the financing should include a palpable "overhead" for the cities' own needs, in order to encourage broad social support in undertaking the long-lasting process of integration within the cities.

In the meantime, national governments, which at present are not finding a shared solution within the European Council, hold the legal decisionmaking power on immigration, and most of the political decision-making power on operationalising European financing. Cooperation between the State and the municipality level, therefore, needs to be strengthened and deepened. By demonstrating the possibilities for refugee integration, cities and municipalities can help their national governments fulfil their duties. This will have a positive impact on their mutual cooperation and communication.

Making available a European funding tool for integrating refugees, which cities and municipalities would be able to apply for, would realise three objectives at once: 1) Establish a humanitarian solution for the settlement of refugees in Europe; 2) Revive a European commitment by bottom-up citizen-led participation, and; 3) Instigate a decentralised sustainable growth initiative on a local level, to overcome unemployment.

There would, however, be certain obstacles to overcome, requiring the following steps:

Convincing national governments that this strategy is in their interest, allowing them to fulfil their legal and moral duties and to revive their economy; finding simple and uncomplicated ways for financing the integration costs for cities and municipalities. Their own contribution could be financed, for example, by a cheap European Investment Bank credit; and identifying ways to match the interests of refugees with welcoming municipalities in such a way that refugees are likely to stop and settle there.

The application of the municipalities should be as easy as possible, whilst of course including the following minimal standards:

- A multi-stakeholder governance model, in order to gain broad support within the cities. The application should be prepared by a range of 
stakeholders, including from the worlds of politics, business and organised civil society;

- An integration strategy for the whole municipality must be included;

- An anti-corruption strategy, and;

- A macroeconomic vision for creating jobs and sustainable growth.

In the long-term, the European Council would need to permit the creation of a trust fund attached to the European Investment Bank, governed in such a way as to control, but also to make it easier for cities to apply for the financing of refugees and of necessary infrastructure.

In the short-term, a pilot project could be launched by a group of European cities that aim to facilitate refugee integration according to this model, and for this reason would be looking to find financial support. This could be managed within the framework of a "Union Action", as an extraordinary measure. This would allow for the testing of the viability of this strategy, and mark the beginning of a visible European "revival", which would empower citizens and strengthen their identification with the European Union, thanks to participation and the sharing of common projects. This could mark a turning point and the deepening decentralisation of the EU, avoiding a tendency towards centralisation, as well as renationalisation. 


\title{
Rebel cities are not utopia
}

\author{
Interview with Luigi de Magistris, Mayor of Naples ${ }^{1}$
}

Behind any rebel city there is an active structure of social movements, civil organisations and active citizens claiming their rights to own their cities' future. These are cities that become the space of radical innovation and democratic regeneration. At a moment where European and national institutions are losing support from their citizens, rebel cities put citizens at the centre of the decision-making process. Local governments defend citizen participation in political institutions and work to protect and strengthen the commons.

These are cities like Barcelona, where the leader of the radical municipal anti-eviction platform won the city elections last year; or examples like Messina, the Sicilian city where for three years its mayor has been leading the city towards a more participatory and democratic political structure. Or Naples, in Southern Italy.

A few years ago, the Mayor of Naples, Luigi de Magistris, was told to fire 300 teachers to comply with strict austerity regulations imposed by the central government of Matteo Renzi. De Magistris, a former prosecutor, refused to comply and appealed to the constitutionally protected right to a quality education for all. He was sued and brought to court, where he argued and won his case. The Italian constitution, the judges concluded, has precedence over regular legislation. The teachers - and the mayor were reinstated to their places.

Today, after De Magistris was re-elected as mayor in 2016 with an overwhelming majority, Naples remains a city of great social participation and political innovation. Naples was the first Italian city to establish a "Department of the Commons" and the first to change the municipal

1 | This interview took place in December 2016. 
statute by inserting the commons as one of the interests to be protected and recognised as the functional exercise of fundamental rights of the person. It has joined the network of shelter cities welcoming refugees. And it is experimenting new forms of co-decision between citizens and institutions.

\section{$* * *$}

You were recently re-elected as Mayor of Naples, supported by civil society lists and social movements, and without any of the main political parties backing you. Some of the activists who protested in the streets against austerity and corruption are now city councillors with you. What is the relationship now between civil society and the institutions?

This is an absolute novelty in the institutional and political panorama: that between civil society, social movements and local institutions there exists a relation under construction, where each has to preserve its autonomy while building new relations and forms of participation. There are traditional channels such as the participation of representatives of social movements or occupations in the Council. But then there is also a new way of working together. For instance, discussing the proposals for new municipal laws together, in a process of co-deliberation of the regulations that govern the city. How does this happen? Through direct contacts, open meetings, popular assemblies in the neighbourhoods, observatories, and by keeping a direct relation with social centres and spaces of activism and active citizenship. An important project to demolish and replace the infamous "Le Vele", a social housing project dating back to the 1960 s, was co-designed by the City, the University and the autonomous neighbourhood committee. This is an open area of experimentation and more ideas and practices will come out in the coming months, including through the use of online technology. But beyond the social network revolution, we also want to be together in person.

Back in 2011, in a landmark referendum, 27 million Italians voted for water to be considered a "common good" and be returned to public ownership. Naples is the only one among the large cities to have followed up on this request, bringing back water management under municipal control and beginning to develop a participatory management for the company. How is the process going? 
We are very happy with this. Obviously, there are legal, technical and financial difficulties, but we have transformed a for-profit company into a public company that is now taking on board the full cycle of water management and has increased the number of employees. We have demonstrated that participatory management can also be an economically viable solution. Now we need to take more steps towards the participation of workers and citizens in the Board and management of the company. But we remain committed to the idea that water is a commons and we aim to continue remaining at the forefront for its participatory management at the European level.

Speaking of commons, Naples has a number of buildings occupied by citizens and social movements utilised for cultural, social, or solidarity initiatives. You have recently passed an innovative law identifying such spaces as social commons. Or, in other words, legitimising and legalising social occupations of unused public and private properties.

These are not occupied but liberated spaces. There are situations where, for whatever reason, public or private owners leave the buildings to decay, shutting them off from the population and creating empty zones in our cities. When groups of citizens take them over, clean them, repair them, open them up to the collective with social, sports, or cultural activities, these spaces are returned to the citizenry. They are a new commons and they should be treated as such. Not criminalised and evicted.

Could the model of the commons, with participatory public management be expanded at a national level with public companies?

Yes, the model needs to be extended to state-controlled companies. This is, after all, what the Article 41 of the Italian constitution demands, with the idea of civic uses. We have taken back this legal instrument. Our project is nothing more than the implementation of the republican constitution. And so the same needs to happen at the national level.

The photos of Neapolitan citizens holding "refugees welcome" signs in Naples went viral in Italy, especially as during the same days in other parts of the country demonstrations against refugees were taking place. What's different in Naples? What refugee policy are you putting in place? 
Naples is a refuge city and a city of shelter. We believe solidarity and welcome policies are the best antidote against terrorism and the best way of building bridges between cultures and guaranteeing peace. In Naples, we are either all illegals or no-one is illegal. This is the history of our city, but it is also our political vision. Naples is at the vanguard of a new "diplomacy from below" working for a Mediterranean of peace and not of wars - for instance we are increasingly working with North African cities. Let me tell you a story that engaged the whole citizenry of Naples. There was recently a large scale arrival of migrants from Libya. Naples is a city with a lot of suffering and great economic difficulties: but we have had a rush for solidarity from all citizens. They were offering not just food and clothing but also opening up their houses to host the migrants. On Christmas evening all those who arrived were hosted by and celebrated with Neapolitan families.

The question of migration is a good example of a possible new relationship between the municipal and the European dimensions. Ada Colau has given momentum to a network of European cities of shelter. Gesine Schwan, amongst others, is pushing for a direct connection between cities and the European refugee relocation scheme. Can we imagine a new European role for cities, also bypassing the nation state?

This is already a reality. I worked towards this aim when I was a member of the European Parliament in Brussels. As president of the Budget Committee I worked for a considerable share of EU funds to be directly assigned to cities. We need a Europe of cities, a Europe of the people, a Europe of justice and of economic equality. We need to push for Brussels to give a greater role to cities and territories, which is a precondition for a more prosperous and democratic future. There are interesting signs emerging not only from Naples but also from Barcelona, Berlin, many cities in Eastern Europe and even London. This is the Europe that opposes the Europe of Hollande, Renzi and Juncker, to the Europe of austerity and budget constraints, of walls and borders. This is what we are working for, from below. And Naples is on the front line. 


\title{
Institutions mean inertia
}

\author{
Interview with Laia Forné, Barcelona en Comú ${ }^{1}$
}

Barcelona en Comú has its origins in the social and political movements that emerged as a result of Spain's economic crisis and the protest movement known in Spain as the $15 \mathrm{M}$ movement. A citizen platform, Barcelona en Comú has been governing the City of Barcelona for almost two years after winning municipal elections by proposing a "democratic rebellion" and the "appropriation of the institutions". Laia Forné, Responsible for Active Democracy and Decentralisation in Barcelona, said in an article published by the Spanish journal Diagonal a few months after the elections that the municipality is formed not by the powers of a local government but by the social and communitarian powers that create a new institutionalism.

\section{$* * *$}

What challenges has the movement faced in becoming part of an institution? And in the specific case of Barcelona en Comú, what have you achieved, and what do you think the complex relationship between institutions and social movements should look like?

The main challenge Barcelona en Comú faces is to be a political organisation with the capacity to mobilise society together with other groups in order to exercise urban counterpower. This first year has been a year of getting to know the tasks of the institution. Coming to understand them, dealing with the challenges of the moment and adapting to the institution's times and structures. The challenge we face now is of an organisational nature: we need to strengthen the relations between the

1 | This interview took place in November 2016. 
institution and the "suburbs" as much as possible. The institutions are designed in such a way that this kind of change is not easy to achieve. The institution means "inertia", therefore this organisational challenge requires a critique of the institution and a review of the foundations on which it is based, for example what regulations have been formulated to determine the nature of its relationships with the external world?

If this inertia remains so powerful and the institution remains the same outwardly, it is difficult for those outside it to perceive the effort to rebuild its walls. Therefore asking for co-responsibility, asking for that task to be a shared responsibility sometimes seems like a poisoned proposal. That is normal. The only thing we can ask is that people trust in a long and difficult process that needs to give indications that it is on the right track, starting with concrete changes, progress and reforms. It is necessary to have a good understanding of the relevant institutional changes. In sum, what guarantees social rights is not the state, but the correlation of social forces. What guarantees the rights of the city is not the city council, but the urban counterpowers. Without organised social forces that demand and at the same time support measures, it is difficult to develop a new urban model.

To influence this dynamic reality we have institutional tools such as those we are creating at the Department of Participation. We have an idea, which we need to translate into concrete measures: participatory governance should not be based on 'conflict management' but rather on 'conflict organisation'. The relationship between institutions and movements is conflictive, and this is how it is meant to be. Let us be clear: the institution wants to produce regulations and static norms, while social movements want to create leeway for a changing reality that is threatened by a financial logic that envelops everything.

If we have learned something outside the institutions, it is to build federated networks with strategies based on solidarity and mutual recognition that are focussed on short and medium-term plans. This is our cultural capital: the knowledge we produce through our political practices. Although it does not fit in with the institutional structures, it is our main asset for changing them.

Ada Colau has already announced her willingness to participate in a network of "shelter cities" as a way to welcome people who are trying to reach Europe and to disobey unjust laws imposed by nation states that go against the basic 
rights of migrants. How does Barcelona express its "shelter city" status? Is the city planning joint actions of disobedience against refugee policies at the European level?

Out of the 160,000 refugees that the member states of the European Union pledged to take in in 2015, only 3,065 have been relocated from Greece and Italy to other countries. This figure is from July 2016, but the situation does not seem to have improved in the meantime. In the case of Spain, only 500 of the 17,000 people it promised to take in have been relocated. Cities and municipalities are taking in and integrating refugees, but in Spain they are not involved in formulating asylum policies, and nor do they receive funding to develop better policies. The state does not fund local integration policies, even though it receives European funds for this very purpose. For example, in the period between 2014 and 2020 the Spanish state will receive more than 330 million Euros, most of which, however, is being invested in border control measures.

In view of these figures, and together with other European cities Barcelona is showing the will to take in refugees directly through Solidarity Cities, a network of European cities formed to help manage the refugee crisis. In addition to assisting with the relocation of refugees this network also aims to support the exchange of information and knowledge about the situation of refugees. It aims to share the practices, challenges and solutions adopted by the cities that form part of the network. This European cities initiative is now trying to increase its visibility in order to push for the reallocation of EU funds all of which currently go to the central state rather than to local governments.

Barcelona is also promoting advocacy actions, putting pressure on administrations to fulfil their European commitments and to design policies that tackle the roots of the problem. In this context, the City Council is campaigning for the establishment of a humanitarian corridor to help refugees get to the European Union safely and prevent further deaths. Its cooperation with other municipalities is articulated in city to city relationships as well as within the framework of the various international networks of which the City Council forms part, such as Eurocities, MedCities, and United Cities and Local Governments.

The City of Barcelona has created a municipal project to care and provide social support for people who arrive here on their own via Greece and Turkey, northern Morocco, Ceuta and Melilla. This project, called the 
Municipal Reception Programme, already offers around a hundred places for migrants. Its objective is to improve the processes of social inclusion and autonomy of these people and ensure that they are able to access the labour market and start a new life on their own once the programme ends.

It is also important to highlight the role that Barcelona's civil society is playing in this process, because this inclusion work is not just the result of public policies but also of the hospitality displayed by many residents and collectives that have already been doing this kind of work for some time now. So the objective is to create pressure at the European level and to design comprehensive solutions at the local level. The goal is not just to redefine Europe's relationship with its border policies, but also to rebuild the relationship between the cities - i.e. the main reception centres - and the EU. The cities need to be directly involved in finding political and social solutions.

As is the case in many other countries in Europe, one of the major problems in Spain has to do with the lack of transparency and corruption in the management of public buildings and urban spaces. Barcelona recognises the social value of the experiences occupied spaces provide, rather than simply the economic value of such properties. How does the government deal with occupied spaces? Do these spaces serve as a meeting point and strengthen the relationship between movements and institutions?

In the past the institutions conceived urban areas as a space in which they intervened in order to generate income without being subject to any democratic control mechanisms. If we drew up a map of the land ownership structures in Barcelona, it would probably show that a large number of financial institutions either own the land or decide how it is used. This limits the democratic instruments and sovereignty of those who live and work in Barcelona. Within this process of "commodification" - in which the state and the markets have acted together - processes of social selfdefence have evolved that sought to regain basic rights and public spaces. Seen from this perspective, occupied spaces take on a different political meaning to that indicated by labels like "uncivil" or "illegal".

Barcelona has resources that are currently being used and managed by groups of citizens cooperating for non-commercial purposes. These social initiatives led by communities of active citizens aim to forge connections based not only on economic values, but on the values of communities that 
continue to solve their problems collectively. The commons in the urban environment represent a challenge, as well as a change in the way public institutions operate.

During previous administrations Barcelona tried to find institutional answers to these social initiatives. Several citizens' groups are managing public resources. "Casales de Barrio" is a project run by an association according to a civic management model. In the "Pla de Buits" programme the City Council allows citizens' groups to use empty premises for diverse activities. And then there is the "Pla de Locales" programme in which municipal land that is not in use is given to citizens for them to develop their own initiatives. When we examined these programmes, we saw that the initiatives behind them always came directly from social movements and that, considering their origin, there are not that many of them. Both the regulations and the institutions' way of relating to collectives were part of an institutional reality that was not flexible enough to understand the meaning of "community", yet was tremendously innovative when it came to understanding what "private" means. However, we also realised that there is no global programme or common public policy that provides a framework for the community management of municipal resources.

What we understood is that we have not made the leap from the reality of the situation (i.e. the use of land and property by active and legitimate communities for social purposes on a district level) to the law (i.e. the creation of new rules and regulations that support or complement these community practices). Rather, the existing regulations have been used to manage, control and limit the power of these practices. This is why we supported a working group that aims to design a proposal for a conceptual and normative framework that defines how the institution should support these community practices, as well as defining the need for the integration of the institution into society and the criteria under which it should operate. This framework should lay the foundation for the creation of a new kind of relationship between the institution and the community through the recognition of community management and self-management practices that may in turn lead to the creation of a new policy of designating certain spaces as "Citizen Patrimony" in Barcelona. This explicit recognition requires that municipalities provide resources and public infrastructure for self-managed common use, according to the agenda of civil society. 
You are a Member of the Department of Participation's Advisory Board. Collective management practices within the party itself, primary processes and open lists are measures that improve transparency both within the party and vis-à-vis the citizens. What mechanisms is Barcelona en Comú using to encourage citizens to participate in politics? And in what type of measures and policies do you encourage citizens to participate?

The challenge ahead is to develop participatory governments that can adapt to the forms of political interaction that already exist in a society. A new model of governance in Barcelona must respond to forms of participation other than those established within the institutional architecture. More and better democracy also means not falling into the trap of creating participation structures, which are devoid of content and have little real capacity for political action. The lesson learned in this political cycle is that not all of us need to participate in everything. It is more about creating means and mechanisms that enable us to have an impact on the problems and issues that interest us most, and on those with which we are most familiar.

We are immersed in a participatory process aimed at modifying the regulation of citizen participation. The objective is to give citizens more power and to create channels of democracy that foster the engagement of citizens. Right now, 80 percent of the time it is the City that promotes forums for participation, participatory processes, etc. We want that to change. We want the citizens to decide how and when they want to participate, we want them to feel sufficiently empowered to demand accountability or to participate in municipal policy-making when they want to.

At the moment, carrying out public consultations that are citizensled is not easy. We are also thinking about creating autonomous bodies that validate the quality of the processes and evaluate the democratic mechanisms of the city and its participatory bodies. The city administration cannot be the only guarantor of democracy. Another priority is to reach the most invisible groups and those sections of the population that have no contact with the institutions (i.e. the majority of the population).

The fundamental question is how to reach out to young people and provide them with good-quality spaces, how to reach out to Latina women; how to reach citizens who work and have family responsibilities and no time to participate, and how to reach people who are simply unwilling to 
engage. We want to encourage inclusive spaces that take inequality into account. A space of participation does not automatically become neutral merely by virtue of being participatory. The balance of power and the inequalities are translated into these spaces, and the City Council must develop measures of positive discrimination to give voice to those who do not have one.

There are collectives and economic elites with specific interests that have begun to realise that the spaces of participation are important for them, and that they need to be part of them if they want to influence public policy.

The election of Ada Colau brought hope to the discourse of governance based on the commons. Has Barcelona been able to inspire confidence among the citizens regarding the concept of "commons"?

I think there are two different dimensions in the interaction between the commons and the citizens as regards ongoing government actions. On the one hand there is a more communicative or rhetorical dimension, while on the other there is a more operational dimension, which is directly connected to specific programmes and policies.

With regard to the first dimension, I refer to how special emphasis is placed on the commons in speeches, in the way the message is constructed. I am not simply referring to the name of the political party, Barcelona en Comú, but to how the commons are introduced as a substantive part of the philosophy and model of the city for which we are campaigning. This is not a strategic approach but an integral part of the trajectory of those who have defined Barcelona en Comú's sphere of action. We came together to solve collective problems through practices of reciprocity, interaction and decision-making generated in spaces of selfgovernment and direct democracy. This has been our "political school", so to speak, and has included learning about institutional relations and making very detailed analyses of how the public administration functions at its various levels.

As regards the second dimension, some of the programmes and policies are already making progress when it comes to talking about participation, but the goal is to translate the philosophy into concrete measures. Consider, for example, housing policies that seek to communalise the 
public. There are many different ways of planning and implementing public programmes within that philosophy.

Our role is to see what kind of policies we can implement in each individual case, taking into account the redistributive role that a local government must play while at the same time transferring power to social initiatives that are organised and capable of ensuring that the commons are integrated into policies. 


\title{
Moment of confluence on the Atlantic coast
}

\author{
Interview with Claudia Delso, Marea Atlántica ${ }^{1}$
}

A Coruña is a city on the Atlantic coast of North-West Spain. It is the second largest city in Galicia and famous for having the world's only Roman lighthouse still in use: the Tower of Hercules. Marea Atlántica (Atlantic Tide) is the grassroots movement that has been governing the city since May 2015. The movement uses the semantics of the sea to designate its decision-making phases. Marea Atlántica is one of the municipalist movements that are now sharing power in state institutions. Although each of these movements has its own specific characteristics, most have certain things in common: an ethical code, open primaries and programmes and infrastructural documents that were created through participatory processes. One of the main characteristics of the municipalist movements is that they are grassroots movements in which members of political parties participate individually, just like other participants. This is why these movements call themselves "confluency processes" (procesos de confluencia).

Marea Atlántica is an example of a grassroots movement that became a political party in order to run in municipal elections. It presented its candidacy for A Coruña's municipal elections in May 2015 and emerged as the strongest party with 30.97 percent of the vote, securing 10 seats on the city council. A Coruña is a port city with around 250,000 inhabitants. Do you think that the difficulties citizens' movements face in terms of maintaining their autonomy and identity once they become part of an institution are easier to handle in

1 | This interview took place in November 2016. 
smaller cities? And in the case of Marea Atlántica, how is the relationship and communication between the original citizens' movement and the institution?

The city's size is a relevant factor and one should always bear in mind that it can have a negative or positive impact, depending on the situation. So even though A Coruña's small size favours a better relationship between the public institutions and the movement, it also weakens the movement since many of its key political groups cannot afford to participate as much as they did before they became part of an institution. Nonetheless I think the fact that A Coruña is a small city makes it really interesting for a political experiment like Marea Atlántica, because it means that people both inside and outside the movement are close to each other, and this facilitates a flux across the boundaries of the two poles: institution and movement. To answer the second question, the relationship between Marea Atlántica and the local government is a strong one, although there are always aspects that could be improved. Government officials participate in Marea Atlántica both as members of its working group (called the "Grupo Municipal") and as individual activists. That means that they participate in the dynamics of the movement just like any other person. In addition, the members of the Grupo Municipal share information and provide explanations on a regular basis at the general assembly, which takes place twice a month. Bearing this in mind, after a very intense period in which we went through four different elections at various administrative levels (local, regional and state elections) we need to focus on strengthening the movement.

A Coruña was declared a "Cidade Refuxio" (Shelter City) for refugees and criticised the policy of closing European borders, while at the same time demanding that the European Union, the member states and the regional government provide more support for migrants. What political measures for the integration of refugees is A Coruñ implementing and to what extent could these measures be jointly implemented with other cities in Europe that declare themselves Shelter Cities for refugees? Would A Coruña be willing to form a network of collaboration with these cities?

Civil society demanded solidarity and a dignified solution to the refugee situation with what is called the "Shelter City" network even before the institutions with responsibilities in this area took action. A call for 
solidarity by the City of Barcelona prompted many other cities and towns across the country to join this network. One of those cities is A Coruña. The network is channelling this demand from civil society, which once again is ahead of the institutions in wanting to join forces and resources to actively collaborate on measures for welcoming migrants.

This network of cities is already working at the European level, with concrete examples such as the collaboration between the City Council of Barcelona and the city councils of Lesbos and Lampedusa.

The Universal Declaration of Human Rights states in Article 14: "Everyone has the right to seek and to enjoy in other countries asylum from persecution." The city of A Coruña has provided a united response to the current refugee crisis, but making this a welcoming city goes beyond that. The City Council wants to design programmes and instruments that turn the city into a flagship welcoming city for immediate crisis situations and for the medium and long term. Our duty as an institution is to manage this wave of solidarity among the citizens so that the City Council agrees to accept an appropriate contingent of refugees, in coordination with the competent public authorities and with entities that have experience working in this area.

The City Council of A Coruña has designed medium and long-term initiatives to help these people and others who have applied for asylum and refugee status. And those who are already our neighbours, living in A Coruña, and have encountered barriers blocking their integration are also welcome to join in as full members of the city. These people must be made welcome and integrated because they have come here to escape poverty, war, femicide, sexual discrimination, and other forms of persecution.

Citizen participation transforms empty spaces in cities into places that create social capital for collective use. Last June the City Council of Naples, also a port city with 900,000 inhabitants, passed a resolution recognising seven public properties occupied by citizens and associations as "emerging and developing commons and civic environments". All these buildings were public property that had been neglected for years. What happens with buildings that are used as squats in A Coruña? Have there been changes in the regulations governing public buildings and spaces since Marea Atlántica gained its political mandate?

At the moment there are no squats in the city, so there is no need to develop a specific policy on this issue. However, the squat movement has a long 
tradition in A Coruña and buildings such as the "Casa das Atochas" and historical social centres like "C.S.A Atreu" and "Mil Luas" were occupied, and some of us were actively involved. So we see the steps taken in Naples as an example of an innovative policy on this issue. It is very interesting for us to observe Naples' experiences with the official recognition of commons and the new experience of property that this has opened up. A few years ago a very exciting initiative called "Proxecto Cárcere" was launched in the city which aims to turn a prison owned by the State into a centre for cultural and social projects. We are trying to collaborate as much as possible with this project, and hopefully the building will be open to citizens before the end of the current legislative period.

In general terms, we are implementing several policies aimed at changing the way people use public buildings and spaces. For instance, we are trying to have all public buildings owned by the Council that are not currently in use opened up for projects to promote the participation of citizens in the decision-making process.

As the Councillor for Participation and Democratic Innovation (Concejala de Participación e Innovación Democrática) in a city of less than 300,000 inhabitants and coming back to the question mentioned above, is it easier to promote and manage processes of citizen participation in smaller cities? Despite all the theory, there is not much of a culture of processes of direct citizen participation, either online or on a face-to-face basis. What kind of citizen do you think it is easier to motivate to take part in participatory processes? And in what kind of political processes and decisions should the citizens be involved?

The size of this city allows us to design participation policies based on methodologies that are more direct and physical in comparison with those used in bigger cities. Our first initiative aimed at organising the city into districts is a good example. The characteristics of individuals who decide to get involved vary depending on the specific objective of a particular participatory process. For example, during this process of organising the city into districts, most of the participants were older citizens, whereas on the issue of the participatory budget most of the participants were aged between 30 and 40. In addition we have had several participation processes specifically aimed at the city's youth. We regard participation as a basic civil right to which every citizen is entitled. For that reason we must create the conditions for those willing to exercise that right to do so 
and at the same time we must raise local awareness of the importance of participating in public decision-making processes. Once such a context has been created, citizens will be able to determine for themselves those areas in which public participation is more relevant.

How do the citizens view the development of political measures that revolve around the concept of the commons? Do they demand comprehensive protection of these assets, even though it entails an increase in government spending?

We truly believe that the policies that we are implementing are contributing to the redefinition of the concept of "common good" 2 , particularly at a practical level. Even though citizens tend to regard common good policies simply as an instrument for protecting and expanding the public sector, we should make an effort to introduce a less limited concept of the common good, together with more innovative proposals in this are

2 | The definition of the common good has been expanded in recent years thanks, among others, to Toni Negri. So far the definition of common good has been challenged mainly theoretically. In this respect the "new municipalism" (nuevo municipalismo) can help to ensure that the theoretical redefinition of the concept is put into practice. 


\title{
This is how you win an election
}

\author{
Stacco Troncoso in conversation with Victoria Anderica, head of \\ Transparency, and Miguel Arana, director of Citizen Participation, \\ City of Madrid ${ }^{1}$
}

How did a group of $15 \mathrm{M}$ activists form an electoral coalition, which, after lagging in the polls, finally had a breakthrough victory? A win that shattered the chronic neoliberal narrative and forged an alternative path bearing little resemblance to the Brexits, the Trumps, to all that we have been conditioned to endure, if not expect. According to Ahora Madrid's Miguel Arana and Victoria Anderica, the key is keeping it real - with real openness and participation. It will not work to pay lip service to those ideals and abandon them later. There is no faking it. Stacco Troncoso, from the P2P Foundation, visited the Madrid city council's citizen participation, transparency and open government department and spoke to Victoria Anderica, head of Transparency, and Miguel Arana, director of Citizen Participation.

\section{$* * *$}

There were some meetings two years ago, in a well-known Madrid squat/ social centre called Patio Maravillas, among other places, where people made a statement: "We are going to take power". That was Ganemos. They were called crazy, yet one year later, you took power. I would like to hear your view of these

1 A longer version of this interview was previously published on the blog of the P2P Foundation on December 29, 2016. The P2P Foundation is a non-profit organisation and global network dedicated to advocacy and research of commons oriented peer-to-peer dynamics in society. 
last two years - first, the transition from Ganemos Madrid to Ahora Madrid, and then the second, the year since the election.

Miguel Arana: First, one important word is power. When social movements think about power, they think about institutions. That is where power resides: you just have to enter the building, become the one who gives the orders, and then things will change. One thing I love about Spain in this recent period is that from the very beginning of the movements on the streets, the idea was that we are not going to the institutions. That was wonderful - we were out there for three or four years in the streets, in the squares, the assemblies, the "citizen tides" (mareas) green, white, etc. - the Stop Evictions movement - and the idea then was, "We do not care about institutions! We will get together and think about how to change everything, press on and make all these crazy actions and ideas and everything we can imagine". And then, just in this last phase, after we tried everything else we said, “... ok, maybe we could also try to enter the institutions. Some part of the power is there - we should get inside". I think this is an important remark. When people are looking from the outside - from other countries - it is difficult to understand what has been happening all these years. We got to the institutions because we spent four years building something really strong, really powerful, and that is what allows us to enter them now. This is also important because the game in the institutions is a difficult and special one. To some degree, it is designed so you usually cannot win when you come from outside. We won because we were in the streets for all these years, thinking about the things we wanted to do and change, being really clear, building the movement without leaders, without faces, without laws - everything. Now, we can be in the institutions and face the attacks, which are really crazy. Outside, you are a lot more resilient against attacks because it is about the ideas, not the people.

Can you clarify who you mean by the attacks?

Miguel Arana: Especially the media and the other parties, the traditional parties - the way they interact with you is by not focusing on problems or solutions; they only focus on you, personally. It is like, "you did this ..." or, "you are coming from this world", or - whatever. Previously, when we were not a party, when we were not the people inside, we never talked about 
ourselves. We just talked about the problems, that was the important thing. We built something serious and now we can enter the institutions. This last phase, building the party, was really different. The values that the movement held as important before - horizontality, avoiding structures, no hierarchies - well, once you get inside, you are required to build some kind of hierarchy. Things are not as horizontal as you would like anymore. Of course this is problematic. You have to understand, and imagine, how you want to solve these things. I think we have been able to get through some of the main problems, for example, building the electoral list. That was done in Ahora Madrid in a very open way. Anyone could just join.

Let us talk about the citizen participation portal, Decide Madrid. Tell us how it works, how long it has been up, and what the general reaction has been.

Miguel Arana: Before coming into the institutions, one of the main problems we faced was that the moment you want to open the movement to everybody and have them make decisions, you start facing the complexity of the situation. If you want to have 20 people debate and decide something, it is easy. You make an assembly, like we had in the squares, you talk, and that is it. If you want to have 100 - or 1,000 - people, maybe you can still have an assembly or some kind of a more complex system, but if you want to scale up, it is impossible. We have 3.2 million people, something like that ... You also want to build an effective system. You do not want just one decision in four years, you want to take all of the important decisions, every day. We believe that this can only be solved through the internet with a digital platform where all the physical barriers disappear, and where you can have thousands of people talking, deciding, proposing, etc. This whole year, we have been thinking about the tools we had available, trying and experimenting with everything that was on the internet. We learned a lot, tried a lot of platforms and got a lot of experience. But still there is no set, proper platform really capable of allowing all these direct democracy processes that we want. Nothing fits what we really need. We decided from the beginning to design a platform that collects our years of experiences and similar experiences we have heard about from all over the world, and build something that allows us to produce mechanisms and reproduce the democratisation we want to see. We started with this new platform. The software is called Consul and the platform is called Decide Madrid. 
We started from scratch in June 2015 , it got built very fast. In September 2015, we opened the first very basic process for the platform to start to work. It is a free software platform; we are sharing it with different cities. Barcelona, Oviedo and A Coruña are using it. We have already spoken with 40 or 50 cities who are interested in Spain but also in other countries.

We are also studying different mechanisms to open the city council for the citizens. For example, we opened the citizen budget, a participatory budget. This year a small part of the budget, 6o million euros (which, anyway, is an important sum of money) is now decided by the people. Yes, people can always make proposals, but this is much more specific because now, they are proposing on how to spend a certain amount of money. You cannot propose just anything; it has to be focused on how to use money. It is close to specific issues. You can build a school, a social centre, maybe fix some streets, but you cannot spend the money however you like. There are legal limits.

You keep a focus on openness with other local parties in different cities, do you mutualise information and best practices with them?

Miguel Arana: All of us are working on the same things. We are just taking the common ideas developed in the last four years and putting them into practice. At the end of the day, all the programmes are quite similar but it is not like we wrote them together, it is just that we are coming from the same place. Common traits include being open to everybody, participatory decision-making, putting social justice at the core of everything we do. This is a very comfortable feeling; it is really great when working together. And we really are working together, in everything. In all the plans. This is significant. Normally, you find a sense of competition among the major cities. But here it is the opposite. We really love each other, we really want to work together and to help. Whenever something bad happens to the people in Barcelona, we are totally outraged and screaming our lungs out: "No, the same thing cannot be happening to them!" And it is the same with the other cities, it is amazing. We meet in lots of forums, conferences, working groups. We really are working together, which makes life much easier. Normally, most city councils work and develop their projects in isolation, and they want to come out on top of the other cities. So, if they want to build software for participation, you go to a big technology company and pay a million euros ... 
... And you make it proprietary ...

Miguel Arana: ... and you get your proprietary software. At the same time, the next city is doing exactly the same. They have exactly the same software but they also paid a million, and it is the same for other cities. You end up with 50 cities using the same software while announcing it as this great new thing. We are doing absolutely the opposite. We started the software from scratch - this is Consul, from Decide Madrid. Some months later, Barcelona started using the same software. Now the developers from Barcelona have come to Madrid and they are working together. And now the people in A Coruña, working together, will adopt it. If we start solving all our problems by applying collective intelligence and debating how to scale everything, we will have something available for everybody in the world.

We talk about politics and counter politics; we talk about power and counterpower. Now that you find yourself within power, how do you enable and make sure that there is a counterpower and respect that? I guess that, through your work, you are enabling the great majority of people outside institutions to still have a voice, to still matter.

Miguel Arana: For sure! Our specific role here could be quite short. This what we need to do: enable people to take decisions, to take control. Once that is done with, we do not need to do anything else. Ok, we have to take care and do the maintenance so it keeps working, and nothing more. We have started all these processes and think that they have the potential to change everything, but up until now, the bulk of the decisions taken by the city council are taken in the traditional way. We cannot forget that $99 \%$ of the system still works that way. People are doing their best to open everything to everybody, but power remains focused on a small group of people.

In 15 M I could identify the Commons as part of the discourse, both explicitly and implicitly. Now that you have come to power, do you think that the Commons is still part of the dialogue? Not just with the activists and the people working here but with the citizens that you interact with? Or, do you think it is a hard political concept to understand? 
Victoria Anderica: I think it is a hard political concept to understand. I think that in cities like Barcelona, they use it more naturally than we do here in Madrid, probably because of the people who are working in the city right now. But the fact that you do not use it as a concept does not mean that we are not actually putting it into place. The feeling that brought everyone in, which nowadays exists in the Madrid government is very similar to the one that struck the people of Barcelona, Zaragoza and other cities. That is something they had in common. I think it is being used, or verbalised, more by people in Barcelona. They have even done a congress about it, talking about it - but I think in Madrid it is also happening. It is probably something we do not say, but I would say it is definitely happening.

I definitely think it is part of the matrix, and I would like to see it become more part of the conversation because it is impossible to define. Because of that, it is actually an interesting conversation to have with people, to engage their creativity. It is not something you just explain with a little pamphlet and no further dialogue: "here is all you need to know about the commons, read it, goodbye."

Victoria Anderica: Exactly. I think it is the philosophy behind the commons that is moving every single department here in the city of Madrid, because the idea is to give the city back to the citizens. That is essentially what we are talking about. That is what we are doing, actually doing, no? I would say there are a lot of concepts that are difficult for people to understand because they do not normally use them, but it does not mean they do not really understand them - they know what is going on. Even if they do not call it "the Commons", they can feel what is really happening. In that sense, I think it is just a different approach in terms of communication, but I do not think it is different in terms of what is actually happening.

Miguel Arana: I think that the Commons, as a concept, is absolutely important because it offers us a new path to follow. It is quite a complex concept, which points to an absolute paradigm change, but we are still ensconced in the old paradigms and it may be difficult to understand the concept and its full potential. Still, it is a beacon to follow and one of the few, new possibilities allowing us to change things because it really questions the matrix of the whole system. It is huge and complex, as it has to do with economy, with knowledge, with power and its distribution. 
However, at this moment I cannot say that it is playing a very visible or specific role.

How do you see this crystallising and scaling up, both nationally and transnationally? These experiences you are building here, do you think they are feasible at other levels? Or do you think that we need to go through a process of maturation of the urban commons before we can tackle national and transnational Commons?

Miguel Arana: All these ideas, including the commons but also focusing on things like collective intelligence or mechanisms for direct democracy - they are not really concerned with scale or the way power and society were previously organised. A true paradigm change will not be fixed to the old structures. For example, take this decision-making platform we are building: once you have built a viable platform that incites tens of thousands of people to work, think and take decisions together, the number of people or the scale does not matter anymore. It does not matter what type of decision you make, it does not matter if it is a local or national decision, none of that matters. The same thing happens with the Commons.

Since one of the characteristics of these ideas is how fluid and open they are, I do not think they are fixed to pre-existing structures. Anything that we can make in Madrid and other cities will work at any scale, anywhere in the world. Actually, inside the department we have built a service, a kind of working group called "The Institutional Extension Service". And that is precisely what they do: they are calling every city council in the world, every country, everybody to tell them: "Okay we are building this platform, it is free and we are going to give you the platform, we are going to give you all the rules and laws we had to write to make it work, and we will give you all the knowledge that we have built around this platform, for free. It is working for Madrid, so it can also work for you - so, why are you not using it?"

Anything else to close the discussion?

Victoria Anderica: We talked about the transparency policies, but I have not gone into much detail about what we have already done and what we can share. For example, in the transparency ordinance, which will include 
what the government must do, we will include the publication of diaries or agendas. That means that every single public official needs to publish their meetings. We need to say who we are meeting, and what we are talking about. This is essential to decision-making transparency and is one of the goals we want to achieve within the three years we have left. We have built the software for that and it is being used very well.

Then, the second thing I have not talked about is the transparency of the lobbies. This ordinance includes the obligation to create a lobby register, which is something that is not very common in Spain. The locations that have put a transparency register into place, like Catalonia, have not had it implemented in a very good way. There are many lobbies that are not registering, because no one is taking care of it. So, we will create a mandatory lobby registry, we are working on it. I think this will be a very good tool to share. I am talking about the software, because we will mix it with the agenda so it will be easy to register a new one, and then access the agendas and request meetings. It will flow - it will be very easy to use.

In terms of losing the fear that many people have about the transparency of decision-making, we are doing it and nothing is happening - in a good sense. I mean, we are publishing the agendas, we have published the CVs of everyone that is not a public official who works in City Hall. We thought it was going to be the end of the world - and nothing happened. We have had positive feedback. People are happy to know who they are working with because actually, we have really good professionals joining us in City Hall. That is great. I think that is something where Madrid can work as an example of how we should lose that fear of transparency, because it can be done. 


\title{
Forerunners of Italian municipalism
}

\author{
Interview with Renato Accorinti, Mayor of Messina ${ }^{1}$
}

\begin{abstract}
Messina is a harbour city in north-east Sicily. It is the third largest city on the island and has a population of 238,000 inhabitants. Messina has become the first Italian city to be governed by a citizens' movement: Cambiamo Messina dal Basso (Let's change Messina from the bottom up). Cambiamo Messina dal Basso is a civil platform made up of hundreds of people with different backgrounds and a common goal: to put human rights, justice and social equality at the centre of the policy-making process. Renato Accorinti was the candidate supported by Cambiamo Messina dal Basso in Messina's municipal elections of June 2013. He is a pacifist, activist and professor, and has now been the mayor of Messina for three and a half years.
\end{abstract}

$$
* * * *
$$

One of Cambiamo Messina dal Basso's main objectives was to support, enhance and inspire a widespread participatory process of government. How has your relationship with the platform developed since you took office? What do you think the relationship between social movements and institutions should be like in order to successfully implement citizens' demands?

I believe that the good governance of a city requires social movements, organisations and collectives of people that want to make a difference, to cooperate and to stimulate progress. Cities cannot be changed from the inside of a building. They can only be changed through continuous engagement in the city, on the streets and in the neighbourhoods. It is

1 | This interview took place in November 2016. 
only natural that this has been one of the key elements of our approach: my door has always been open for those willing to help. And if before we used to have a queue of people waiting outside who wanted to ask for favours, now there is a queue of people who want to do something for their city. Obviously, in this context there is a unique link to Cambiamo Messina dal Basso, which is the political reality that emerged during the election campaign from the desire not to waste all the energy that had gathered around the large civic coalition that supported my candidacy. Within Cambiamo Messina dal Basso, while we respect each other's autonomy (which in my opinion is indispensable) we constantly discuss issues and organise common actions, each of us according to our role (mayor, city councillor, activist). And by so doing we help each other and stay in close contact with the situation in the city and the demands coming from the grassroots.

Cambiamo Messina dal Basso has an open and inclusive position towards migrants and refugees in the region. It opposes the dogma imposed by the economic crisis and the stigmatisation of those fleeing war and devastation. As a Mediterranean city, could Messina organise a joint action together with other European cities to develop a network of cities without borders?

This is one of the topics that is closest to my heart. When I think of the "least important" - whom I believe should be at the centre of the government actions of any administrator - I cannot help but think of them, of the migrants. We Sicilians are a migrant community ourselves: we have been all over the world and we know all too well what it means not to be welcome. This is why we must not make the same mistake. It is our duty, as human beings first of all, but also as administrators in this historical moment, to promote different welcoming policies that are humane and focus on human dignity. Over the last few years we have grown used to receiving boats - though one never really gets used to it full of migrants (full of life, full of hope) in our city's port. The solidarity shown by Messina's community has been extraordinary and encompasses many different integration initiatives, the taking in of unaccompanied minors as well as a number of reports on the living conditions of migrants who are kept inside a "welcoming" system, which is sometimes inhumane (and which unfortunately does not depend on us). A network of welcoming cities without borders would be a very relevant message to send to our 
governments, to show that things really can be done differently, provided there is the will to do so.

Squatters at the Teatro Fiera said in 2012 that their goal in occupying the theatre, which had been abandoned and left to decay for decades, was "to give the city a key asset for the civil and cultural growth of the community". What is happening with the theatre today? What are the developments as regards legislation on occupied spaces in Messina?

Our experience with the Teatro Fiera was amazing. I myself participated and that was when the thousands of signatures demanding my nomination began to accumulate in 2013. Nowadays, unfortunately, the theatre has reverted to a state of neglect because the entity that manages the building - the Port Authority, which is directly subject to the national government closed it down again to wait for it to be renovated. Faced with this situation we are taking action: in those cases we consider it appropriate, we claim ownership of a building or space for the municipality. The theatre belongs to the city and its citizens and therefore it should be managed by the municipality. This is not just a quarrel between entities: it is about putting politics at the service of the common good and giving back to the city what belongs to it. If we manage to achieve this, it will be the final proof of how a bottom-up initiative, the action of a social movement, can be brought to successful conclusion by an attentive and responsive public institution. This is how we try to work also as regards other commons, or community resources, in the city. We created an institution - the Commons Lab - in which citizens jointly wrote the rules for the management of commons, the management of urban gardens and for the execution of the participatory budget. Our administration recognises the social value of self-management experiences. And despite many obstacles we will soon start an experiment on commons in the city, as we have also created a selfrecovery and self-management project for families living in emergency housing. The municipality can do a lot in this respect.

Messina has been described as "the first example of municipalism in Italy". What participation initiatives has the City Council implemented in recent years? What has been the reaction and level of engagement from the citizens? Has Messina's City Council established contact with other Italian or European 
cities to exchange insights on practices for increasing the level of citizen participation in the institutions?

There have been many initiatives, mainly because this was a sleeping city that was not used to participating. The Commons Lab, for one, comes to mind, but also the popular assemblies we organised on particular issues, and the Municipal Board meetings that were open to citizens in the city's various neighbourhoods. We are also currently implementing a project for the participatory redevelopment of certain properties in the suburbs (through popular assemblies in which the citizens themselves decide how a particular area should be redeveloped). Yes, it would be nice if there were more opportunities and more citizens who want to get involved. But this is a start, and not just a little step. Clearly, exchange with other cities - from Italian ones like Naples to cities outside Italy like A Coruña or Barcelona - can help us greatly. Exchange, dialogue, and sharing skills and experiences on critical issues can only be good for all of us. 


\title{
Don't let them d(r)own
}

\author{
Interview with Dobrica Veselnovic and Ksenija Radovanović, \\ Ne da(vi)mo Beograd
}

The citizens' initiative "Don't Let Belgrade D(r)own" ("Ne da(vi)mo Beograd") was formed in 2014 as a reaction to the imposition of the "Belgrade Waterfront" project ("Beograd na void"). According to Belgrade's planning department, "Belgrade Waterfront is a project for which the city has waited for more than 50 years ${ }^{2 "}$. The entire project is worth more than 3 billion euros and could take 30 years to complete. By the time it ends, Belgrade should have a new opera house, shopping centre and luxury hotels and apartments. Critics say that the whole process of planning and decision-making lacked any transparency and democratic legitimacy. Since its beginning $\mathrm{Ne} \mathrm{da}(\mathrm{vi}) \mathrm{mo}$ Beograd has organised a number of actions. It is collected and disseminated much needed information about the project of "national significance", actively made use of all existing institutional ways of citizen participation and called people to the streets. These protests that started as a reaction to an urban development project have recently drawn up to 25,000 people, making them among the largest protests in recent Serbian history.

"Ne da(vi)mo Beograd" is made up of people of different profiles, professions, and beliefs, who share the feeling of responsibility for their city, its processes and its problems, its present and its future. Their activities have one aim in common: to stop the degradation and the depletion of the city's public spaces, done in the name of ostentatious urban and architectural mega-projects in Belgrade and other cities in

1 This interview took place in November 2016.

2 | "Controversy surrounds Belgrade Waterfront development" Guy Delauney, BBC News June 212016 (http://www.bbc.com/news/business-36576420) 
Serbia. They aim to reassess urban and cultural policies in view of the sustainable development of cities and argue for a more just distribution of common resources, while enabling the inclusion of citizens in the development of their environment.

\section{***}

How did the protests start and what have been the key moments and achievements?

From its initial launch, we have opposed the Belgrade Waterfront megaurban development project. We were trying to stop the city government of Belgrade from changing laws and procedures that regulate the development of the city, that they wanted to do to allow for the continuation of this project. For instance, when representatives of the city government proposed changes to the General Urban Plan, we organised professionals and interested citizens and proposed around 2,000 complaints. Needless to say that the Commission did not pay attention to them. Once they showed that they do not care about public debate and the opinions of professionals and citizens, as well as about legislation and law in general, we decided to stop participating in legislative processes regulating city development. We started protesting in various ways at the public hearing where the new Spatial Plan for this area was proposed. After that, we staged protests, entitled "Let's show them duck!" on the occasion of the signing of the investment agreement. In Serbian slang 'to duck' means to trick or to commit fraud. Because of this, we established a yellow duck as a symbol for the protests, as it is the most common visualisation of this.

The latest protests brought more than 25,000 citizens onto the streets to oppose the Belgrade Waterfront project and to denounce the criminal deeds that were committed in order to proceed with the envisaged plan. The occasion for this protest was the demolition of a whole street, including privately owned houses, and the severe violation of the citizens' rights of freedom of movement, liberty and security. In detail: during the night of April 25th 2016, a group of masked people illegally demolished the whole street within the area designated for the project with three dredgers, including several privately owned houses. During the demolition they temporarily detained passers-by and security employees of private enterprises, restricting their freedom of movement and severely violating 
their liberty, personal integrity and right to property. The police were advised not to react to citizens' reports during the demolition, deliberately refusing to respond to citizens' calls for help, while those on site were harassed.

What impact has the protest had on Belgrade's politics? How do established politicians react to it?

Politicians that are "in power" have made a conscious effort to ignore what happened that night in Savamala and, for weeks, they tried to ignore the people on the streets asking for answers. Because this strategy failed they turned to plan B, which includes ongoing attempts to discredit the people who lost their homes and property that night and in the last two years, as well as attempts to discredit individuals and organisations helping the protests. It seems like their strategy is to distract the public from the main question: what kind of society do we live in if the citizens' well-being is considered less important than anything else? In addition, parties of the opposition tried to take over the protests, while constantly failing to make use of their institutional position, confirming that the path towards a people-oriented politics will be hard, but is necessary.

What do you hope to achieve in the end? And what would be a success today?

My hope is that we can show that a different politics is possible, and in that line, that also a different city is possible. With our actions we are trying to get back the hope that change "from the bottom" is possible. In that process we are also trying to empower the citizens to reclaim rights that are under attack. On a smaller scale, we believe that there is a strong and tangible chance to force the government to give up this problematic waterfront project, while also not to attempt anything similar in the future. That argument is called public pressure. We are aware that this is a marathon, but as the number of people who are ready to say "no" to the disrespectful behaviour of the government is increasing, we are more and more confident that we will succeed.

Can the "Belgrade Waterfront" project and the protest against it be seen as a representative case for general developments in Post-Yugoslavian Eastern Europe? 
Yes of course. This project is a paradigm of how cities are shaped upon entering the "transition" period. The main characteristic is that the processes happen without respect for the public interest. We see a constant shrinking of the public sphere, leading to violent changes in the environment, city neighbourhoods and natural surroundings. All of this for the profit of the narrow circle of people who are members of the economic elite associated with the political elite. But, to be optimistic, the resistance shown in Belgrade and other cities throughout Europe tells us that citizens are aware of this.

What can other cities learn from the protest?

We think that the citizens of other cities in Serbia and throughout Europe are starting to realise that they have lost the power to make decisions concerning the design of their everyday life. This is most evident in cities where we see more and more voices demanding the availability of public spaces for public use, increased participation in public affairs and generally more democracy. In the broadest sense we can see the emergence of calls for the appropriation of the right to our cities.

In Belgrade we are very carefully watching the experiences of other movements such as Podemos, Barcelona en Comú, the Democracy in Europe Movement (DiEM25), European Alternatives, the International Network for Urban Research and Action (INURA) etc. Because only with collective action and solidarity we can drive the waves of change. In that sense, every contact, every visit, every support and exchange that we make is crucial for our fight. Europe will not be changed by itself. We, the citizens of Europe, must do it together. 


\title{
Cities rejecting surveillance
}

\author{
Renata Avila
}

The city of the future I see in promotional videos ${ }^{1}$ for systems of mass surveillance and mass control seems to be subsumed in a permanent state of normalcy. It is a city with no traffic, no protests, no visible disasters, no spontaneous mobilisations, no surprises. Spontaneous events, as if they were system errors, are suppressed before they occur. Movement analysis and decision-making happens in a control room that looks like a spaceship, where technicians work in real-time, watching all of us, without us being able to see them. There is no citizen access. To the contrary, these are closed systems, difficult to monitor. Where actions are regulated by a system, designed elsewhere, that pretends it is not political. But technology is political.

Cities where everything is controlled by invisible technology, almost imperceptible in daily life. Those surveillance cameras now visible on street corners are replaced by systems of constant monitoring integrated into the landscape. Cities of sensors collecting our data all day long, where each movement is registered and stored, where decisions are automated and dehumanized, monetised to optimise consumption, to predict behavior, control people. And where the benefits of not knowing who decides and why, stand to be gained by the same conglomerate who bets on this vision. A few companies developing software, hardware and capacities in countries that can be counted on one hand. A market of 8 billion US dollars, which is expected to grow tenfold by the year 2020 . Fed with meagre public funds in a world where austerity is the default.

1 | For example SMART CITY - The interconnected city: improving the quality of life of citizens. September 2012 (https://www.youtube.com/watch?v=qvGuw2zZ3qc) 
Although discourses keep feeding the imaginary, descriptions of cameras detecting pickpockets, this is something radically different. Matrices that combine lots of data in real-time. This vision for the city of the future, promoted by a small group of technology conglomerates (Environmental Leader 2013), is one where quality of life is directly proportional to the predictability and homogeneity of its inhabitants, clashing with the struggle for diversity and diverse behaviours. To achieve this vision, much more is sacrificed than privacy. We pawn off our security to those in the sealed-off control room. It is to sacrifice the purest form of democracy we have, our right to protest freely and anonymously in the town square.

Local surveillance systems are rapidly expanding everywhere, much earlier and faster than the regulatory frameworks for adequate protection of privacy and personal data, without democratic mechanisms, community or neighbourhood consultations to determine their necessity or appropriateness. They are sophisticated and ephemeral systems that require updates and costly maintenance and show vague results. In Tegucigalpa, Honduras, for example, the city could not maintain the surveillance system due to a lack of budget to maintain the cameras (Pachico, 2013).

The contracts that are signed tie the hands of more than one public institution, borrowing from future municipal budgets, with a coordinated marketing and data machinery that does not offer solid evidence to prove effectiveness. Public authorities assure us that cameras, scenario modelling and mass surveillance will eliminate the problem of insecurity, advancing these over other public policies meant to attack extreme poverty and inequality of access to basic services, as well as the recovery of public space. The studies that vouch for the effectiveness of surveillance as a crime reduction measure are incomplete; they do not take local internal and external factors into account, and cannot be applied to different contexts (Murakami Wood, D. and Webster, C.W.R. 2009: pp. 259-273).

Cities of the future, promoted by the technology industry and real estate developers benefitting from them, allow for events to be pre-empted, for preventive decisions to be made to control the masses, block protests, predict civic mobilisations for more and better rights. To discriminate by algorithm. To exclude by patterns of behaviour. 
Do we want a future without surveillance? A future where diversity, and not uniformity of behaviour, is the rule? Let's start by eradicating (the now invisible) vigilante culture of the neighbourhood and the city. Let's start by participating in all public spaces and if they do not exist, let's open them. Before the final bastion of democracy becomes a memory erased by someone behind a screen. Among the steps we can all take, here are three I will elaborate on:

\section{Prevent the arrival of surveillance}

If mass surveillance is still at the exploratory stage as a security measure, it is important to organise neighbours against it, asking if municipal goods or services will be sacrificed in favour of surveillance, and question the impact that prioritising it will have on community and neighbourhood life. Moreover, it is important to ask about the long-term sustainability and viability of such projects, the conditions by which the municipality is acquiring them and the time frames. It is important to quantify what is being sacrificed to invest in surveillance. For example, indicating how many programmes for children and youth at risk could be started for the same price, offering more complete and long-term solutions. Once a mass surveillance system is installed, privacy and intimacy are only for those who can afford them (Alwin 2014). ${ }^{2}$

\section{Question mass surveillance already installed and the costs of maintenance and updates}

Decisions to improve security and quality of life of neighbourhoods and cities should be participatory. The benefits of installing mass and continuous surveillance mechanisms in public space should be weighed against analogue, social alternatives. Technological surveillance is expensive because for every camera installed there are not just related fixed costs for maintenance and updates, there is also a sacrifice in terms of public spending on social programmes. Moreover, almost all

2 I Pic Six Ltd. is based in Israel and provides authorised law enforcement forces and governmental agencies with a selection of interception products, standard off-the shelf or custom tailored solutions.(http://www.pic-six. com/? module $=$ catalog\&item_id $=3 \& c \_i d=12$ ) 
the technology providers are not domestic companies. Mostly closed technology, running on proprietary software, makes effective citizen oversight impossible. Contracts with camera providers and services are generally in the millions of dollars, and are binding long beyond the term of the signing government, without considering the realities of a municipality.

Only making the cost of surveillance in the city visible, we could aim at its reduction: the cost of surveillance is paid by cuts in the budget of the neglected community hospital, sacrificing the youth and arts programme for marginal areas.

\section{Connect with other rebel cities and collectives}

To free ourselves from surveillance and other repressive and authoritarian forms of power that this opens, we must immediately activate the mechanisms of law that allow us to oversee the functions of mass surveillance systems in our cities. And do this collectively, in coordination with other cities affected by the problem. Just as there are Smart Cities networks we should form our own Rebel Cities networks where surveillance is rejected and participatory democracy is affirmed, a democracy framed in respect for human rights and diversity, focused on collective solutions, which is the true path to safer cities. Not cameras.

We can then simultaneously activate collaborative mechanisms to prevent their expansion, and the actions could start regionally.

Given the robust access to information institutions and laws and the current political moment, Europe is the perfect region to start with. As cities are aggressively securitising every corner to combat terrorism and manage crises, it is important to start a coordinated watch dog to be vigilant on the approval and deployment of surveillance technologies.

An idea will be to use the current initiatives facilitating access to information, such as Frag den Staat ${ }^{3}$ or My Society's What do they Know? ${ }^{4}$ to simultaneously file standardised freedom of information requests in different cities across Europe, revealing the cost of surveillance, providers, vendors and who is benefiting from it. Data could also reveal in a given

3 | Official website (https://fragdenstaat.de/)

4 | Official website (https://www.whatdotheyknow.com/) 
geographical area which social inclusion programmes were left out of budget, where cameras are now installed instead.

Furthermore, a coalition of concerned citizens, supported by local parliamentarians or even the European Parliament could demand studies on the results of such technologies deployed. A coalition of European Rebel cities could also take serious legal action in face of possible illegal uses of surveillance for the adoption of discriminatory policies and practices. After a proactive series of actions in Europe, a second region could be added, ideally Asia or Latin America, where the expansion of Smart Cities is in its golden age. Only with facts and data on the harm of surveillance we could effectively demand from authorities' protection of personal data where it exists, and where it does not, demand that human rights authorities undertake feasibility studies before surveillance is deployed, weighing the impact on individual guarantees before installing such systems. Democracy begins and ends there. In its exercise.

\section{BibLIOGRAPHY}

Environmental Leader (2013): “IBM, Cisco 'Top Smart City Technology Vendors'” (http://www.environmentalleader.com/2013/o7/ibm-ciscotop-smart-city-technology-vendors/)

Alwin J. (2014): Has Privacy become a Luxury good? In: The New York Times (https://www.nytimes.com/2014/03/04/opinion/has-privacy-be come-a-luxury-good.html?_r=o)

Pachico, E. (2013): Fiscal Crisis Forces Honduras to Turn Off Security Cameras. In: InsightCrime (http://www.insightcrime.org/news-briefs/ fiscal-crisis-honduras-security-cameras)

Murakami Wood, D. and Webster, C.W.R. (2009): 'Living in Surveillance Societies: The Normalisation of Surveillance in Europe and the Threat of Britain's Bad Example', Journal of Contemporary European Research. 5 (2), pp. 259-273 
Shifting Media 



\section{Introduction}

Shifts in media technologies have been at the centre of the debates about the latest shifts in politics. While new media are now referred to as one of the main underlying factors for the era of post-truth and the rise of populists, some years ago they were celebrated for enabling horizontal communication which would pave the way for horizontal power structures. As Jan Rohgalf, one of the authors in this chapter, puts it: "Hitherto hailed as tools of democratisation and the weapon of choice against autocrats worldwide, social media recently became the target of a lot of fingerpointing".

While there are many interpretations about the meanings and consequences of the shift happening in media, the shift itself remains without doubt: traditional media is losing its power to distribute news. For centuries, the dissemination of information was in the hands of those who created it, who then sent it to the masses for consumption through printed newspapers, radio and television broadcasts. Today, gathering almost 1.8 billion users, Facebook is already the largest media company on the planet with advertising sales of billions of dollars a year. In a digital era where information loses its limits and boundaries and content flows between Instagram, Snapchat and videos on Facebook, the need to organise beyond the nation state becomes not necessary, but mandatory for media and communication experts and activists.

As Robin Mansell reminds us, living in a "digitally mediated society" means that not only the visible streams of information are of importance but also the invisible streams of data and their management by algorithms.

In a time of post-truth, how can we combat the rise of a false reality? Which media infrastructure is necessary for alternative narratives that finally bring transnational agenda to the citizens? What can be learned from existing alternative media platforms in this regard? Is social media 
still offering resources for new ways of protest? And how do we deal with the new power of algorithms when for most of us they are blackboxes? While the first and the last article address some of these questions from a theoretical standpoint, the contributions in between come from voices that already are proposing and implementing new models of media, successfully shifting the mainstream narrative and responding to the rise of nationalism.

The chapter opens with Jan Rohgalf, researcher at the University of Rostock, pointing out the similarities between the structure of social media and communication strategies of populist actors. Alena Krempaska and Peter Weisenbacher from the Human Rights Institute in Bratislava, analyse the change in Slovakia's media which is as vicious as it is representative for the situation in many Central and Eastern European countries. Adam Ramsay, editor at openDemocracy UK, presents his reflections on the possibilities of establishing a transnational media agenda that helps breaking boundaries in Europe and beyond. Jakub Dymek, journalist and analyst for Krytyka Polityczna in Poland, explains new forms of transnational cooperation and exchange of information between journalists. The chapter continues with two interviews presenting innovative examples of journalism in Europe: Esther Alonso, marketing director at eldiario.es, explains the working process and structure behind the online newspaper eldiario.es and Ramy Al-Asheq, founder of Abwab, explains the origins, objectives and challenges of launching Abwab, the first newspaper for newcomers in Germany. In the last article of the chapter Robin Mansell, Professor of New Media at the London School of Economics, thinks about the back-end of our "digitally mediated societies" and asks whether algorithms can be subjected to governance. 


\section{The Populist Challenge 2.0}

\section{How populism profits from social media}

Jan Rohgalf

The current momentum of nationalist populism, and especially Donald Trump's election as president of the US, has provoked a heated debate about 'post-truth politics', or even the 'post-fact society' in academia and the media. Hitherto hailed as tools of democratisation and the weapon of choice against autocrats worldwide, social media has recently become the target of a lot of finger-pointing. It has been accused of having assisted political actors who mobilise voters through a crude blend of outlandish conspiracy theories and suggestive half-truths, barely concealed hatespeech, as well as outright lies. Charges against social media have culminated in blaming Facebook, practically, for enabling the spread of fake news and hate-speech at an unprecedented scale, thus influencing the 2016 US elections in favour of the Republican candidate.

There is no doubt that neither lies, nor the blending of fact and fiction, are new phenomena in politics. They are part and parcel of politics, not only of populism, as are emotions, in contrast to rational arguments. And, of course, there was populism before social media and Facebook.

Nonetheless, the advent of social media has had a tremendous impact on the structure and workings of the public sphere in modern democracies. This essay argues that the current populist challenge to liberal, pluralist democracy profits in a number of ways from the kind of public sphere embodied by Facebook. This discussion is preceded by a brief outline of the populist challenge and concludes with remarks concerning the defence of pluralist democracy. 


\section{The populist challenge}

There is no doubt that populism is a fighting word. Accusing a political opponent of populism usually has the aim of discrediting them. Notwithstanding this, populism is also a useful category for analysis. It can be characterised by a particular understanding of the political and of democracy (Müller, 2016; Urbinati, 2014; Rosanvallon, 2010; Mudde, 2004; Taggart, 2004). Let us take a brief look at how populism conceptualises the political, as well as democracy, and why this understanding challenges liberal, pluralist democracy.

First of all, populism revolves around the idea of the righteous people put under pressure from various sides. Populism always identifies the main threat as the invariably corrupt elites in politics, the economy and the media conspiring against the people. These enemies 'from above' are said to team up with other enemies 'from outside'. Basically, anyone can be declared an enemy, immigrants of course, but also other groups such as progressives, the LGBT-community, feminists, environmentalists etc. The equation is very simple: those who do not fit, or indeed oppose the way of life and interests of the populists' supporters, are excluded from the people. In short, populists idealise their own clientele as the true sovereign of democracy.

Populism entails the feeling that the people were deprived of their autonomy and self-realisation. Its enemies purportedly prevent the people from being who they truly are, and, thus, what is ultimately at stake here is identity and the recognition of identity. This identity is, however, not a matter of individual choice, but of descent and fate. Usually this identity is in one way or the other coded in terms of a distinct ethnicity or culture.

Secondly, the populist interpretation of the political is anti-pluralist and plebiscitary. Once the way of life and interests of the populists' supporters count as the unadulterated popular will, no longer can there be political fault lines among the people. As a result, the exchange, bargain and compromise between conflicting interests - the bread-andbutter business of democracy - is met with disdain. To the populists, it is just the business of the corrupt, selfish elites, always eager to increase their share. In contrast, populism assumes there is a common good, and a popular will oriented towards this common good, which precedes the 
political process ${ }^{1}$ (cf. Fraenkel, 2007; Urbinati, 2006). Ultimately, it is nothing but the expression of the people's identity. Hence, according to the populists, true democracy is about polling the authentic will of the people as directly as possible, in order to circumvent the bias caused by lobbying for particular interests.

Thirdly, and because of this, mood and affect are extremely important criteria in populist politics. Bleak scenarios of conspiracies, decline, and perdition - evoked over and over again - are defining features of populist affect management. Scenarios such as these suggest that the world is nothing more than a snake pit of lies and deceit. Hence, one is well advised to exclusively believe in what is in tune with the interests and values of one's own group. In other words: truth is that which affirms the group's outlook on the world and which promotes its cause. Populism thus tends to blur the distinctions between proven facts, half-truths, lies and fantasy in favour of sheer assertiveness and impact. It is pretty much the same phenomenon, which Harry Frankfurt in his classic essay, discussed as "bullshit" (Frankfurt, 2005). Hannah Arendt's "emancipation from reality and experience" captures something very similar. (Arendt 1986: 965).

\section{Facebook: No neutral network}

Facebook was not designed to host meaningful public discourse. In 2004, it was launched as a service to stay in touch with friends, colleagues, former schoolmates and the like. In the beginning, it was a tool for networking, for sharing experiences and thoughts with other users or for work on one's personal identity. The network of friends and acquaintances rapidly grew into something much bigger. The company still likes to think of its product just as a place where people personally connect, but in fact today this social network - with about 1.7 billion users worldwide - figures as a decisive factor in the strategies of businesses, journalism and political campaigns. It has become an important part of the public sphere. But what are its defining traits and to what extent does populism benefit from these features?

Firstly, Facebook is marked by personalisation and thus fragmentation. Introduced in 2006 , the personalised news feed is now at the heart of

1 | However, a common good and a popular will are actually the outcome of the political process. 
the social network experience. The news feed is a digest of content considered most relevant to the respective user. The exact workings of the complex filter algorithm are a business secret, undergoing constant adjustment (Constine, 2016). Very broadly put, from the content posted in the respective user's extended personal network, it picks roughly 10 per cent that will probably matter most $^{2}$ (cf. Mosseri, 2016). Criteria for relevance are derived from past behaviour, and from how intensely other users interact with the content.

The recent concerns about the effect that echo-chambers and filter bubbles might have on public discourse originate from this feature (cf. Sunstein, 2001; Pariser, 2011). On Facebook, users decide who populates their 'world' and, consequently, also make a choice on the content that they wish to be exposed to. The news feed algorithm amplifies this deliberate filter further, delivering ever more of the same. As a result, critics argue, manual and automatic filtering work to create enclaves of like-minded people and, not bothered by alternate points of view, these enclaves run the risk of radicalisation and the fostering of hostility towards other groups.

Because of this, Facebook provides an ideal environment for all those who are convinced of the grand conspiracy of the elites and of manipulation by the 'crooked' mainstream media. The social network invites them to retreat into counter-publics tailored to their needs, complete with a diet of hyper-partisan 'alternative media' and fake news that flatter their own opinions, prejudices and feelings.

Secondly, while the social network fosters fragmentation through personalisation, at the same time, it overrides other distinctions. Namely, it calls into question the well-established distinction between the few who produce media content and the many, largely passive consumers, who consume such content (Poster, 1995). Now everybody can - or at least has the potential to - directly address a large public, without any cost or the need to gain access to established media outlets.

Social media has been praised for toppling the gate-keepers who, from the editorial departments of the old mass media, decided what was worthwhile to put into the public sphere (cf. Chadwick, 2013). It goes without

2 According to Adam Mosseri, Vice-President of Product Management at Facebook, on average users actually read 10 per cent of the posts from their network. 
saying that this narrative of emancipation is also attractive to populists and their supporters, who feel hostility towards the 'mainstream' media ${ }^{3}$.

Furthermore, the common markers that help distinguish content with respect to quality, origin and intention, have also moved to the background or vanished altogether. Reliable news or cat-themed memes, birthday greetings or the latest celebrity scandals, life hacks or conspiracy theories - on the news feed they not only appear next to each other, there also appears to be no substantial difference between them ${ }^{4}$ (Remnick, 2016).

These are near ideal conditions for the blurring of fact, fiction and fantasy typical of populism. Consider, for example, on the one hand, a journalistic report on the integration of immigrants based on serious investigation and a hastily penned rant on the same subject on the other. Once you deny that there is a difference in quality and assume instead that they are merely two equally legitimate conflicting standpoints, you are free to pick whatever suits you best ${ }^{5}$ (cf. Lynch, 2016; Harsin, 2015).

Thirdly, as the number of senders and the amount of content produced keeps growing, while the attention of potential consumers remains by and large the same, the news feed turns into an attention economy (Franck, 1999). Content of varying natures enters a cut-throat competition for the scarce resource that is the users' attention. A recent study confirms the intuitive idea that the news feed algorithm decisively guides the users' attention and their interaction with the content they are exposed to ${ }^{6}$ (Tufekci, 2015: 1130-1132). If the goal is to maximise outreach, such as is typically the case in advertisements, journalism and politics, it is therefore imperative to secure one of the top positions in the news feed. The algorithm creates feedback loops: posts on popular, so-called trending topics, stand a higher chance of receiving a top position in a user's news

3 | However, the relationship between populists and old mass media is diverse and too complex to be summed up in a single sentence.

4 | As also Barack Obama aptly put it: 'An explanation of climate change from a Nobel Prize-winning physicist looks exactly the same on your Facebook page as the denial of climate change by somebody on the Koch brothers' payroll'.

5 | They argue that the Internet and social media proliferate competing standards of what establishes facts. We are confronted with ever more 'truth games' (Harsin), which cannot be decided.

6 | Zeynep Tufekci has pointed to this aspect in the inhouse study conducted by Facebook employees, Bakshy, E./Messing, S./Adamic, L. 
feed and in turn are more likely to provoke user engagement and thus even increase their popularity. The social network's metrics provide a simple, yet all too simple means to measure value and importance: the intensity of interaction that content provokes. Or in one word: impact.

As research suggests, content that induces emotions like awe, anger or anxiety, is more likely to provoke interaction, regardless of other qualities such as novelty or practical utility. Users are also motivated to engage with social media because they want their own identity and lifestyle to be visible and recognised (Bennett\&Segerberg, 2013; Papacharissi, 2010; Papacharissi, 2015).

The flood of pro-Trump fake news during the 2016 US presidential election provides a good example. Journalists managed to track down a number of fake news producers. They tinkered fake news for Trump supporters for the simple reason that this group of voters was the most determined to engage with fake news and hence created the largest revenue in advertisements. Fake news producers also discovered something else: the messages that got the most interaction were those that affirmed the audience's prejudices and anxieties, but also their hopes and wishes, regardless of how outlandish they were. Fake news consumers also click what they want to be real, not only what they believe to be true (cf. Silverman, C. et al, 2016; Horning, 2016).

In their study on political mobilisation in social media, W. Lance Bennett and Segerberg showed that users assess politics in a highly personalised manner; one's own lifestyle and the presentation of one's identity are crucial (Bennet\&Segerberg, 2013). Ideologically thin messages, like memes and hashtags, which have a high potential to stir emotions whilst also being easily personalised and distributed, do a much better job in promoting a political cause these days than unattractive, cumbersome party organisations. They can initiate cascades of the sufficient thrust to be trending and, hence, garner even more attention.

This new form of political mobilisation does not only resonate with populist disdain for organisations and the fantasy of the spontaneously erupting popular will. With regards to the Tea Party Movement, and the Swedish Sverigedemokraterna, Bennett also points out that populists might pursue authoritarian politics, but they are successful in this new mode of mobilisation because they do not impose a strict party line Bennett\&Segerberg, 2013). Rather, they aim at unleashing anger and indignation (on the German case of PEGIDA cf. Rohgalf, 2016; 
Bizeul\&Rohgalf, 2016: 49-67). For this purpose, they offer diverse, ambiguous materials and the vague narrative of omnipresent traitors and enemies, which can be individually adapted to fit one's own anxieties and grievances. The populists, so to speak, offer an outlet for various, individually felt forms of discomfort - and social media provides the infrastructure for this.

Donald Trump was mocked for his inconsistency and eclecticism. However, eclecticism is not a deficit here. On the contrary, it is a promising way to mobilise crowds - not only online audiences. Yet the Trump campaign had a different take on personalised politics than the one identified by Bennett and Segerberg. Social media, combined with big data and cutting-edge psychometrics, enabled the micro-targeting of a huge range of groups of potential voters. It allowed for the addressing individual citizens, delivering content tailored to their personality, life situation, opinion, etc (cf. Krogerus\&Grassegger, 2016).

\section{In defence of pluralist democracy}

With nationalist right-wing populism on the rise, liberal, pluralist democracy is under pressure. The open society and its emancipatory development since at least the 1960 s is being jeopardised from within. The preceding remarks have set out to contribute to an adequate understanding of the present challenge. In this conclusion we shall ask what to do in defence of a pluralist, liberal democracy and argue that it is not social media that is at the centre of this answer.

First of all, do not settle for the diagnosis of the post-fact society. It is important to note and criticise a recently successful wave of politicians to whom facts do not seem to matter. However, announcing the era of posttruth equals a declaration of surrender (cf. Pörksen, 2016). The proponents of a pluralist democracy should not consider themselves to be the relics of an era that has come to an end, but approach the future with a realistic, yet forward looking mindset.

Secondly, do not let the populists define the rules of the game. Populists attack politicians and journalists - and, at times, also scientists - as members of an allegedly corrupt elite. But the reaction to this depends on who is attacked. Far too often, those attacked do their challengers a favour and behave just like the elite they have been accused of representing. Instead of banding together against the populist newcomers, political 
parties should sharpen their respective profile and engage in a serious competition for the best solutions to urgent problems, but also for the most promising vision of the future. Journalists should report critically on populists, but a near $24 / 7$ coverage will, at the end of the day, not help the pluralist cause, but rather the populists. Facing the populist challenge, journalists need to also resist the temptation of discovering, again, 'the man in the street who feels neglected'. This paternalistic attempt to win back trust will surely backfire (cf. Haemin, 2016).

Thirdly, fight hate-speech and misinformation on social media. Part of this struggle is a matter of criminal prosecution. But it is also the business of independent fact-checkers to debunk hoaxes and urban legends. All social media users are called upon to exercise counter-speech whenever hate-speech appears online. Last but not least, it is the duty of social media companies like Facebook to intervene - whilst there are also good reasons not to make Facebook the arbiter of truth. For the sake of a pluralist democracy, we cannot allow a single corporation to decide what is fact and what is fake. Nor should a government agency play this role. In a pluralist democracy, what is true remains subject to an ongoing process of trial and error and of the exchange of reasoned arguments. The willingness to listen and to consider your opponent's arguments is a mandatory precondition. Here we touch on the aspect of a political and civil culture on which a pluralist democracy depends.

Fourthly, maintaining this political and civil culture is an everyday task. Let me conclude with just two thoughts on this complex endeavour. To start with, make sure you do not start seeing society through the populist lens. The Manichaean distinction between the people and the elite is ultimately a pre-modern, pre-democratic, anti-political one, echoing the insurmountable hiatus that separated the commoners from the nobility ${ }^{7}$ (De Saint-Victor, 2015). On the one hand, this is an inadequate paradigm for understanding politics in modern societies, including actually existing power asymmetries and inequality issues. On the other, it downplays the political opportunities the 'ordinary citizen' indeed has in modern democracies. Blaming nebulous elites for everything may be a convenient way to cope with reality, but it is an act of intellectual and political surrender.

7 | Jacques de Saint-Victor aptly pointed to this aspect of populism. 
What is more, a pluralist political and civil culture will be the ongoing task of political education in schools, in academia, in adult education and beyond. And last but not least, this culture is the result of lived experience.

\section{BIBLIOGRAPHY}

Mosseri, A. (2016): How's Your News Feed, Tech Crunch, 14 September 2016 (https://techcrunch.com/video/hows-your-news-feed-facebooksadam-mosseri-speaks/57d9862e1c689950401c9c1c).

Arendt, H. (1986): Elemente und Ursprünge totaler Herrschaft, München.

Bakshy, E./Messing, S./Adamic, L. (2015): Exposure to ideologically diverse news and opinion on Facebook. In: Science, Vol. 348, No. 6239, pp. 1130-1132.

Bennett, W. L./Segerberg, A. (2013): The Logic of Connective Action. Digital Media and the Personalization of Contentious Politics, New York.

Bizeul, Y./Rohgalf, J. (2016): Singularität und Verschmelzung. Rosanvallons contre-démocratie und der Wandel des demokratischen Imaginären. In: ZPTH, Vol. 7, No. 1.

Chadwick, A. (2013): The Hybrid Media System. Politics and Power, Oxford.

Constine, J. (2016): How Facebook News Feed Works, Tech Crunch 6 September 2016 (https://techcrunch.com/2016/09/06/ultimate-gui de-to-the-news-feed/).

De Saint-Victor, J. (2015): Die Antipolitischen, Hamburg.

Fraenkel, E. (2007): Gesammelte Schriften, Vol. 5, Baden-Baden.

Franck, G. (1999): The Economy of Attention. In: Telepolis 7 December 1999, (https://www.heise.de/tp/ features/The-Economy-of-Attention3444929.html).

Frankfurt, H. G. (2005): On bullshit. University Press, Princeton.

Haeming, A. (2016): Vielleicht sind wir noch $\mathrm{zu}$ retten. In: taz 30 December 2016.

Harsin, J. (2015): Regimes of Posttruth, Postpolitics, and Attention Economies. In: Communication, Culture \& Critique, doi:10.1111/ cccr.12097.

Horning, R. (2016): More on Fake News, Tumblr. (http://robhorningreallife. tumblr.com/ post/153219515415/more-on-fake-news). 
Krogerus, M./Grassegger, H. (2016): Ich habe nur gezeigt, dass es die Bombe gibt. In: Das Magazin, No. 48, (https://www.dasmagazin. ch/2016/12/03/ich-habe-nur-gezeigt-dass-es-die-bombe-gibt/).

Lynch, M. (2016): The Internet of Us. Knowing More and Understanding Less in the Age of Big Data, New York.

Mudde, C. (2004): The Populist Zeitgeist. In: Government \& Opposition Vol. 39 No. 3 (2004).

Müller, J.W. (2016): Was ist Populismus? Ein Essay, Berlin.

Papacharissi, Z. (2010): A Private Sphere. Democracy in a Digital Age, Cambridge.

Papacharissi, Z. (2015): Affective Networks. Sentiment, Technology and Politics, New York.

Pariser, E. (2011): The Filter Bubble. What the Internet is Hiding from You, London.

Pörksen, B. (2016): Die postfaktische Universität. In: Die Zeit 15 December 2016.

Poster, M. (1995): Second Media Age, Cambridge.

Remnick, D. (2016): Obama Reckons with a Trump Presidency, The New York, 28 November 2016 (http://www.newyorker.com/maga zine/2016/11/28/obama-reckons-with-a-trump-presidency?mb $\mathrm{id}=$ social_twitter).

Rohgalf, J. (2016): Gegendemokratie und Volksgemeinschaft. In: prager frühling, No. 25 (June 2016).

Rosanvallon, P. (2010): Counter-Democracy, Cambridge.

Silverman, C. et al. (2016): Hyperpartisan Facebook Pages Are Publishing False And Misleading Information At An Alarming Rate. In: Buzzfeed 20.10.2016, (https://www.buzzfeed.com/craigsilverman/partisan-fbpages-analysis).

Sunstein, C. (2001): Republic.com, Princeton and Oxford.

Taggart, P. A. (2000): Populism, Buckingham and Philadelphia.

Tufefkci, Z. (2015): How Facebook's Algorithm Suppresses Content Diversity (Modestly) and How the Newsfeed Rules Your Clicks, (https://medium.com/message/how-facebook-s-algorithm-suppres ses-content-diversity-modestly-how-the-newsfeed-rules-the-clicksb5f8a4bb7bab\#.hy 1ksddfp).

Urbinati, N. (2014): Democracy Disfigured, Cambridge.

Urbinati, N. (2006): Political Representation as a Democratic Process. In: Redescriptions Vol. 10. 


\title{
Contesting the shrinking media space in Slovakia
}

\author{
Alena Krempaska and Peter Weisenbacher
}

The March 2016 elections took Slovakia by surprise: the neo-Nazi Kotleba - LSNS (Kotleba - People's Party Our Slovakia) won 8 per cent of the vote. It was an already dissolved party, which had renewed its activities, having hardly ever won more than 1.5 per cent in the polls. Now they are in the Parliamentary opposition, rather silently, but some NGOs have already received emails from one of the Kotleba members asking for them to disclose all their sources of income and the party has proposed a law to make a compulsory registry of foreign-financed NGOs in order to "protect the country from foreign ideologies". Although politically marginal, the direction of the party's activities does not make Slovak liberals feel at all comfortable.

How did we get here? As the post-election analysis shows, the majority of voters did not vote for them because they are neo-Nazis, but in spite of this. For many, it was a protest vote, against mainstream parties that were either perceived as embroiled in corruption scandals or as no alternative at all. Part of the problem here is the absence of any progressive movement that would embody a different narrative. There is no established Leftist party or credible Leftist political institution. All that remained of the former Communist Party (renamed the Party of the Democratic Left in the 1990s), as well as the "original", pre-war Social Democrats, have been consumed into SMER-SD, the ruling Social Democrats, who implement only very rudimentary Leftist policies, otherwise being a very mainstream party in the true sense of the word.

The disintegrated trade unions are of no help either. Over the years, they were only able to achieve very small victories and it is up to smaller associations and journalist platforms to represent any sort of counter- 
narrative. Increasingly, this gap is filled by far-right parties and the proliferation of conspiracy-prone, self-declared "alternative" media, active online.

\section{Divisive media sphere}

Since 2013, we have witnessed the exponential growth of so-called 'alternative media', initially published online, but also increasingly in print. These media groups portray themselves as alternatives to the mainstream media, delivering 'uncensored' truth. They also often collaborate with traditional far-right websites and organisations, which have had a political presence since the 1990s. These media groups have turned seemingly harmless conspiracy theories into a platform for hate-speech, extremism and anti-Semitism. From the absurd 'hollow-Earth theory', suggesting that an alien race has its headquarters in the middle of the Earth and that the entrance is the very spot where the Slovak, Hungarian, and Austrian borders meet, to the more sinister 'world Zionist conspiracy' or blaming the Roma for Slovakia's economic situation, and the demonising of LGBT people, it did not take long for human rights activists and NGOs themselves to be demonised as "American agents" or worse. By 2014, this so-called 'alternative media' began to enter mainstream public discourse in their own special way.

While still referred to as 'controversial', these media sources have also started to be quoted in the mainstream press, a fact that would have been unheard of just a year earlier. The most prominent example is that of the so-called Slobodný vysielač (Free Broadcaster), an internet radio station and website, notoriously extremist in its content, which slurred the name of the short-lived radio station of anti-fascist insurgents during the Slovak National Uprising (SNP), during what was arguably the Slovaks' finest hour, in August 1944. It also promoted, and largely assisted, in the victory of the openly neo-Nazi candidate for regional governor, Marián Kotleba, the head of LSNS, presenting him as an alternative to the current "establishment and state", thus legitimising neo-Nazi leaders. Neo-Nazis and fascists are often guests on the radio, where they are introduced as experts on "Roma issues"', international affairs, human rights or even science.

Another example is the a monthly magazine ZemaVek (Earth\&Age), edited by the notorious conspiracy theorist and anti-Semite, Tibor Rostas, 
which saw phenomenal success, with sales in its first three months rocketing by 500 percent. The biggest 'success', and a real cause for concern, is the extent to which these media sources present the extremist message in a more sophisticated way, making it harder to discern at first glance. By doing so, these publications reach larger parts of society. Public discourse has deteriorated considerably as a result. One could argue that it is in large part due to these forms of media that the anti-immigrant mood in Slovakia today is as high as in Hungary, although no refugee has sought to settle in the country.

It becomes increasingly acceptable, and easy to find online, discourses that are populist, xenophobic, homophobic, anti-Semitic, or other similar rubbish, and social media helps to spread such messages. These media forms buy their reach to farther audiences, and as Facebook algorithms work in creating bubbles of people interested in similar issues, the audiences of 'alternative media' are becoming less and less exposed to the more traditional media. All the less so, when the traditional media is more and more often locked for only registered users - why would someone pay for content he or she thinks can be reached for free on online websites?

The situation is getting worse. Virtually any significant alternative to the existing mainstream media promotes fascist ideas. It is unexceptional today for Leftist, or even environmental activists, to appear in the same studio, or give an interview to the same magazine, as neo-Nazi leaders. In addition, more and more establishment figures, such as right-wing MPs, are starting to accept the 'alternative media' as mainstream media outlets, and regard their output as true journalism, instead of unsupported, incendiary opinion with no regard for professional standards or ethics. The attitude of the publishers is thinly veiled self-righteousness. They often defend themselves by citing freedom of speech, claiming that they are open to everybody and everything, and even accusing all those who refuse to appear in one of their 'talk-shows' of censorship. The effect on their recipients is the perversion of the very idea of freedom of speech, by maintaining that our country's biggest problem is the 'censorship' of fascism and other extremist ideologies, in the media and by law. 


\section{Shrinking space for progressive voices}

For those who want to build a tolerant, inclusive and just society, or for those who want to simply live, work and raise a family here, Slovakia's current trajectory is troubling. On the one hand, we face a situation in which conspiracy-prone and fear-mongering online platforms are gaining ground, while the mainstream media does not shy away from lowering their journalistic standards further, in order not to lose their audience (and sources of income) to 'alternative media'. The almost universally abhorrent mainstream media coverage of refugee issues during the events of last year is a case in point.

On the other hand, there is no political alternative formed on the Left, no party that could gather the protest vote. At the same time, since the 2016 elections, the leading opposition Liberal party has had no shame in claiming that their economic programme is essentially the same as that of the neo-Nazi's, and their leader has issued statements claiming that the neo-Nazi leader is "not really a neo-Nazi", thus effectively normalising and legitimising their existence and political activity. The signs are all there that mainstream politicians may be tempted into seeking tacit alliances with the neo-Nazis in order to secure votes in the future and who knows on what kinds of deals, or policies, these alliances will be built.

Neo-Nazis in Parliament, the failure of mainstream politics, no alternative on the Left, and a divisive media landscape with a proliferation of 'alternative' information, all culminate in creating a critical situation. While there is, objectively, a space and need for Leftist ideas that promote unconditional support for human rights, including economic and social policies, currently the Leftists have no vehicle, as any alternative to the existing system comes in a proto-fascist package. The Leftist voter is thus vanishing; either turning idle or towards radical groupings. The task for the progressives in Slovakia is therefore as glaring as it is pressing: to not let the public agenda be dominated by conservative forces attempting to, in various ways, curtail human rights, and to, by all means, reclaim public space for the diffusion of values for a more just society. 


\title{
Fluid media landscapes
}

\author{
Adam Ramsay
}

Benedict Anderson argued that the invention of the printing press was key to the rise of the modern nation state. As written material could be mass produced, common languages formed, shared discourses developed. Communities started to imagine themselves into existence over large geographical areas, to see themselves as peoples, and to organise politically into administrative units based around these new-found identities.

Later on, broadcasting became key. The radio, it has been said, did more to unite Italy than Garibaldi. The BBC was launched three weeks after Ireland became independent from the UK, so that, as its founder Lord Reith put it, "the chimes of Big Ben could be heard in the remotest cottage in the country". The powerful have long understood the role of the media in the construction of identity.

Similarly, it seems almost inevitable that future historians will look back at the rise of the telephone, texting, TV and the internet as key to shaping how those of us stumbling through the first half of the 21st century see ourselves. It is still less than 100 years since the first television broadcast, and less than thirty years since Tim Berners-Lee coded the first browser for the World Wide Web.

And, of course, it is not just geographical areas or historic nations, which are defined by these shifts. From magazines for airline pilots to websites for kayakers; journals for conspiracy theorists to forums for people with muscular dystrophy, our civilisation is a veritable forest of media platforms. And through debate and news and in-jokes and jargon, these often begin to form a particular function. Consciously or not, they start to build up imagined communities with shared identities.

It is in this context, and with debates around Britain's European referendum still forming eddies from the Carpathians to the Balearics and 
Sápmi to Crete, it is worth surveying the landscape of European media. Because, of course, there are plenty of significant European institutions. Every football team in the continent yearns to win the Champions League. The Council of Europe facilitates collaboration to protect human rights and the rule of law. The various European courts are key corners of our trans-continental justice system. Much of Europe shares a currency and free movement area. And all countries in the EU, of course, have a common parliament, commission, and council of ministers; and agree to pool policy on everything from international trade to hedgehogs.

Never before in all of human history has a collection of independent nation states been so intertwined. Never have different, self-governing peoples chosen to collaborate in so many ways, share so much in eachother's cultures and institutions, travel so much to each-other's countries, learn each-other's languages, or study at each other's universities. Never have different peoples so frequently fallen in love.

And yet, despite all of this, there is no common European mass media. Beyond the annual Eurovision bonanza, there is no shared broadcasting on Europe's airwaves. Beyond a few, rare projects, like Euronews or openDemocracy's Can Europe Make It?, there is no major European common media outlet.

Some of this, of course, is a linguistic question. While $5^{1}$ per cent of EU citizens had conversational or fluent English even a decade ago ${ }^{1}$, this means almost half do not. But real news journalism is expensive, and it is cheaper to translate than to start again from scratch.

The lack of a European media clearly causes a problem: not so much in its impact on our identities. After all, why should those of us on the left particularly care whether we identify more with Europe, Eurasia, Spain or the Basque Country? So long as we are open and inclusive and treat people from everywhere as equal, questions of identity as such are not worth falling out about. But they do matter, because European institutions need to be held to account and, more importantly, because without some kind of shared political narrative, it is hard to mobilise people across a continent against the powerful forces, which shape our world for the worse. Some kind of shared media ecosystem is not sufficient to build

1 | 'Europeans and their languages' Special Eurobarometer Summary European Commission (2006) (http://ec.europa.eu/public_opinion/archives/ebs/ebs_24 3_sum_en.pdf) 
among the peoples of Europe the sense of being a public, but it is probably necessary. And at the moment, our media is not so much a continent as an archipelago.

This, though, is not an insurmountable problem. The collapse in revenues in the media delivered by the loss of advertising money to social media, the loss of small adds to Google and Gumtree and the loss of cover prices to the norm that online content is free means that the future of the press is up for grabs. And while it is not a future which always fills me with hope, this chance to invent new things is exciting.

While revenues are falling, the capital and payroll costs of producing media are collapsing too. Where once you needed a printing press to disseminate a pamphlet to a few hundred people, now you can access thousands with just a laptop, Wordpress blog and a Twitter account. Where, only recently, you needed a TV studio and network access to produce video that anyone beyond your friends could see, now, a decent smartphone and a little editing software are enough to make reasonable quality videos. Where once, typesetting was skilled work, now, it is all done automatically.

In this context, it seems likely that the media landscape across Europe will remain fluid for some time: new publications will appear, build audiences, and then collapse as fast as they arrived. Oligarchs will continue to buy up media empires to assert their political influence, but smaller projects have a chance of breaking through in a way they have not in recent decades. It is worth remembering that the best-read newspaper on earth in 1933 was the now defunct Daily Herald - the paper of Britain's trade union movement. There is little reason to believe that modern social movements could not grow our own media to a similar scale. After all, America's radical right has managed to do so (though cash is always easier for those on the side of the rich).

If these new players want to build cross-continental and international narratives, to hold European power to account and build movements across borders, it seems to me that the simplest way to do this is not through new conglomerates, but through practical collaboration between different projects. Expertise needn't all lie on one payroll or one website, so long as people are happy to share, collaborate and support each other rather than competing. It will not be through one large organisation, but lots of different groups, reaching their own audiences, where they are: whether that is a geographical community or a community of interest. 
Some of the more liberal media have become obsessed of late with questions of filter-bubbles and social media echo-chambers, believing they were the protectors of truth. But that is now the terrain of reality, and while it can be scary to watch as the right seize the initiative in this new world, there is no reason to believe that the left cannot win it back. It is the old order which got us here in the first place, after all.

Building the solidarity we will need in the future will be difficult: it is hard to escape from the endless turning of the news cycle in each country to try and make the time to create your own narratives. But it will be vital. Because the problems we face are international and so our media must be too. 


\section{Networked protest for a populist age}

Jakub Dymek

In the autumn of 2016, the parliament in Poland was presented with one of the most restrictive anti-abortion bills in the modern world. Proposals included jail terms for women terminating pregnancies, the possibility of persecution for miscarriages and provisions posing legal risks even for performing prenatal diagnostics on the foetus. It understandably provoked wide outrage in society. This began through the usual socialmedia channels and soon the spark had ignited into the explosion of mobilisation - it culminated in a nationwide women's strike that involved around 100,000 people not showing-up at schools and offices and instead taking to the streets in protests that spanned the entire country and went beyond the borders of Poland, with demonstrations of solidarity taking place in Berlin, London and Brussels among other places. While demonstrators in Poland formed a human chain around the headquarters of the ruling party, those in solidarity with them outside the country picketed Polish embassies in European capitals with banners in Polish, English and French.

It did not take long after the protests began for my phone to start beeping - friends, fellow journalists and activists requesting information and up-to-date assessments of the situation. Although that quickly changed later, I found out, to my surprise, that there was really next to no information about the situation as it unfolded. No wonder, since the scale and intensity of the protest came as a shock in Poland as well. "What is going on?", "Translate this for us", "Do you have some pictures" - requests poured in. Of course, subsequently, respected European news organisations either sent their correspondents to report on the issue or provided their readers with detailed accounts post-factum. But at the very moment, timely, passionate and potentially viral messages were what was 
demanded. Those few who provided it benefitted clearly - retweets and likes went into the thousands worldwide. Thanks to that, the protests indeed gained worldwide attention and were noticed globally.

If this example would conclude with the usual thesis on the strength of social-media and the "networked individual", there would be little to ponder. Multiple examples from the past, of situations of extreme importance for communities and nations - like the Maidan in Kiev or Tahrir Square protests in Cairo - have been embedded in our collective imaginations for years already. The Polish Black Protest is however important in the way it contradicts some prevailing narratives, not in the way it reinforces them.

What happened quickly after the national strike dissolved and the organisers, as well as participants, went back from the streets to online debates - as well a number of televised ones, thanks to the broad interest the protests got - is that knowledge sharing, gestures of solidarity and support and inspiration created networks where there previously were none. Coincidentally, the same week the clergy of the Russian Orthodox Church came forward with an idea to restrict abortion, which had until then been legal in Russia. Images of protesters against this proposal in Moscow, when they surfaced online, showed an image very familiar to those who had seen the protests in Poland from a few days before. Protesters were spotted bearing placards with an easily identifiable illustration: a sketch of an uterus with ovaries crossed to show a "fuck you" gesture - the same image that came to symbolise all of the earlier protests in Poland this year, including of course the last one. How did this come about? The usual means of exchange between the liberal opposition in Russia and Polish civil society - foundations, exchanges and scholarship programmes - of course exist, but here was a clear example of peer-to-peer, community-tocommunity, protest-to-protest exchange in the absence of any meaningful dialogue on the official level.

This by no means is an argument against traditional media and the need for sustaining and fostering real face-to-face debate whenever possible to help social movements in Europe and beyond. On the contrary: it is an argument for media and civil society to utilise all forms of communication and inspiration and new networks, for they most often spring from the bottom up. Images, slogans and ways of organising from one country or community prove themselves most useful and universal when they can be utilised elsewhere. 
Sometimes one can see herself or himself best in somebody else's struggle. And let us put the notion of "cultural" or geographical proximity as a necessary condition for that to flourish aside - it seems that initiatives inspired (at least in part) by the Polish Black Protest are taken from initiatives in South America and South Korea. And the Black Protest and national women's strike were also in themselves modelled and inspired by different historical and political influences - the idea for a strike was directly based on the women's strike in Iceland in the mid 1970s when women, outraged about the lack of political rights, practically brought the country to a halt when they took to the streets. Black, which became synonymous with the Polish protest, as a symbol of indignation, anger and mourning is a clear reference to traditions as diverse as the Catholic Church and the anarchist movement. Like many successful initiatives this was also a brainchild of many diverse influences. And a profoundly networked idea.

One can learn a couple of things when the Black Protest and Women's Strike are put in the broader European context of conflicting narratives, contrary political responses and institutional impasse that is troubling the continent. It is true that it is next to impossible for the European Institutions - the Commission, Parliament and Council with their PR departments and communications strategists - to put forward a progressive idea or image that will genuinely involve and inspire people across the EU and possibly beyond. For good and bad even the best (or worst) single idea or message conceived between the corridors and in the back rooms in Brussels or Strasbourg is bound to lose traction, dilute and eventually disappear among broad discontent with European elites and political institutions. What is painfully true for the institutions however, does not hinder or stifle ideas and initiatives that spring from the bottom up. Grassroots ideas, conceived by people not belonging to the transnational caste of professional politicians and lobbyists, have the attribute of authenticity, universality and intuitiveness to them that so many PR efforts of parties and political bodies lack. It would be unwise and ill-informed to only look to nationalist and xenophobic surges in Europe to discover that, especially in times when so many ideas are bubbling under the surface of mainstream politics and discourse and the vast majority of them are neither violent nor anti-European.

The international media, too, are learning just that - that however good their coverage and message is, it will be harder for them to fully participate 
in social and political processes unless they, instead of only reporting, take the effort to amplify the messages that are already there and work along the lines of popular demand. Nothing will obliterate the need for good reporting and the necessity of having correspondents wherever something important happens. But there is a visible change - from institutions to individuals, from established trademarks to alternative sources, from just covering issues to participating in them.

That is what my beeping phone made me think of, on the day of the protest - that there is some aspect of media and political verticality that is coming to an end. All of those who called or messaged me that day wanted, in principle, one thing: to know what the protest - the community or multitude - was saying right here and now. They did not want to know what was being said to the protest by the politicians and experts, neither did they want to wait for what the reporters had to say about what they thought of it. What was prized most was timely and networked transmission of the most accurate messages, the relaying of the demands and giving space for visions that are present at the moment - is that not what today's journalism should be about? 


\title{
Journalism in spite of everything
}

\author{
Interview with Esther Alonso, eldiario.es ${ }^{1}$
}

Following the decision of the Socialist Party to abstain in a confidence vote on the Popular Party government, the same prime minister who governed the country with a majority for the past four years will stay in power. Mariano Rajoy, who has been implicated in several cases of corruption within his own party, will continue as Spain's prime minister thanks to the abstention of the Socialist Party deputies. Spain appears to be one of the most corrupt countries in Europe and it is in this context that the online newspaper eldiario.es was launched in 2012, in the midst of the worst economic crisis the country has ever experienced. Eldiario. es is a digital newspaper that defines itself as an online media newspaper that provides "information and analysis with a focus on politics and the economy in their broadest sense: on how they affect people rather than how they affect the parties or the markets", explains Esther Alonso, Marketing and Development director at the newspaper. Eldiario.es works independently (more than 70 per cent of the company that edits eldiario. es belongs to the journalists who write for it) to give a voice to the many people in Spain who are suffering the consequences of a media that is becoming less and less plural.

$$
* * *
$$

Eldiario.es is proving to be a sustainable business model for journalism, having established itself as an authoritative and reliable source for its readers. Can you explain what the key to eldiario's success is, and to what extent your model

1 | This interview took place in November 2016. 
could be reproduced in other European countries? What is its audience profile and what is making readers trust your content?

Our key to success is a unique business model based on the support of our community of readers. 20,000 people ("socios") make financial contributions to eldiario.es in order to strengthen our editorial and financial independence. But there is no paywall: our "socios" do not pay to read the content, they pay for it to circulate freely and thus have a social impact. They pay to belong to a community of citizens who share values like equality, democracy, social justice, and more importantly, independent journalism. Our model could easily be implemented in other European countries. I see no reason why it would not work outside Spain. There are examples of other digital media outlets that are experimenting with similar models in Europe and America, for instance The Texas Tribune, Tiempo Argentino, and Ojo Público in Perú.

As regards gender, 53 per cent of our readers are men and 47 per cent are women. And 52 per cent of our readers are aged between 24 and 44 . They trust our content because we deliver what we promised to deliver: independent journalism based on values like transparency and honesty. Their expectations are fulfilled.

The information most mainstream newspapers and journals provide on Europe tends to focus on the EU institutions and the austerity measures imposed on member states. What type of stories do you think should be covered in order to communicate more and more effectively about Europe and the EU? Do you think a shared European agenda is needed? If so, how should journalists go about creating such an agenda?

I think the general public might be interested in a deeper analysis of why and how certain decisions are being taken at the EU level, and what the alternatives to those decisions might be. In addition I would like to believe that readers would enjoy content with a focus on social values that informs people about the impact European policies have on the citizens. As regards creating a shared European agenda, it is important for each media outlet to ask itself this question first and find its own agenda before addressing the task of creating a common one. 
Although nowadays there are examples of good media platforms, newspapers and video formats operating around Europe, it seems they still lack the capacity to connect and cooperate with similar platforms beyond the national level. How would eldiario.es and its readers benefit from collaboration with similar media platforms? And what challenges does establishing these synergies pose?

Bringing voices together is a good practice that enriches your content as a media outlet and gives your readers a more comprehensive perspective on certain topics. At eldiario.es we warmly invite collaborators and other media projects that share our values to publish on our site. When it comes to cooperation between media projects beyond the national level, one of the main challenges is to agree on the mission and purpose of the collaboration, as well as to find the right balance between the different members of a network in terms of the level of participation. Once these challenges have been met the next step is to develop the collaboration to the point where it is mature.

Economic crisis, unemployment, new forms of government, migration... Many of the issues the Continent faces affect most European countries. Yet we lack the capacity to establish transnational movements that can provide effective solutions. What do you think should be the role of journalists and media platforms in the process of challenging the status quo in Europe? And what can the media do to help restore trust in the European project?

Nowadays there are media projects like eldiario.es that focus on social values and new forms of government and democracy and that are generating content on these shared issues. Media platforms can cover these issues provided this is consistent with their editorial line. Restoring trust in the European project is a complex task that should not be performed by media platforms alone. I believe there are other social agents that should be part of this process, and we the citizens are one of them.

Online media can use new narratives and participative formats, beyond commentaries, to help restore their readers' trust in the European Project. For example media outlets can host online debates with members of the EU parliament and/or other institutions, and invite the public to participate by asking questions on social networks. Another idea might be to launch a blog and invite different European media partners to submit posts. 
The journalists of Hungary's leading daily, Nepszabadsag, are facing the newspaper's demise and have expressed doubts about the official explanation that it was closed for purely financial reasons. How do you keep eldiario.es independent, and what pressures from power structures are you exposed to?

Our editorial independence is a result of the financial independence our socios give us. These 20,000 "socios" are our partners in crime, and they make our project viable and sustainable. They shield us from pressure from power structures and we thank them for supporting independent journalism. We do the journalism we know we have to do and no pressure from above can stop us from doing this. We do investigative journalism and publish exclusives that sometimes expose political or economic power structures unconditionally and without restrictions. 


\title{
We are the newcomers
}

\author{
Interview with Ramy Al-Asheq, Abwab
}

Germany has long been a primary destination for asylum seekers. According to the Pew Research Center, over the past 30 years Germany has received at least 3.6 million asylum applications or nearly one-third ( 32 per cent) of all asylum applications in Europe. The overall increase of asylum seekers between 2013 and 2015 is a reflection of the trajectory of migrants arriving from each of the three leading countries of origin: Syria, Afghanistan and Iraq. Abwab ('Doors') is the first Arabic newspaper in Germany. An independent monthly newspaper that addresses the needs and concerns of Syrian, Iraqi and other Arabic-speaking refugees in Germany. Over 60,000 copies of $A b w a b$ are printed and freely distributed every month in public libraries, NGO centres and refugee shelters across Germany. Ramy Al-Asheq is its editor-in-chief.

$$
* * *
$$

Abwab is the name of the first and so far only Arabic-language newspaper for refugees in Germany. It aims to provide information and serve as a platform for discussing integration-related issues. Who is your target audience? Who are 'the newcomers' and why do you refuse to use the word refugee? In using the term 'newcomer', how do you hope to change people's perceptions of migrants?

Well, let us say, it was a newspaper for 'refugees', but after just one month we realised that we cannot talk about understanding, integration and living together without also talking to the locals. So from the second issue onwards, we started to address a German audience too, with two pages

1 | This interview took place in January 2017. 
written in German. Not only that, we also wanted to 'integrate' German authors, journalists and writers into the Abwab family. Abwab has now become a newspaper by refugees and locals, for refugees and locals.

I think there has been a huge misunderstanding regarding my critical stance on the topic of integration. This is especially true when you look at the response to my article 'This integration is a big lie'. I did not at all refuse to use the word 'refugee'. I am a refugee. I was born a refugee in Syria, because my grandfather was kicked out of his house in the city of Akka, when Israel occupied Palestine in 1948. My father was also born a refugee in Syria. I do not have a passport and I do not have a nationality on paper. I have always been a refugee. I was never anything else, except that here in Germany I became a 'stateless' refugee. I brought my personal story to tell you: I have no problem with this term at all. Being a refugee means you are seeking refuge, safety, dignity and freedom. In this context, the term 'newcomer' is meaningless. 'Newcomer' does not give any information about what the other person needs. However, I do have a problem with the German version of refugee, which is 'Flüchtling', because it means 'runaway'. It is negative and does not carry the meaning of asking for refuge, safety, dignity and freedom. In addition to that, it only has a masculine form.

But the question is not always the meaning of the term 'refugee'. At the moment, we see the entire media machine trying to demonise refugees. We see how the police, media and society at large care more about the nationality of the criminal, than about the crime itself, and definitely more than about the victim. If the criminal is a refugee, all international and local media will talk about the crime. But if it is the same crime, the same victim, but committed by a criminal who is not a refugee, nobody will care. To be a refugee now is to have a 'sexy' identity. Some people will help you, take a selfie and post it on Facebook with the caption "with my refugee". Some people will say, you should look poor and ugly, "you do not look like a refugee!" Some people will ignore your experience, education and thoughts and will deal with you as if you were nothing. The point is; you are only a refugee. In this way, you will find many events called 'refugee in concert', 'refugee reading', 'refugee carnival'. But when I want to attend a music concert, I am not going to watch refugees, I am going to watch and listen to musicians. Refugees are not monkeys in a zoo or a circus. 
When we see how the word 'refugee' is being used to discriminate against people and create barriers between humans, when we see how it is used to put a large number of people of many different backgrounds, nationalities, religions, ideologies, levels of education and generations in one box called 'refugees', then I do not believe it makes sense to use it. It does not make sense to me to create a team of 'refugees' to participate in the 2016 Olympics. In fact, it is shameful! We are living in a world that, in 2015, had created 65.3 million refugees. This fact is really shameful and not a reason to celebrate. To be a refugee is not shameful, but to live in a world that has created 65.3 million refugees is extremely shameful.

So when you see this discrimination, labelling and stereotyping, you will refuse to be labelled. Even if that means that you will lose the meaning of refuge, safety dignity and freedom. This is why a lot of people decided to use the term 'newcomer', which carries a different meaning; newcomers are also human beings, they are equal to the locals. The only difference is that they arrived in this country later, and now they just need to feel welcome and part of the whole, not to be seen or treated as guests.

Abwab addresses issues such as foreign policy, integration and social issues for migrants. Who writes for Abwab and from what perspectives? Do you also aim to reach other sectors of society and have an impact tackling racism and xenophobia, for example? What have been the results so far?

Abwab is the Arabic word for 'doors'. That is why our newspaper has a number of doors: international news, local news, Arabic-speaking community news, a guide to Germany for newcomers, feminism pages, success and survival stories, art and literature pages, and German pages. The authors of $A b w a b$ are from Syria, Palestine, Germany, Egypt, Morocco, Tunisia, Eritrea, and Jordan. All of us have different perspectives, which are reflected in our writing, and there is a lot of communication going on between the different editors and contributors. Our aim is to be a bridge and facilitate communication between people on the same level. We are trying to communicate with activists from both societies. For example, in Dresden we met a group of German anti-racist activists and now we are planning to do a project together. We are equally in contact and engaged with different initiatives run by newcomers. 
With $A b w a b$, we were very successful in reaching locals and refugees alike and we had a lot of interesting input. We print more than 60,000 copies every month and have 50,000 unique user sessions per month on our website, which also has a German and English version. We are focusing on both societies, opening critical perspectives to allow both "criticism and self-criticism", because both societies have their own stereotypes and ready-made images. I have received many emails from Germans who I do not know, telling me that they appreciate our newspaper. I am not exaggerating when I say that there are dozens of messages that make me feel proud and hopeful. All the Germans that I have met have been positive and friendly. Maybe I am lucky in this, as my German friends tell me, but I think that everywhere in the world the percentage of good people is always greater than the percentage of bad people.

For many European citizens, Facebook, Twitter and even Instagram are becoming important sources of information on topics such as Brexit, the US elections, but also on the migration crisis and the war in Syria. How do you evaluate the information people are getting from social media? How does Abwab contribute to clarifying doubts, fake-news and misconceptions around such a complex crisis, whilst also fighting against stereotypes about migrants?

One of the reasons that $A b w a b$ was created was to give refugees access to quality news and journalistic stories in their own language. Facebook is full of fake news and hate speech. We are trying to fight that as much as we can. Abwab now has around 93,500 followers on Facebook. As great as that is, it has also meant that we have faced a lot of hate speech, but this was expected from the beginning, and it definitely happens less now than before.

If you want to create a deeper understanding, you need to talk to people in their language and from their cultural point of view. Our German editor Lilian Pithan has made a lot of tasks easier with her comments and editing, especially when she manages to make the stories closer to German understanding and culture. And this is also why we manage to be closer to our Arabic-speaking audience, because we are from the same culture and we know it very well and we know how to use the right language to critique and inform, etc. So we're not making the 'teaching refugees how to use the toilet', or 'teaching refugees how to have sex', mistakes. 
As the migration crisis in Europe continues, one particular fact gets cited over and over: that this is the biggest migration movement since World War II. Do you think the model of Abwab can and should be reproduced in other European countries? Can you imagine establishing a partnership, or alliances, with other European countries to develop such a project? What would you need in order to develop such collaboration?

First of all, I do not believe in the term 'migrant / refugee crisis in Europe'. The real crisis is in Lebanon and Jordan, which have taken in the biggest number of refugees, being the poor, small countries that they are. More than 40 per cent of the current population of Lebanon are refugees. This is where the crisis is. Furthermore, I think that there is no migration crisis in Europe as a whole, but only in some European countries. For example, there is no huge migration movement in the direction of France, Switzerland, Portugal, the UK, or the Eastern European countries. The crisis is in Greece and in other countries, which are closer to Asia and Africa. The EU definitely did not assume its responsibilities as a union in this context of events. Even in the case of Germany, I do not see what is happening as a crisis. If you look at the total population number and compare it with the number of refugees, can 1 per cent really unleash a crisis?

However, for refugees the 'refugee crisis' really is a crisis. For those who have been kicked out of their homes and cities, who have lost their families, hope and lives. It is not only a crisis, it is a catastrophe. Since we started $A b w a b$, we have had many requests to launch similar newspapers in countries like France, the Netherlands, Switzerland, Sweden and the UK. Unfortunately, our capabilities are limited. Our network of writers and journalists is ready, the audience exists, but it is very hard to find financial support. We are an independent newspaper, which also means that there are many funding sources we would never accept, for example funding from government, political parties, companies or any other source which would seek to influence our content.

How do you finance Abwab? Have you faced political obstacles or pressures thus far?

We finance Abwab through advertising. Our publisher New German Media Ltd has a marketing department which is responsible for that. We 
started with two sponsors, MoneyGram and Ortel, and now have some more advertisers like the German Ministry of Education and the German Federal Office for Migration and Refugees. Until now, we have not faced any political obstacles or pressure.

Germany has filled a particular position in the migration debate, as Merkel is often celebrated for her 'open door policy', while also having contributed to the tightening of asylum laws, having signed the deal with Turkey to curb migration to the EU. In this debate the term 'Lügenpresse' has gained renewed popularity with the far right, often being used to discredit the media. How have you witnessed these developments? What responsibility do you see, on the side of the media, in shaping this discourse, and what room for change can you see?

In general, people like to hear what they believe in or accept. This is not only true for Germans, but also for Syrians and all other nationalities. The mission of a journalist is to show the truth. The question we are facing now is, which media outlets are showing us the truth? How much propaganda is out there? We cannot deny that there are media outlets out there who do not show the truth. People have the right to say that something is a lie, but then the media has to prove what they say is true, nevertheless. This said, it does not make sense to me, when the right wing groups attack the media, because they know that a lot of media indeed support their extreme ideas. In addition to that, the media does not talk enough about crimes committed by members of the extreme right, like burning refugee shelters, or attacking people. In my opinion, if you tell half the truth, you are a liar. We do not need to present people as angels, but neither do we need to present them as demons. This is the biggest mistake the media is making at the moment, and you could say the same for politicians.

How do you foresee the next steps for Abwab?

Abwab is bigger now and our responsibilities have grown accordingly. Our plan is to make $A b w a b$ into a bilingual newspaper as soon as possible, and to create a platform to discuss all essential issues for German and European societies. We are already actively pursuing our goal of addressing a larger German audience. 


\title{
Our digitally mediated society
}

\author{
Robin Mansell ${ }^{1}$
}

This article focuses on how we imagine our digitally mediated society and on whether alternative worlds or pathways are possible (Mansell, 2012). What is happening to the public's right to access information, to the right of citizens to be free from surveillance, and to their privacy, as a result of the growing technical ability to track, analyse and act on data? Have dominant trends in digitally mediated surveillance, power and practice congealed, or, can they be better aligned with citizen interests in social democracy and a good society? What algorithms are, who or what governs them, and what values are embedded in them, are questions that are crucial to answer. Research on algorithms, artificial intelligence and their applications is a growth industry and is attracting a lot of research funding. Researchers treat algorithms as a sensitising concept, as active agents, or as black boxes that need to be unpacked. Some work is focusing on the consequences of algorithms for social sorting and discrimination, on whether users are aware of them and on whether they are politically accountable through governance measures.

It is essential to locate these questions in the context of what kind of society is desirable and for whom. Surveillance using today's networks and algorithms is obviously connected with power relationships. These relationships are understood differently by algorithm makers and their corporate and state overseers, as compared to many social science scholars and internet users. Common to many perspectives on the growing use of

1 | An earlier version of this essay was presented as a keynote at the International Communication Association Conference, Fukoka, 13th June 2016 and published in modified form at openDemocracy, 20th July 2016 (https://www.opendemocracy.net/digitaliberties/robin-mansell/surveillance-power-and-communication) 
algorithms is a core societal problem. This is an increasing fascination with - and attachment to - the quantifiable. Even when the algorithm is treated as a sensitising concept, research is often very algorithm-centric, and it is at risk of forgetting why questions about power, surveillance and algorithms matter. They matter because of their relation to very big social, political and economic problems.

Wittgenstein said that 'we cannot [...] say what we cannot think' and in this sense algorithms are both effective and unfathomable. Most people, most of the time, do not think about what is happening when they go online and algorithms are at work. Bucher's (2016) work shows that we can imagine that something is happening, but that it is almost impossible for us to think about what choices are being made for us and by whom. For algorithm makers, however, algorithmic computation is mainly about patterns of data. The problems are about prediction, with the aim of rubbing out the foibles of human beings, and of optimising the quantification of behaviour.

\section{A society mediated by algorithms}

Algorithms make digitally mediated surveillance, or watching over us, technically very easy. Applications can support and mitigate the damage of disasters, they can help protect people in public spaces, they can help signal health risks and, in that sense, they combat disease. They also help in monitoring climate change. Algorithms are being used to help companies to boost profits and countries are (in some cases) experiencing economic growth as a result - a claim that can be verified. Algorithms also support surveillance or undersight, as Mann (2003) and others call it; and so algorithmic based watching from below can support a radical politics of resistance.

The digitised world is becoming more inclusive by some measures. Some 914 million people have at least one international connection on social media such as Facebook, Twitter, LinkedIn and WeChat and most are using it for electronic commerce. Global data flows raised the world's GDP by more than 10 per cent to USD 7.8 trillion in 2014. Small businesses can become 'micro-multinationals' and around 12 per cent of global goods trade is done via electronic commerce on platforms like Alibaba, Amazon, eBay, Flipkart, and Rakuten. Company platforms and automated processes are operating at hyperscale and, thanks to Airbnb, 
Agoda and TripAdvisor, data analytics-driven decision-making is the order of the day. The Internet of Things is feeding this and companies are investing to improve productivity, innovation and customer retention.

Digital services are becoming central to the majority of people's lives in the Global North. Global flows of data are becoming more inclusive of people in the Global South, although McKinsey notes that lagging countries are catching up extremely slowly (Manyika et al., 2016). Some six billion people do not have high speed broadband, some four billion do not have Internet access at all, and some two billion do not have a mobile phone. With the growth of the big data ecology, new types of risk are commanding public attention, but data processing using algorithms is expected to come to the rescue if power grids fail, financial crises worsen, or there are information leaks. For McKinsey and some other corporate analysts, the biggest sources of vulnerability for society are disgruntled employees, criminals, political activists, and other countries, not the algorithms themselves.

The rate of inclusion and the penetration of digital technology and statistics on gaps cannot be the sole criteria for deciding whether the pathway towards an algorithmic society is a good one. Alongside the spread of algorithms, inequality is growing within countries, even as digital divides start to close. Countries are facing economic instability, bubbles and financial crashes. Poverty, lack of housing and poor water sanitation and asylum seeking, are all too visible. For some, these are symptoms of calculable risks that can be managed by relying on algorithms and data analytics.

We have a society that increasingly privileges quantification. We encounter big data and algorithmic computing as if it is novel in a way that is similar to the way we responded several decades ago to the birth of the digital revolution and the information society. We encounter it as new partly because debate about big data and algorithms is being hyped by powerful actors as a solution to big social problems. There is no coordinated or organised conspiracy, but there is a campaign to assure people that, whatever the functions of today's algorithms, they are designed to keep us safe, happy, and make us wealthier. Attention in the media to the role of the state in war, migration and terrorism threats is bringing digital monitoring and algorithms more prominently into the public eye. This, 
to some extent, is deflecting citizens' attention away from threats to their privacy and their rights to freedom of expression - at least for a while.

The catch phrase, 'big data', is new, but data processing itself is not. What is new to the public realm is the move into behavioural analytics and learning algorithms where the analytics may occur beyond the knowledge of the algorithm makers. It is this possibility, which is deepening the fascination with the quantification of everyday life. MIT's new AIbased Cyber Threat Analysis Framework, for example, aims to ramp up the speed and accuracy of analytics to find threats in the Dark Web by scanning for malware releases and ransom-ware tools. The technology is intended to be used to identify new threats and observe the activities of hackers, but some experts question both the effectiveness and the human rights implications of the algorithm-driven techniques - they are not a 'silver bullet'. The digital communications skills gap generally is big and there is much debate about deskilling and up-skilling. Few people have the knowledge to understand what an algorithm is or what it means to do data analytics. Skilled people in areas like artificial intelligence, data management, data quality control, and data visualisation are short in supply, but debate about what to do about this is not new and solutions continue to fall short of aspirations especially for the general population.

We are moving ever more rapidly towards a computational theocracy as Ian Bogost suggests in the US The Atlantic 2015. The cathedral or temple of computation is a societal issue that is becoming more problematic alongside growing social and economic inequality. The challenge isn't only whether digital communication - based on algorithmic computation - is exploitative or liberating, inclusive or excluding. It is to keep in mind that, although it may seem as if algorithms are the drivers of society and that these developments are negating human agency, human agency still matters. All these developments are influenced by norms and rules of governance and these are humanly constituted.

\section{Governing computational black boxes}

The term governance is often used loosely, but it refers to the rules, norms, and practices that are accepted or resisted in a given society. Governance influences the kind of world that is being borne; it is about the fundamentals of life, the quality of people's lives, and whether, by any measure, societies aspire to be good societies - societies that are inclusive, respectful, and 
enabling. Governance involves legislation and policy and it is needed to make sure that the algorithms that are currently signposting Twitter tends and the most read press articles or supporting surveillance by the police are as transparent as possible. It would be useful to understand computational biases, who or what algorithms hide, and when they are successful and when they fail. But governance is also about more subtle issues. Algorithms involve networked information assemblages - 'institutionally situated code, practices, and norms with the power to create, sustain, and signify relationships among people and data through minimally observable, semi-autonomous action' (Ananny, 2016: 93). In this sense, algorithms can govern by structuring future possibilities. When the results they produce are treated as if they are certain, our capacity to think about alternative worlds and development pathways is discouraged because these assemblages are disciplining technologies and they discipline the mind.

If governance is the 'the ensemble of techniques and procedures put into place to direct the conduct of men and women and to take account of the probabilities of their action and their relations' (Lazzarato, 2009: 114), then we need to understand why it is acceptable to so many that machine learning or algorithmic computation are set to become an even greater part of our lives in the future. Algorithmic 'calculative practices are established as legitimate (or true)' (Introna, 2016: 39) increasingly, and they are being internalised. But, while they may be more effective in producing self-governing subjects than earlier technologies, they are not 100 percent effective. We need to remember that algorithms do not make a society. It is human beings in their institutional settings who make the world. The biggest governance challenge today in this area is not so much the algorithm itself, but the assumption that human conduct is predictable enough to allow human beings to defer to machine-driven decisions. When such decisions exacerbate inequality, unfairness, and discrimination, we are not on a pathway aligned with most people's ideas of a good society.

Resistance to the algorithmic computational drama, as it has been called, is definitely needed. The black box that needs unpacking is not the inner workings of an algorithm - although this is a nice theoretical challenge. A different black box should be the principal concern. In digitalisation's earlier history, a Stanford University economist who studied technological innovation said that researchers should look inside 
the black box of technology (Rosenberg, 1982), but he meant research should focus on points of economic or political power and control. This means that instrumental social science treatments of algorithmic black boxed power need to be challenged with the aim of understanding how the velocity, volume, and value of data are increasingly encouraging us to bow to the cathedral of computation and quantification.

Data derivatives - the combinations of data traces left by people - are being used with probabilistic techniques to yield correlations and new possible risks in the surveillance and security field (Amoore, 2011). These risks are acted upon, but who has the power to act and which companies, states or social movement groups can and do respond? Empirical analysis of who has the power to act is needed to examine which data analytic results are privileged. Power asymmetries in the digital ecology are framed by global capitalism and we should not forget this. But when the present and future are visualised as risk maps, scores or flags based on sophisticated computations, someone - a human - takes a decision to act. Designers and engineers choose algorithms based on how quickly they return results or on their computational elegance, but this should not be the main determinant of actions that are taken.

The shift from data analysis and patterns to action is a gateway or control point through which power is exercised. This is the control point we should focus on - who can and does take action? The algorithmic world negates the vast majority of people's agency, but some retain the power to make choices for us. Citizens who rely on the Cloud, self-managed bioteams, avatars or Facebook have little chance of mastery. They have few resources to take action. But for others, such as the military and big companies, choices and actions are leading to judgements about the use, for example, of aerial surveillance and drones or geo-mapping, and the targeting 'persons of concern'. These actions reinforce inequalities and they expose marginalised populations. Those who interpret, make choices and act on data analytics results can be questioned and formal governance arrangements could be devised to hold them to account, at least in societies that respect the fundamental rights of citizens. Unfortunately, growing captivation by a computational theocracy means that relatively little research is focusing on how the people who act on data can be held to account more effectively. This is different than seeking to hold the algorithmic code itself to account or the individual algorithm designers. 


\section{A seductive computational theocracy}

A computational theocracy is very attractive because a reification of a calculated future is taking hold. An example comes from social computing, a field that brings computing science together with engineering and social science. Social machines are being built with the aim of achieving a web based social and technical system for 'the mechanistic realisation of system-level processes' (Smart \& Shadbolt, 2014). The goal is the 'webextended mind', which can participate in the mental states of human beings. Developers aim to give equal weight to the technological and the social. But how do the social machine makers understand social issues?

They draw from business and management studies in which desirable behaviour is anything that helps to exploit economic returns. The digital platforms supporting algorithm-based services are seen as neutral conduits for data transmission. Algorithms are likely to be seen selforganising agents in a system that 'creates itself out of itself' and selects the fittest (Arthur, 2009). The human being is seen as an object to be predicted as a rational agent. Values are not neglected, but justice linked to how well resources are allocated using rational choice procedural models and transparency is a property of the technical system. In relation to policy requirements such as privacy, the goal is to make digital records of behaviour automatically and to accurately predict personal attributes. Rational expectations models are preferred because they help with the coding of human behaviour, and uncertainty and emotion are not yet reliably codable. The aim is to develop an axiomatised computational logic in order to formalise values such as fairness and equity (Pitt et al., 2013).

For decades the ultimate aim has been to build a unified theory of artificial intelligence. This involves solving the problem of making inferences about the internal structure of a system when all that is known about that system is the input and output signals. The aim is to automate human intelligence by creating 'an all-powerful executive homunculus whose duties require almost Godlike omniscience' (Dennett, 1978: 164). Examples of technologies moving in this direction are driverless cars, the augmented soldier and the digitally enabled consumer. The semiconductor manufacturer, Qualcomm, is working on neuroprocessing engines for smart phones and many more artificial intelligence developments are starting to come out of the laboratory. In summary, for scientists and engineers, despite a commitment to working with social scientists, 
algorithms are understood to 'reason' about reliability and honesty and they are expected to facilitate good behaviour.

The computational goal is, 'changing what it means to be human' (Rheingold, 2002) and there is resistance to a calculable good life in other areas of the social sciences. Some scholars understand, for example, that the internet is radically incomplete and so is the development of algorithms. But relatively few researchers are asking fundamental questions about what it means to be human and about whether a different pathway is possible. Algorithmic techniques can 'rule out, [and] render invisible, other potential futures' (Amoore, 2011: 38), but when it comes to big social problems - policing, migration, climate change or inequality and poverty - what alternatives are being concealed by the gleam of riskbased algorithmic solutions? Even if algorithms operate at speeds and scales beyond the threshold of human perception, this doesn't mean we should give up on governing the control points where the algorithmic results are translated into action.

\section{Conclusion}

What alternative pathways are there? Much more attention needs to be given to the control points of surveillance, power and action. This is where choices are made and action is taken by relatively limited numbers of human beings who are setting the pathway for social, economic and political development. Governance is needed, not so much of individual algorithm developers, but of states and companies who finance their work. Governance using conventional approaches to privacy legislation and policy are one part of this and countries are limiting data processing and data flows in ways that are more or less democratic. Indonesia, Nigeria, Russia, Vietnam and the United Kingdom have passed legislation and Brazil has its 'Internet Bill of Rights'. The European Court of Justice has upheld the 'right to be forgotten'. But companies are innovative. They can evade legislation by, for instance, running their analytics engines on separate databases without breaking the law. States are calling for open data flows to facilitate their security agendas and companies are lobbying for self-governance, claiming their formal representations of data access rights, copyright, and privacy norms in algorithms are, by definition, consistent with good behaviour and a better life. 
Conventional privacy protection and human rights legislation has some traction, but rights-based approaches to privacy and surveillance that rely on informed consent are becoming unenforceable. If the quantification of everything means that life itself is likely to become humanly ungovernable, then care of the self and others could also start to become meaningless. The default assumption is that humans are empowered by an immersive mediated environment and they benefit as a result. Focusing on regulatory toolkits that might govern social machines and their developers is important, but better insight is needed into how to combat the notion that quantification is synonymous with the good life.

The digital world is not benign, but it is not predetermined either. Alternative societal outcomes are possible, but only if we can say and think about them; only if we can imagine them. Research is needed on who orchestrates actions based on the technologies of surveillance. We need a clearer view of who funds algorithmic computational research, who commercialises it, and who is using it to act on and shape our world. Coalitions of actors - scholars, activists, politicians and captains of industry will need to collaborate if the pathway we are following to a calculated and unequal - future is to change. The current pathway is incompatible with human agency, and most likely with greater equality, for the great majority of the world's citizens. It is for this reason that the overwhelming fascination with the quantification of society needs to be questioned and resisted when it is inconsistent with human rights and values. The growing data driven intensity of our lives is only pre-determined if we persist in believing that it is and if we fail to change direction.

\section{BIBLIOGRAPHY}

Amoore, L. A. (2011): Data derivatives: On the emergence of a security risk calculus for our times. Theory, Culture \& Society, 28(6): 24-43.

Ananny, M. (2016): Toward an ethics of algorithms: Convening, observation, probability, and timeliness. Science, Technology \& Human Values, 41(1): 93-117.

Arthur, W. B. (2009): The nature of technology: What it is and how it evolves. New York: Allen Lane. 
Bucher, T. (2016): The algorithmic imaginary: Exploring the ordinary affects of facebook algorithms. Information, communication \& society, Online $25 \mathrm{Feb}$.

Dennett, D. C. (1978): Toward a cognitive theory of consciousness. In C. W. Savage (Ed.). Perception and cognition: Issues in the foundations of psychology, volume ix minnesota studies in the philosophy of science, (pp. 201-228). Minneapolis, MI: University of Minnnesota.

Introna, L. (2016): Algorithms, governance, and governmentality: On governing academic writing. Science, Technology \& Human Values, 41(1): 17-49.

Lazzarato, M. (2009): Neoliberalism in action: Inequality, insecurity and the reconstitution of the social. Theory, Culture a Society, 26(6): 109133.

Mann, S., Nolan, J., and Wellman, B. (2003): Sousveillance: Inventing and using wearable computing devices for data collection in surveillance environments. Surveillance \& Society, 1(3): 331-355.

Mansell, R. (2012): Imagining the internet: Communication, innovation and governance. Oxford: Oxford University Press.

Manyika, J., Lund, S., Bughin, J., Woetzel, J., Stamenov, K., and Dhingra, D. (2016): Digital globalization: The new era of global flows. McKinsey Global Institute, McKinsey \& Company, Washington, DC.

Pitt, J., Busquets, D., and Riveret, R. (2013): The pursuit of computational justice in open systems. AI Q Society, Dec.: 1-19.

Rheingold, H. (2002): Smart mobs: The next social revolution. New York: Perseus Press.

Rosenberg, N. (1982): Inside the black box: Technology and economics. Cambridge: Cambridge University Press.

Smart, P. R. and Shadbolt, N. R. (2014): Social machines. In M. KhosrowPour (Ed.). Encyclopedia of information science and technology, third edition, (pp. 6855-6862). Hershey, PA: IGI Global. 
Shifting Alliances 



\section{Introduction}

All of the latest major events in European politics have had a twofold implication. Wherever the challenges grew, the potential for a progressive European civil society also became visible. From austerity politics to free trade negotiations, from the refugee movement to Brexit, from nationalist governments to the rise of far right movements: in all these cases European citizens organised themselves and stood up for a Europe of openness, tolerance and solidarity. But despite these signs of hope, the overall political situation undoubtedly requires much more in terms of coordinated answers from a progressive left. The challenges, with rightwing populism at the top of the list, can only be faced through broad alliances that have the capacity for strategic political thinking and acting. In order to reclaim discourses, streets, parliaments and governments, liberal civil society has to "get out of its comfort zone" as Pia Eberhardt from the Anti-TTIP protests puts it: "Let's not lecture ourselves on our positions, but let's focus on what we have in common".

Therefore the main question of this chapter is: how can existing actors and networks improve their cooperation in order to build capacity and gain political influence? Finding answers to this question, which has often been a struggle for the internationalist left, is now more important than ever with major elections ahead that will set the course for the future of Europe. Which approaches will help stop the paradoxical development of nationalism becoming the most dominant internationalist movement again?

By bringing together some more general thoughts with examples of successful European protests and movements, we hope to not only present important lessons learned from past experiences, but also to outline possible paths for the future. Lorenzo Marsili, co-founder of European Alternatives, opens the chapter with reflections on the need of establishing 
democracy beyond the nation-state. It follows with his conversation with Barbara Spinelli, Member of the European Parliament for the European United Left group (GUE/NGL), about fundamental strategic questions concerning the future of the European Union. Dieter Plehwe, senior research fellow at the Berlin Social Sciences Centre, traces back the dominant neoliberal ideology and shows the role political networks played in its path to hegemony. Andreas Karitzis, former member of Syriza, asks which conclusions the left should draw from the case of Syriza and Sophie Bloemen, policy advisor and co-founder of the Commons network, proposes the commons as a unifying political vision and practice. Three interviews follow: Pia Eberhardt presents the case of the Anti-TTIP protest and ideas for what other movements can learn from it. Two new movements from Eastern Europe follow: we talk with Razem (the new political party in Poland) and Demos (a civic coalition in Romania) about their origins and the ways they are organising. The chapter ends with an exciting example of political organisation and culture beyond the nation state, Europe and state-based democracy: The Rojava Revolution that happened in the middle of the Syrian civil war. Jonas Staal, visual artist and scholar, introduces the Revolution and the model of stateless democracy together with Sheruan Hassan, member of the Kurdish Democratic Union Party (PYD) and Staal ends the chapter with an interview with Salih Muslim, Co-Chair of PYD, about the fight for democratic autonomy and the concept of democratic confederalism. To illustrate these two contributions from Jonas Staal, we also included a series of his pictures on the construction of the parliamentary assembly in Rojava. 


\title{
A rigged economy in a rigged democracy
}

\author{
Lorenzo Marsili
}

Beijing. Late summer 2015. A few weeks have passed since the surrender of Syriza, the Greek anti-austerity governing party. Greece is forced to sign a new memorandum with its creditors and to hold new elections. Despite a crisis that has wiped out 30 per cent of the economy, left over half of the country's youth unemployed and rendered all of the political parties illegitimate, the Greek parliamentary system remains intact. Widespread protest is followed by an orderly vote at the polls and growing apathy and abstention in the streets.

"All of this would have been unthinkable in China" says Zhang Ying, a prominent spokesperson of the Chinese Communist Party. "There is one thing we envy greatly about your democratic system: its resilience. In our country, an economic crisis of such a magnitude and social conflicts of such a scale would have brought a collapse of the system. Instead, you are waiting for the next elections."

The long years of the European crisis have not passed unobserved. While on the one hand they have confirmed all of the prejudices of the Chinese elite about the inefficiency and short-termism of democracy, they have also demonstrated its capacity to survive prolonged periods of economic collapse and social discontent. This resilience, it should be noted, is absent in authoritarian regimes, which are instead rigid, often incapable of adapting themselves to new circumstances and therefore structurally fragile and prone to rupture. In the Middle East, the Arab Spring transformed rapidly into a revolutionary wave precisely due to the incapacity of the political system to insert the demands for transformation that were coming from the squares into a framework of non-violent change. The first meeting of the Politburo after the collapse of the Berlin Wall in 1989 was dedicated, as planned, to discussions of agricultural 
reform. 'Stiffing up', pretending nothing is going on, using coercion and authority to avoid change can prolong the life of a discredited and unpopular system. But when change comes - as it no doubt will - it will be disruptive and destructive.

By contrast the democratic system appears, at least in principle, highly elastic, able to transform the conflict between political parties into a conflict with agreed rules - to regulate demands for change, allowing them expression before they reach breaking point.

There is a great body of work describing the profound anxieties of the early 2oth century elite that the expansion of suffrage might allow the proletarian masses to take power and upturn the system. It was argument that also resonated among the first Marxists, who imagined that a politically emancipated working class could potentially seize power through democratic means. But the opposite happened. Liberal capitalism used the enfranchisement of workers and the majority of peasants to bring revolutionary fervour and popular rage inside the system. The parliamenterisation of class conflict provided a mechanism for channelling social unrest and gave birth to a new set of policies which, however incompletely, were able to respond to some of the concerns of the weakest in society, ultimately saving capitalism from itself.

Take the United States following the Great Depression of 1929. Roosevelt's New Deal was the most significant intervention in the economy to that date and marked a significant split with the unfettered and unequal laissez-faire capitalism of the 19th and early 20 th century. It put a nation back to work, built income support structures and social security, restarted the economy with a fairer distribution of resources and put a halt to the excesses of financial speculation through the separation of commercial and investment banks. It saved American capitalism through a profound transformation of its premises, even at the cost of attacking the privileges of the ruling classes themselves.

We could tell a similar stories for the 'boom years', the glorious thirties that followed the Second World War. From the ashes of conflict European capitalism transformed once again, giving life to an articulated vision of a welfare state that seemed to indicate a third space between the excesses of liberalism and of communism. It was a period of hegemony for the system born out of the New Deal; a capitalism guided strongly by the public hand, protected by the Breton Woods agreements - which restrained global finance - and which codified important social and labour rights. 
The terrible inequality of the first half of the 2 oth century was outlawed and a new pact between labour and capital brought a new and fairer distribution of the fruits of development. So much so that large sections of the proletariat and peasantry were transformed into the new 'middle class' of advanced capitalism.

Ultimately, these were years characterised by the primacy of democracy over economics, with policy decisions directly reflecting struggles for social justice, equality and the extension of rights. Parties, mass trade unions, social movements and a high electoral turnout helped to keep power in check, while the threat of the Soviet model put pressure on the ruling class to meet popular demands. It was widely agreed that democratic processes, rather than market forces, should guide economic policy and that full employment and the provision of social protections were the responsibility of the state. It was no $E l$ Dorado, as the intensity of public protests in those years clearly shows, but it was democracy, with an economic model that worked for the majority and was capable of responding to the will of the people.

Today, this is no longer the case.

\section{"Misery acquaints a man with strange bedfellows"}

Faced with the proliferation of openly anti-systemic forces and the increasingly real prospect of the disintegration of the European Union, many have implicitly referred to this prophetic expression from Shakespeare's masterpiece 'The Tempest'. It's the austerity, stupid!

Donald Trump's victory disproves those who have tried to maintain that, unlike Europe, the United States has successfully exited from the economic crisis. Yet the signs were there. One might point to the fact that food stamps, alimentary assistance for the poorest, almost doubled under Obama's presidency; that the majority of new jobs are those that David Graeber defines as 'bullshit jobs', repetitive, badly paid and with little social value; that a large part of these are 'fake' forms of self-employment, such as people that work for home delivery services in the gig economy or Uber drivers who work without any contractual guarantees. Yes, unemployment has fallen to a historic low, but only because 90 million Americans have stopped searching for jobs. If these individuals were to be included, the real figure would be over 20 per cent. Meanwhile, unprecedented inequality and the decline of the middle class has undermined social 
cohesion, leading to increased violence, an exploding prison population and even decreased life expectancy.

A similar but even more extreme situation can be found in Europe, where growing inequality and the devaluation of work have generated paradoxical effects such as declining living standards even in conditions of economic growth. Just think of Germany, the continent's largest economic power but also the EU country with the highest number of 'working poor.' It is not often remarked upon, but over 20 per cent of Germans live below the poverty line. Or Britain, which despite having monetary sovereignty, and soon perhaps control of its borders, has the highest level of child malnutrition in Europe.

The misery of Southern Europe we know well. If a third of the inhabitants of the world's eighth largest economy and, the second industrial power in Europe - Italy - are at risk of poverty and social exclusion, this means that the system is profoundly dysfunctional. This dysfunction is accentuated by the poor design of the Eurozone, and in turn by the great differences within the European Union. 'Two speed Europe' is visible not only in the asphyxiated economic growth figures but also and especially in the varying life possibilities available for the youngest. The European space was supposed to guarantee freedom of movement and the sharing of intelligence and creativity. But the reality for most looks more like the sad forced migrations of the past than the ideal of the much-lauded Erasmus generation. Indeed, the flux of people across the European space is one of the most powerful symbols of the imbalances of power: it is young people from the South that are moving to the North. This one-way migration creates a huge loss of resources in some countries and, in a tragic, vicious circle, becomes an additional cause of impoverishment in and of itself. In 2016 more than 100,000 Italians abandoned their home country, while countries like Latvia and Romania have lost more than 10 per cent of their populations since the start of the crisis.

There is much that is true in the view that sees the rejection of the establishment - whether that of the European Union or of national elites - as a result of years of shambolic economic policy and of a growing exclusion and marginalisation of increasingly more important sectors of society. The economy is rigged. And in these conditions, demands for dignity and equality are no doubt central points. But we need to add another element to the equation. 


\section{"You are destined for a great Monday! Pity that Sunday will never end."}

So wrote Franz Kafka in his diaries in a moment of profound melancholy. Today, this line appears to be the only response that the governing elite is able to offer to those arguing for real change. The exit from the 'tempest' of poverty and exclusion, from a rigged economy that works only for a minority, continues to represent a Monday that will never arrive. What's offered in its place is the eternal return of the same, a Sunday defined by the status quo, propped up by repression and cosmetic changes: business as usual.

If the crisis that erupted in 2007-8 has the dignity of being compared to that of 1929, the same cannot be said of the political response offered by Western democracies. Unfortunately, and despite his many merits, Barack Obama is the most significant example. A few days after his first election, Newsweek wrote candidly that the task for the new President would be nothing less than "to lead the conceptual counterrevolution against an idea that has dominated the globe since the end of the cold war but is now in the final stages of flaming out: free-market absolutism." Obama came to power shortly after the financial bubble burst, on the back of an extraordinary wave of public participation. With a Senate still under the control of the Democrats and the image of the economic establishment in pieces, he had a great window of opportunity to put into act his own New Deal and break with a system in crisis. Instead he chose the old path. He appointed Tim Geithner and Larry Summers to the Treasury, the same individuals who during the Clinton administration enthusiastically removed the last obstacles that were holding back the financial sector, among them the Glass-Steagall legislation, approved by Roosevelt himself and which prevented speculators playing roulette with the savings of the middle class. Instead of fixing the disaster, Obama called for help from the same people that had created it. This was no moral drama of penitence and redemption but the reproduction of the same financial privileges that had brought the world to the brink of abyss. In the words of Tim Geithner, the role of the States was to "foam the runway" for the banks in crisis.

Europe of course is little different. In the course of many years of permanent crisis we have seen the proliferation of various protests, platforms and social movements arguing for a reconfiguration of the 
European system. Some of these initiatives have come from parts of the establishment, others from a grassroots level, some are composed of intellectuals and academics, others come from political parties and in a few cases have emerged directly from progressive governments. And yet it has all led to nothing. On the contrary, the direction of travel appears stubbornly wrong, with the economy managed in an increasingly inept manner and the absence of democracy more entrenched by the day.

The result of all of this is that more and more people have lost faith that the European Union can be transformed in a positive manner. Some critics focus on an institutional system that is irredeemably dysfunctional, others on the damaging intransigence of Germany, others still on the intrinsically neoliberal nature of the European project. Some of these voices come from the right, others from the left. But whatever the analysis or political position the conclusion is always the same: the time has come to limit the damage and declare the end of a disastrous project incapable of reforming itself. For many, the experience of the defeat of Syriza by the Troika and Eurogroup was a watershed moment. The enthusiasm with which so many people had participated in and supported the struggle against the politics of austerity was replaced by a widespread feeling of melancholy and hopelessness. Democracy returned from the Athens Spring with broken bones.

The elasticity of democracy resides in the capacity of political struggle and the demands of the weakest to produce real compromises and real social changes in institutions and in politics, opening up the possibility of going beyond the failed status quo within the very system that is in crisis. Democracy is a constituent process, capable of redefining the distribution of wealth, power and privilege. Today, however, our democracies are less and less capable of guaranteeing the effective transformation of dissensus into coherent political alternatives. More and more they are the victims of oligarchies that thrive with an extraordinary concentration of wealth and power. Disliked by most, these democracies are becoming rigid systems, capable of offering no alternative to the status quo other than their own implosion. The resilience of which Zhang Ying was speaking is disappearing. Is it still possible to create change without rejecting the system in its entirety? More and more people have begun to believe that it is not. 
This is why Trump, the Brexiteers and many other of the forces of the new far right have become the symbols of an exit from the eternal Sunday of the Clintons, Camerons and Junkers of this world. An exit that doesn't care where the road is leading and which is driven by exasperation at the terrifying mix of authoritarianism and economic failure that characterise Western democracies today: a rigged economy in a rigged democracy. After years in which the act of voting seemed to have become a purely performative act, charged with symbolism but lacking real agency, it is anti-systemic populism itself that has restored seriousness and weight to the electoral ballot. Capable, with a vote in London or Paris, of making Europe tremble; with a vote in Washington of making the world shake. Tragically, it seems that it is the far-right populists to have been the first to have clearly broken the mantra of there is no alternative and to have restored an illusion of sovereignty and democracy.

The real crisis of our time is a democratic crisis. Change you can believe in was one of the most famous slogans of the Obama campaign. But those promises of change, in the US and even more so in Europe, have been dashed again and again. The system is entrenched in a failing status quo, incapable of offering real alternatives to the poverty and exclusion of a growing number of citizens. Countless promises of splendid Mondays to come have been wasted without us ever arriving an hour closer. The great clock of democracy appears jammed. Or rigged.

This is no time for despair. Just as the Greek sailors sung by Homer, we know that melancholy and sadness are the first enemies to fight. And that we need to look towards the horizon if we are to set sail again. This is the time to come together and to show that beyond a bankrupt establishment and a rising nationalist international we can open up a third space: a joyous, victorious, future-oriented alliance of all those Europeans that refuse to be mere spectators of the decay of their continent. For every Trump there is a Sanders; for every Le Pen there is an Ada Colau; for every xenophobic movement there are millions on the streets of Europe to say refugees welcome and even for every ISIS fighter there is a woman or a man in Rojava building another Syria. Another Europe is not merely possible: it exists already all around us. In the countless municipal movements that are changing the meaning of local democracy from Barcelona to Naples; in the pan-European mobilisation for the commons, against unfair commercial treaties, for gender equality and much more; in the countless 
instances of cooperative economies and autonomous spaces; in the new social movements that are rising up to take head on the political challenge, from Podemos in Spain to Razem in Poland and Demos in Romania; in the tens of millions of Europeans who already inhabit a shared continental space by living, studying or working abroad, and in the many more who have children or grandchildren who do so. There are countless numbers out there working to go beyond our failing system without listening for a second to the devil's tune of the xenophobes.

It is time for us to come together in a European mobilisation capable of saving Europe from itself by transforming it. It is time to settle accounts with one democratic deficit that in good part still depends on us to repair: the construction of transnational movements, transnational parties, transnational activism and active citizenship, and the symbolic presentation of such an alliance as a democratic front representing a clear alternative to both the status quo and the sirens of national retreat. The European elections of 2019 should give us a deadline for this to happen by. Yes, the economy is rigged and our democracy is broken and this is when we come together to repair it. 


\title{
Breaking with the rules that ruin the Union
}

\author{
Lorenzo Marsili in conversation with Barbara Spinelli ${ }^{1}$
}

In your response to Verhofstadt $t^{2}$, you have argued that before considering any constitutional change to the European institutions, we need to invest in policies capable of restoring citizens' trust in the European project. Failing that, any effort of Treaty reform will likely be hindered by a profound mistrust towards the EU. This two-step approach is also at the core of the manifesto of DiEM253: stabilisation of the Eurozone first, and then constitutional reform. Can you tell us what kind of reforms you think are necessary to recover trust in the European project?

If we really want to defend the European project, it is completely illogical to start institutional revisions without first radically changing the policies that brought us to this multi-faceted crisis, so similar to that of the Thirties. The root cause is not only in the EU's economic-financial makeup, but also in its democratic failure, the disintegration of societies, and a loss of orientation and hope experienced collectively by European citizens. The mainstream version of institutional federalism is essentially no more, but yet it somehow still clings to the belief that modifying the balance of power between the different bodies of the Union will be enough to solve all the current problems. But the revolution has already taken place, or rather, it is still under way, and we know that it has produced what Jürgen Habermas calls "post democratic executive federalism". The

1 | This interview was first published in openDemocracy in August 2016.

2 | "Il Cigno Nero che Verhosftadt ignora" Barbara Spinelli July 2016 (http:// barbara-spinelli.it/2016/07/14/il-cigno-nero-che-verhofstadt-ignora/) 3 | DiEM25 (Democracy in Europe Movement by 2025) is a pan-European and cross-border movement founded by Yanis Varoufakis in 2016. 
repercussions of a breakdown of the Union would be so great that the order of priorities must change. Politics is not losing importance, but policy is the priority today. European politics will hopefully be of a federal nature, but such a goal must be the consequence, and formalisation, of a fundamental reconsideration of the policies adopted as of now. In the EU, we have arrived at a tipping point where the obsessive insistence on the institutional method - be it intergovernmental or community-based - is not sufficient alone. It is a technical masking of a political substance that does not change, of a European project that does not want to become either political or democratic, but deliberately tends towards a programme of oligarchic domination.

In other words, we are facing a clear strategy: the aim is not advancing towards a normal democratic government, but towards a socalled administrative "governance" that serves to protect the interests of small power cliques and privileged groups, insulating them not from the markets, but from the uncertainties of universal suffrage and of constitutional democracy.

Why should we believe that a shift of gear is any more likely today, after eight years of avoidable crises? We are yet to hear of a convincing argument as to how any ambitious and disruptive proposal would be able to survive the haggling between 27 Members States, all of which have national vetoes, several of which are ruled by openly nationalist and xenophobic governments, and some of which have deeply ingrained economic obsessions. We have seen it all before: ambitious proposals for investment reduced to the risible Juncker plan; a migration agreement reduced to a few hundred relocations from Greece and a bribe to Turkey's Erdogan. And then there is the ineffective Youth Guarantee, and a dysfunctional Banking Union. Why should it be any different this time?

Clearly the current Treaties are not enough. And we definitely need an authentic Constitution, signed not by the governments of the Member States but starting, as the American Constitution does, with the words: "We, the people ...". However, policies must change before this. How can this be done with the current institutions? I am convinced that a democratisation of their mechanisms and their decision-making would be a first step, although certainly not the only step to be made. If the heads of government, the ministers, the commissioners, and the members of the Parliament felt themselves under permanent scrutiny from well-informed 
citizens (and thus "enlightened", according to Kant, and treated as adults), they would have quite some difficulty behaving as an oligarchy. It would not be possible for the Eurogroup to take a decision against the opinion of a Member State, as happened in the meeting of 27th June 2015, when the former Finance Minister Yanis Varoufakis demanded for the Greek objections to be formalised, and the legal services of the Union replied that it would not be possible, in light of the fact that the "Eurogroup is not mentioned in the EU Treaties and operates as an informal grouping. As such, it is not subject to any written rule".

Concrete transformation plans could come from citizens and not only from the European Parliament. Transparency is important but it is not everything, the citizens ask for more. They demand first and foremost a true European New Deal, which would create jobs and fight against poverty and growing inequality. The proposals are many: from those illustrated by Yanis Varoufakis, to those which came out from the Citizens Initiative "New Deal 4 Europe" (tax on financial transactions and carbon tax for investments in ecologically sustainable growth). Only by starting a New Deal will we be able to face the refugee crisis, build an economy based on solidarity and avoid falling into xenophobia, racism and widespread violence.

Agreed. But who are the subjects capable of filling the gap? We hear over and over a string of empty exhortations to build "another Europe", but few believe in this rhetoric any more. National parties do not seem interested, or able, to see beyond the failed Euro-reformist rhetoric (Francois Hollande was the first to promise a transformation of austerity policies - we are now left with the Loi Travail and the State of Emergency). Transnational parties, a series of acronyms without a true strategy or common campaign, have proven to be unfit to lead a democratic revolution. Is it perhaps time to imagine a true European party? Or maybe even, in light of the next European elections, to imagine a "democratic front" to bring different political and social forces together with a simple but firm reform programme of the Union? Could this include disobeying EU rules?

In reality, the subjects are there, one just needs better eyesight, the language, the curiosity and the capacity to listen and meet halfway, because this is what is needed so that we are able to tell them, as the old prophets did, "here we are". Here not only to represent you, but also 
to understand and spread what you think, what you fear, what you need, what has happened to you and what has let you down. Class war has not ended, even if the social question naturally presents itself in new clothes today. It is not only that the representation of these subjects is missing, and that all intermediary bodies of society - beginning with the trade unions - are under attack, but there is something more: the division today is not between who is "up" and who is "down", but between who is "in" and who is "out". We are faced with old impoverished classes, with a new, downgraded middle class full of fears, and with new classes that are deprived even of a name. And all of them tell us, as the Commendatore in Don Giovanni: "Ah tempo più non v'è" - "Your time is up". We have to speak with these groups, so as not to fool ourselves into denial about the reality we are stigmatising.

Let us not keep to ourselves the fact that Syriza's failure has left many, far-reaching wounds, to the point that millions of citizens today just do not believe that there are possible alternatives any more, and this is not only in Greece. Quite rightly, they think that universal suffrage has been undermined. We have to admit that democracy, as a whole, is left with broken bones. The capitulation of the Syriza government after the referendum of 5 th July 2015 has to be recognised and represented as something similar to the primal scene, which unsettles the child who was used to imagining his parents as gender-neutral, as "innocents". Once the primal scene has been recognised, you can decide not to consider it, or pretend to have not seen what you have seen, but the effect remains and it will be devastating if you do not go forward with some precautions and new knowledge.

Such a denial of reality is also one of our ruinous deficiencies. The Greek traumatic breaking point is still being hidden, or worse, is being totally repressed, or embellished, even by a great part of the radical left who keep demanding "another Europe". What we must restore is the relationship with reality and the truths that it tells us: the reality of a humiliation which Syriza does not recognise, the reality of Trump's success, the reality of Brexit, the reality of a Polish society that has had enough with the pseudo-liberal lies of the post-communist élite and has given the majority to Jaroslav Kaczynski and the PiS.

You ask me what can be done concretely in order to build a European transnational party, a sort of "popular front" that could stand in the next European elections with a programme of rupture with the powers-that- 
be of the Union. First of all, we have to clarify a few concepts by asking ourselves some fundamental questions: what does it exactly mean to take back our sovereignty? How do we distinguish between popular sovereignty and national sovereignty? What is the cost of a non-Europe? What are the demands of the impoverished and expelled classes? And what is the meaning of the rupture strategy you have mentioned?

Then we have to respond to the fears of the people, voluntarily provoked by the hegemonic powers, but fears nevertheless. Let us take the migration and refugee question as an example: we have to condemn the indecency of the construction of walls and the carrying out of collective expulsions by Member States, with the complicity of the European Commission, and we have to denounce their will to bolster the extreme right with the purpose of using it as a scarecrow deterrent. But at the same time, we must help to get rid of the feeling of fear of our fellow citizens, because this sentiment too is a "reality".

We have to break with the rules that ruin the Union, but we must also reassure citizens: it is a matter of urgency. It is useless to say that we will "mobilise the masses" against racisms and neo-fascisms, because the masses we are talking about simply do not exist as they did, and a great number of them have ceased to vote anyway.

This much we have learnt over the last years: it is EU decision-making itself that is broken and unable to result in coherent and ambitious policies. We must, at some point, talk about reforming the European institutional structure. But this is a tortuous path. The so-called "Schäuble plan", namely the integration of the Eurozone through the appointment of a European Finance Minister essentially tasked with enforcing the austerity rule-book, seems a step in the wrong direction. Many speak about the need for a Constituent Assembly directly elected by European citizens. Others, such as Piketty, advocate the idea of a Parliament of the Eurozone. What is the most promising path to trigger a reform of the government of the European Union?

I agree with the idea of a Constituent Assembly, but without leaving the project in the hands of an intergovernmental process. It already happened once, in 1984, when a constitutional project put forward by the European Parliament was devitalised and deformed in this way.

The Schäuble plan you are talking about goes in a completely different direction. It does not even limit itself to proclaiming a European Finance 
Minister. Since Great Britain voted for Brexit, Schäuble is recommending the simple return to an intergovernmental Europe, to the old "balance of power" which caused two world wars in the previous century. He distances himself from any federal vision in order to save and protect the austerity policies imposed during these years. The very word "vision" is abhorred. The key expression today, according to Habermas, is the following: "No more vision, everything by now is just a question of "Lösungskompetenz", of solution skills". The goal of the German establishment, and Schäuble, is to consolidate the definitive victory of ordoliberalism.

Every State must first reorder its accounts, and only then common economic resources, cooperation and New Deals may come. In the international headquarters nothing must be decided in common; at most, it is a place of information where the strongest impose adjustments on the weakest. Ultimately, the essence of this doctrine, pure and simple, is a return to nationalism. A nationalism that today also risks contaminating the minds of left-wing anti-austerity forces. To them, I would like to say: be careful, in the battles for an "exit" from the Euro, or the Union, you risk finding at your side not those who want to shield Europe from the global markets, but the barely masked nationalism of Wolfgang Schäuble. 


\title{
Social networks of influence in Europe - and beyond
}

\author{
Dieter Plehwe
}

The transatlantic financial crisis has led to a backlash against European democracy. Even if the previous efforts to increase participation remained quite limited (Quittkat, 2011: 653-674; Hüller, 2010: 77-107), there had been a clear emphasis on strengthening supra-national and transnational democracy in Europe up until around 2008. Enhanced NGO participation, citizen initiatives and online consultations reached out to social groups not normally involved in supra-national policy-making. After 2008 however, austerity policies were imposed by regimes outside the community framework, pitting rich States against poor States and reviving old centre-periphery notions and constitutionalising inequality. It is not entirely wrong to blame these developments on the Schäuble model, or, previously, that of Tietmayer (as argued by Bourdieu, 1998). The "dangerous idea of austerity" (Blyth, 2013) has certainly been promoted by Germany's treasury and the Bundesbank. Lids on budget deficits, an eye to a maximum level on public debt and low inflation are trademarks of German supply-side economics and stealth neo-mercantilism.

But simply blaming Germany does not answer important questions relating to structural and ideational change, which in fact does not rest within national borders. And with regards to this, we need to ask a number of questions. Where did the ideas, which have strangled Europe for quite some time now, come from? And why do influential circles in many EU Member States support these ideas, rather than call for a united opposition to German austerity leadership? Why do so many neighbouring countries defy calls for solidarity in the refugee crisis, rather than asking for a quid pro quo deal on public finance and crisis management? Why has Europe 
seemingly become stuck on notions of neo-liberalism and nationalism, eventually paving the way for Brexit?

In this essay, I will argue that the once, more dominant frame of European inter-governmentalism is indeed misleading and inadequate in explaining the transnational rise of neo-liberal ideas behind much of the recent orientation of European integration. In order to explain this paradigm shift, we have to pay more attention to cross border elite networks, which have been involved in important controversies regarding European integration.

The competing European integration framework of neo-functionalism has always emphasised the role of elites in European integration processes, but scholars working in this tradition were exclusively focused on pro-European elites. The trajectory of integration, spill over, or more integration, never considered competing elites with different orientations. Elites were naively perceived as being in favour of Europe, not against it. In order to comprehend the recent struggles over the future of Europe, we have to disentangle this allegedly homogeneous social class, to make visible competing political elites.

Serious competition has emerged to the traditional mainstream elite perspective of an ever-closer union. The roots of this opposition are not nationalist, as one might think, in light of the also growing opposition from Le Pen and friends. The roots of 'limited integration', or 'economic integration only'-elites, can rather be traced back to organised neo-liberal circles that already opposed important aspects of the European project in the early days of the Treaty of Rome. The 1980 s moved European integration and globalisation a good deal closer to ideals of free market capitalism. But the prospect of economic and monetary union followed by political union, after the collapse of the Soviet Union and German unification, reinvigorated neo-liberal opposition to deeper integration. Instead of the inter-State federalism, which Hayek had envisioned, already back in 1939 (Hayek, 1980 [1948]: 255-72), a centralised supra-national State - political union - seemed to be on the horizon. From Maastricht onward, European networks of organised neo-liberals mobilised to intervene in European debates in unprecedented ways.

We can trace some of the trails of the groups involved in the formation of neo-liberal perspectives back to the Mont Pèlerin Society and related think tank networks. The Mont Pèlerin Society was founded, amongst others, by Friedrich August von Hayek and Wilhelm Röpke in 1947, to start 
competing with Socialist and Social Liberal ('Collectivist') convictions in particular, but also to work against certain strands of Conservatism. Hayek's reflections on the competitive implications of inter-State federalism has been credited, by Wolfgang Streeck (2014), for much of Europe's development. But Hayek's ideas did not play such a big role in Europe in the 1960 s and 1970s, which begs the question, why they took on such a major role from the 1990s onwards (Höpner\&Schäfer, 2012: 429-55).

\section{Mont Pèlerin's neo-liberal Europe: From opposition to ambivalence to partial disintegration (never closer union!)}

Hayek had in mind the model of the Fabian Society when he called a number of ideologically close colleagues and friends to convene in the Swiss Alps in 1947. The Fabian elite socialists developed a reformist programme of social reform in the late 19 th century. Instead of entering party politics, public debate and politics at large, Fabians preferred to devote their effort to research, and to channel their findings and interpretations to powerful decision-makers.

From a liberal perspective, the 1930 s were a dramatic, if not traumatic period. The Great Depression, Soviet rule in Russia and Nazi rule in Germany, were all not promising in terms of the prospect of global market Liberalism. Concerned circles of intellectuals were invited to Paris in 1938 in the framework of the League of Nations intellectual committees to discuss Walter Lippmann's book 'The good society'. At the Walter Lippmann meeting, participants which included Hayek, Mises and Röpke agreed on the need for a new programme in the face of (a) the failure of traditional Liberalism and (b) the rise of Collectivism, a lose category designed to capture all perceived enemies of the market and individuals on the Left and the Right. This programme was given the name "neoliberal" (Denord, 2009: 45-67).

Critics of neo-liberalism frequently overlook the first part of the mission: addressing the weaknesses of classical Liberalism, which had perceived market capitalism as a natural, self-stabilising order. Neo-liberals instead recognised the need to secure market-capitalism, and ventured to compete with others ideologies on what kind of future direction social orders should take. For neo-liberals, it was clear that 
market capitalism was preferable to alternative perspectives of mixed or planned economies. But the statement of aims of the Mont Pèlerin Society embraced social minimum standards "not inimical to initiative and the functioning of the market", and aimed at redefining "the functions of the State so as to distinguish more clearly between the totalitarian and the liberal order" (Hartwell, 1995: 41-42), making clear that the State should be in support of freedom (of contract), property rights and individualism. Democracy, on the other hand, was notably absent from the core of the neo-liberal programme. In any case, neo-liberals were, and are, looking for public policies that suit their project, not naïve supporters of pure or free markets, no matter how important this slogan became in the fight against the welfare state.

Already in the 1930s, participating scholars were to join forces in think tank offices in different countries, including in the UK, France, Switzerland and the U.S. The war intercepted this effort, which was taken up again by Röpke and Hayek when they allied after World War II to found the Mont Pèlerin Society. Much like the Fabians, Mont Pèlerin members did not directly seek political influence. They focused on internal debates and networking on the basis of shared norms and principled beliefs, like property rights, individualism, rule of law, and an adherence to absolute values in religious and philosophically idealist traditions. The values and principled beliefs of neo-liberalism have subsequently been constantly reproduced and applied to concrete fields in many discussions of the Mont Pèlerin Society conferences. For public purposes, many Mont Pèlerin members helped directing and staffing neo-liberal think tanks, like the Institute of Economic Affairs in the UK, and the Foundation of Economic Education and the American Enterprise Institute in the U.S., as well as the Aktionsgemeinschaft Soziale Marktwirtschaft in Germany (compare Walpen, 2004). The Mont Pèlerin Society meetings and think tank activities in turn were supported by a broad range of businesses and corporate foundations. Neo-liberalism was not created by business interests, but there clearly has been an elective affinity between neoliberals and certain business perspectives from the very beginning. More importantly, Mont Pèlerin and think tank venues secured the interrelation of academic, business, media and policy making circles. The conscious networking across fields and domains provided neo-liberal networks with interdisciplinary and inter-professional competencies, which have undoubtedly proved very useful in exercising influence in policy arenas 
and political circles. Operating in a mode "between network and complex organisation” (Plehwe\&Walpen, 2006: 27-70), Mont Pèlerin searched for and directed efforts at developing alternatives to modern welfare state capitalism.

Ironically, a publication of the Fabian Society was early to observe the development of considerable intellectual capacities and new orientations challenging the mainstream in public debate emanating from Mont Pèlerin related circles:

"Hardly a week goes by without some conference of teachers, social workers or medical men being told that, for economic reasons, consumers must be charged directly for welfare services [...] Bits and pieces of the New Right's doctrine appear in various places, from the writings of Enoch Powell or the Bow Group to the propaganda of Aims of Industry, but it is most coherently expressed in the publications of the Institute of Economic Affairs (IEA). The IEA's output has been considerable." (Collard, 1968: 1)

Collard pointed to the systematic publishing activities of the neo-liberal think tanks and warned the Progressive movements as early as 1968(!) of the rise of a new social force:

"My own rather different worry is that the Left is being successfully outflanked by the New Right. While we argue about possible (marginal) extensions of public ownership the really important hard core of the present public sector (health, education and other social services) is being undermined. We are now at the beginning of a series of major assaults on the welfare services and rather than foraging around in the private sector we should look to our defences." (Collard, 1968: 5)

\section{From defence to offence and flexible response: Neo-liberal ambivalence with regard to Europe}

Between 1959 and 1987, Europe's economic and social policy was torn between the protection of mixed economies, public services, industrial policies and agriculture on the one hand, and the drive to remove obstacles to cross-border economic integration. Up until the 1980s, harmonisation played a considerable role as a perceived precondition of successful integration. From then on, the emphasis was on 'negative', rather than 
'positive' integration, on deregulation and liberalisation, rather than harmonisation and convergence.

One member of the Mont Pèlerin Society, Fritz Machlup, an Austrian economist who had been forced to emigrate to the U.S. in the 1930 s from his native Austria (like von Mises, Haberler and von Hayek), gave much time to studying the basic meaning of 'integration'. Confronted with notions of political integration in Europe, he delved into the history of economic integration, pointing to the necessity for the removal of obstacles (negative integration), rather than harmonisation, coherent regulation, or structural funds etc. (positive integration) (Machlup, 1977). Not only was he able to counter the dominant notion of political integration on this basis, he also refined the neo-liberal counter-proposal: economic integration requires the commitment to the removal of obstacles of all kinds, including political obstacles like public enterprise, regulatory competencies, non-tariff barriers, etc. And Europe was only a regional part of a larger task: the neo-liberal perspective on integration was global. 'Cosmopolitan capitalism', as Herbert Giersch wrote in 1989, on the eve of the post-Socialist expansion of the capitalist order (Giersch, 1989: 1-16).

Both Social Democratic and Conservative ideas of regulated capitalism eventually came under siege by neo-liberal ideas of deregulated or 'free market' capitalism across borders. Machlup's preceding intellectual efforts to develop a competitive notion of integration on behalf of neoliberal strategies went unnoticed, by and large, until it attained relevance in the single market project of the 1980 s and important court decisions like the Cassis de Dijon case of 1979. EU Commissioner Davignon proposed trade policy based on this ruling, which essentially required the removal of non-tariff trade barriers (like diverging consumer protections standards etc.). In economics, Mont Pèlerin member and president from 19861988, Herbert Giersch's analysis of 'Eurosclerosis' added momentum to the negative integration pathway chosen in the 1980 s (Giersch, 1985). In political science, Fritz Scharpf's work on the negative integration bias of Europe seemed to validate the inevitability of European neo-liberalism. With hindsight, Fritz Machlup's historical investigation suddenly seemed to matter a lot.

But the collapse of the Soviet Union and German unification changed the terms of the debate again. The EU Commission president Jacque Delors jumped on the occasion to pursue a more ambitious agenda of 
economic, monetary and political union, which turned out to be highly divisive. Progressives blamed the Maastricht Treaty as a major turn to neo-liberalism because it would for the first time institutionalise austerity criteria in an international treaty for the European members of monetary union. Overlooked by many, right wing neo-liberals (like Herbert Giersch, and a letter writing community of economists) also attacked the Maastricht Treaty because the criteria were considered soft, and difficult to enforce. In addition to such economic criticism of Maastricht, the 'British' Eurosceptics formed in even stronger opposition to political union.

\section{0s: Neo-liberals move on and to Brussels}

All those who are interested in Europe remember the famous Bruges speech, delivered by Margaret Thatcher, the founding event of the Bruges Group against an ever-closer union. Neo-liberal civil society networks had not mobilised many resources in Brussels before the 1990s, but did now with a vengeance. The Bruges Group started a considerable publishing activity of policy papers against many aspects of integration. Its Manifesto for Europe, of Europeans against technocratic rule from Brussels, attracted 600 signatures from Euro-sceptic academics. When the convention process was started to debate a political constitution, neo-liberals from across Europe pulled together the European constitutional group headed by Professor Christian Kirchner, a public choice economist from Berlin. In 1993 the network contributed a neo-liberal draft constitution to the process. The following members joined in the writing: Peter Bernholz (Switzerland); Francisco Cabrillo (Spain); Gert Dahlmanns (Germany); Jacques Garello (France); Henri Lepage (France); Angelo M. Petroni (Italy); Joachim Rückert (Germany); Frank Vibert (Great Britain); Peter Stein (Sweden); Pascal Salin (France).

The group included seven members of the Mont Pèlerin Society. It remained active after the collapse of the constitutional process. An open letter of the group (in modified composition), to the head of the European Council, Donald Tusk, in 2015 (dated December 1), opposed measures to increase solidarity across borders and presented yet another agenda for a limited Europe.

Around 2008-2010, an interruption in the neo-liberal networks occurred. For example, the Stockholm network, which had connected more than 100 
think tanks, ceased activity in 2010. A major reason for this development - apart from the global financial crisis - was the formation of the Alliance of European Conservatives and Reformists, led by the British Tories and other right-wing parties from Poland and the Czech Republic (Vaclav Claus, a Mont Pèlerin member), among others. Its founding document, the Prague Declaration, states a clear neo-liberal programme for Europe, a blueprint for partial disintegration. The language is mostly Euro-sceptic. The only positive reference is the expressed desire for equality of Member States, big and small, as would be expressed by any good federalist.

The new party alliance opposed the collaboration of Conservatives and Socialists in the EP, and aimed at creating centre-right-wing majorities against deeper integration. Many activities of neo-liberal civil society networks now moved closer to established European party politics. AECR forged a new neo-liberal think tank network under the umbrella of the party foundation New Directions (Plehwe\&Schlögl, 2014), which combines many former Stockholm network members. Brexit will certainly weaken the political party coalition of the AECR, but the Cameron wing of the Tories have already established their own 'open Europe' think tank, which operates with offices in London, Brussels and Berlin. Think tanks, in fact, are much less restricted with regard to their partners and affiliations than political parties, and can be considered extremely valuable in maintaining ties and promoting specific ideas and projects across parties and worldviews. It still remains to be seen if Brexit will weaken neo-liberal perspectives. Neo-liberal networks are deeply entrenched in the various nations across the EU.

\section{Opposing deeper integration, defending the status quo of corporate globalisation, losing Europe}

Neo-liberal circles have been one of many competing social forces in the process of European integration. Their influence has always been relative. In the beginning of the European integration odyssey, the circles of Jean Monnet were arguably quite a bit stronger than the neo-liberal opposition. Neo-liberal perspectives gained influence in the 1980 s, against a backdrop of the crisis of Fordism and a welfare state model plagued by rising unemployment, increasing expenses and public debt. The neo-liberal transformation of the welfare state has since become the mainstream in the age of "permanent austerity" (Paul Pierson). 
With regard to the EU, the picture of the 1990s is more complicated: neo-liberals advanced in terms of deregulation, cross border liberalisation and the supply-side oriented austerity. But European integration also expanded in areas of environmental, social and labour market policies, much to the dislike of the friends of negative integration. Fighting these developments, European neo-liberals have now become more political in the framework of the European Alliance of Conservatives and Reformists and their New Direction foundation. Their programme is best understood as a prospect of partial disintegration, a limited EU that is imagined to come closer again to neo-liberal ideals.

Readers may still doubt that neo-liberals actually exist, since few are willing to officially embrace the label. But thankfully, Sam Bowman of the Adam Smith Institute recently declared a 'coming-out' of neo-liberals, which included the following (incomplete) positive list of essentials, notably excluding any reference to democracy, just as in the statement of aims of Mont Pèlerin:

1. Pro-markets

2. Pro-property rights

3. Pro-growth

4. Individualistic

5. Empirical and open-minded

6. Globalist in outlook

7. Optimistic about the future

8. Focused on changing the world for the better

(Bowman, 2016)

Unlike in 1947, social minimum standards are also notably absent, let alone notions of social citizenship. The paradoxical effect of the permanent neo-liberal hammering on the EU and the welfare state has of course helped the rise of neo-nationalist tendencies, culminating in Brexit, and Le Pen and Frauke Petry ante portas. This is the choice neo-liberals, and all Europeans face: promote neo-liberalism and move Europe ever closer to the brink of disintegration, or reconsider the scope of integration. Victims of globalised 'free market' capitalism look for protection. If workers and employees do not, or cannot, organise trade unions, they will get a Donald. Social security may be framed as an exclusive right of legitimate members of the Nation State, protected from outsiders and others that do not belong. 
Or social citizenship may be considered solidarity of inhabitants of a social space shared by all who live together and need solidarity in order to tackle the problems and issues that result from common economic, political, ecological and other challenges, not least from the now extremely burdensome heritage of neo-liberal orders.

Neo-liberals united on the basis of common norms and principled beliefs back in the inter-war and post-war periods, which provided them orientation in their effort to organise across borders, which they aim to maintain to control people, but not capital. Progressives have been lost in national varieties of capitalism, welfare states and so on, instead of developing a competitive base across borders. The Left, in fact, has much to learn from the right-wing efforts to organise and coordinate across borders. Paradoxically, the Right has become the international party. Can the Left overcome its parochial inclinations?

\section{BIBLIOGRAPHY}

Bauman, S. (2016): Coming out as Neoliberals (https://www.adamsmith. org/blog/coming-out-as-neoliberals).

Blyth, M (2013): Austerity: The History of a Dangerous Idea. New York: Routledge.

Bordieu, P. (1998): Acts of Resistance: Against the New Myths of Our Time. Polity Press.

Collard, D. (1968): The new right. London: Fabian Society.

Dahrendorf, R. (1995): LSE: A History of the London School of Economics and Political Science, 1895-1995. Oxford University Press.

Denord, F. (2009): French Neoliberalism and its Divisions. From the Colloque Walter Lippmann to the Fifth Republic. In: Mirowski, Philip, Plehwe, Dieter, eds., The Road from Mont Pèlerin. The Making of the Neoliberal Thought Collective. Harvard University Press.

Giersch, H. (1985): Eurosclerosis. Discussion Paper 112. Kiel: Institute für Weltwirtschaft.

Giersch, H. (1989): "Anmerkungen zum weltwirtschaftlichen Denkansatz," Weltwirtschaftliches Archiv 125, no. 1.

Hartwell, R. M. (1995): A History of the Mont Pelerin Society. Indianapolis: Liberty Fund. 
Hayek, F. A. (1980[1948]): The Economic Conditions of Interstate Federalism. In: Individualism and Economic Order, edited by Friedrich A. Hayek, Chicago: University of Chicago Press.

Höpner, M\&Schäfer, A. (2012): Embeddedness and Regional Integration: Waiting for Polanyi in a Hayekian Setting. In: International Organization 66, Summer 2012.

Hüller, T. (2010): Playground or Democratisation? New Participatory Procedures at the European Commission. In: Swiss Political Science Review $16(1)$.

Machlup, F. (1977): A History of Thought on Economic Integration. New York: Columbia University Press.

Plehwe, D\&Walpen, B. (2006): Between network and complex organization. In: Plehwe, Dieter, Walpen, Bernhard, Neunhöffer, Gisela, eds., Neoliberal Hegemony: A global critique. London: Routledge.

Plehwe, D\&Schlögl, M. (2014): "Europäische und zivilgesellschaftliche Hintergründe der euro(pa)skeptischen Partei Alternative für Deutschland (AfD)." WZB online (2014). Accessed July 22, 2016. https://biblio thek.wzb.eu/pdf/2014/iii14-501r.pdf.

Quittkat, C. S. (2011): The European Commission's Online Consultations: A Success Story? In: Journal of Common Market Studies, 49(3).

Streeck, W. (2014): Buying Time. London: Verso.

Walpen, B. (2004): Die offenen Feinde und ihre Gesellschaft. Hamburg: VSA Verlag. 


\title{
Learning from Syriza
}

\author{
Andreas Karitzis
}

The government experience of Syriza provides us with valuable insights regarding the implications for the Left's diminished power and the neoliberal transformation of the State within national and international networks of power. Furthermore, we are able to identify and examine inadequacies of the approach of the traditional Left. It seems that the strategy of building social alliances in terms of representing beliefs and demands at the political level is not enough. It is not sufficient to engage effectively with the State and the government in order to effect a coherent transition strategy to a new political economy and a robust democratic social and institutional configuration. Less ambitiously, it is not sufficient to check the imposition of austerity policies and neoliberal transformation. It is not enough to pave the way for the restoration of democracy and popular sovereignty.

If this is our current predicament, then I argue that we need to redesign the "Operating System" of the Left. The Left needs to initiate a process of adaptation in order to respond effectively to the new conditions shaped by the neoliberal national and international financial and political architecture. I argue that the urgent question is not whether we should do politics within the State, or not as it is traditionally conceived, but to set up a new conceptual and organisational framework of doing politics, both within the State, and outside of it, such as it is relevant today.

\section{Time lag}

The Left - but not only the Left - in Western societies of a robust democratic constitution, has been trained to do politics within the coordinates of a post-war institutional configuration. According to this, the elites are 
committed to accepting the democratically shaped mandate of an elected government. If they do not like the policies that it promotes, they have to engage in a political fight; opposition parties must push the government, through their political activity, towards more moderate directions, they must convince the people that this policy is not desirable nor successful, and use democratic processes for a new government of their preference to be elected ${ }^{1}$.

According to this conception, the post-war global balance of forces inscribed in State institutions has a considerable amount of popular power, rendering them quasi-democratic. This amounts to tolerating the fact that people without considerable economic power have some level of access to crucial decisions. Of course, the quality and the range of the access has been a constant issue of class struggle. The elites have been obliged to fight according to the rules (or at least to appear to do so), and at the same time they have worked deliberately to diffuse any kind of institutional configuration contaminated by popular power. In the last decades (not accidentally, after the fall of the Soviet Union), they made decisive steps towards diffusing this kind of power and hence limiting the ability of the popular classes to influence crucial decisions. Today the elites feel confident to openly defy democracy. Democracy is not a taboo any more.

The strategy of Syriza was implicitly based on the premise that the institutionalised popular power of the past is not exhausted; the elites will respect at least a shred of the democratic mandate of the new government, and provide it with some degrees of freedom required in order to, at least, heal social wounds and restore economic activity. We could say that the implicit idea was that by winning the elections, remaining institutional powers would somehow be enough, and it would be used to stop austerity. And then, in a relatively stable environment, we could enhance people's power using the State institutions. We all know the results of such a

1 I It could be argued that this was not truly the case even for the so-called Western societies after the Great War. This is surely a debatable issue. However, for the argument I present here, it is sufficient to assume that this was at least the dominant conception of the political functioning that shaped the methodology and strategy of the political agents, even if it does not correspond fully to reality. I would like to thank Leo Panitch for the clarification of this point. 
strategy, now. The outcome was totally different. There was virtually no change of policy. The elites are no longer committed to the post-war democratic rules of the political and social fight ${ }^{2}$.

\section{Avoid oscillation}

It seems that the traditional strategy of building social alliances in terms of representing beliefs and demands at the political level is not enough. The traditional strategy may give us access to traditional institutional power. But, we know from the Greek experience of the last years that the popular power, once inscribed in the traditional institutional configuration, is seriously depleted, if not exhausted. We do not have enough power to make the elites accept and tolerate our participation in crucial decisions. The amount of power we can reach through traditional political practice is not enough to pave the way for the restoration of democracy and popular sovereignty in Europe.

But in order to overcome our impotence to challenge financial despotism in Europe, we must avoid an unproductive oscillation. Usually, in the Left, there is a hot debate regarding the nature and the place of the State within our strategy: should we intervene in State institutions, or not? However, in my opinion, the pressing question is not whether we should do politics within the State or not, as it is traditionally conceived. We usually articulate Left strategies that either include the State, or exclude it, and then we compare them and debate over their comparative pros and cons. Our strategies implicitly presuppose that doing politics in both cases is 'a given', and it remains only a matter of articulation: what is our priority, and in cases of non-exclusionary approaches, what are the best ways of connecting them. I argue that we must reformulate these kinds of debates, taking into consideration that there is a deeper issue that needs to be addressed: our know-how of doing politics is seriously outdated, undermining all our strategies, from the outset.

2 | We can see the same attitude in other areas of current politics as well. The elites have developed ways to avoid taxation that render any political decision of a government to increase their taxes extremely difficult to implement. Elites gradually detach themselves from societies, shifting the ground and the nature of class struggle in ways that need to be specified and analysed. 
We must reformulate the point of view from which we are approaching our current situation, otherwise we may trap ourselves in an oscillation: every time a state-oriented Left strategy fails, a movement-oriented strategy will prevail, and vice-versa. There is the danger of constant oscillation between irrelevant and feeble strategies that are failing by design. It leaves us always blaming our impotence on the last decision to intervene with State institutions or the last decision to abstain from doing so. According to my experience and understanding, we must initiate a somewhat daunting process of setting up a new conceptual and organisational framework; of doing politics both within the State and outside of it, which indeed would be relevant to the current situation.

\section{Redesign the 'Operating System' of the left}

We know that the popular power once inscribed in various democratic institutions is exhausted. We do not have enough power to make the elites accept and tolerate our participation in crucial decisions. More of the same just will not do. If the ground of the battle has shifted, undermining our strategy, then it is not enough to simply be more competent on the shaky battleground; we need to reshape the ground. And to do that, we have to expand the solution space by shifting priorities: from political representation, to setting up an autonomous network of production of economic and social power (NESP).

We must modify the balance between representing people's beliefs and demands, and coordinating, facilitating, connecting, supporting and nurturing people's actions. Instead of being political representatives of the popular classes in a toxic, anti-democratic European political environment, designed to be intolerant to people's needs, we must contribute in a meaningful way to the formation of a strong 'backbone' for: resilient and dynamic networks of social economy and co-operative productive activities, alternative financial tools, local cells of self-governance, democratically functioning digital communities, community control over functions such as infrastructure facilities, energy systems and distribution networks. These are ways of gaining the degree of autonomy necessary to defy the control of elites over the basic functions of our society.

It is not only in Greece that there is a growing exclusion of people from employment or from opening a bank account, from having a "normal life'. Modern society in general is in decline. From history we know that 
societies in decline tend to react in certain ways in order to survive. It is up to us to grasp this and start building networks that can perform basic social functions in a different way - one that is democratic, decentralised and based on the liberation of people's capacities.

For example, exploring ways, models and methods of building the NESP requires evaluation and the use of concepts such as the 'commons'. Expanding this notion even further and putting forward a project of shaping political representation as 'commons' could give us valuable insights into new ways of performing vital functions like political representation, transcending the traditional, institutional framework of representative democracy.

Redesigning the "operating system" of the Left also means the elaboration of a multi-level democratic transformation strategy of the State, and its effective interconnection with the NESP. The Left talks too much about the democratic transformation of the State. In practice, the driving concept is the restoration of State functions, as they were before the neoliberal transformation. The expansion of a network of economic and social power under the people's control would further unlock our imagination, facilitating the targeted reforms of State institutions that are needed in order to connect them with the NESP. In theory, this is an old idea: the transformation of the State is a complementary move to the selforganised collectivities of the people outside of it, driven by these forms of self-governance.

First, this would allow people, who are being excluded today, to survive. Second, this could begin a transition towards a better and more mature society. And last but not least, there are no empty spaces in history, so if we do not do this, the nationalists and the fascists - with their own militarised ways of performing these basic functions - may well step in to conclude the decline.

\section{Shifting the battlefield}

The elites have already spotted the shifting nature of the battlefield and have moved to new unclassified ways of organising and acting. They have developed new kinds of institutions (a Greek example of successful 
clustering $^{3}$ ) compatible with the emerging environment of fast flows of information, digital frameworks of action and production etc. They are also exploring new methods and models; for example, "open innovation" models have emerged in the last few years to enable the R\&D departments of big multinational companies to cope with today's distributed nature of knowledge and expertise, which exceeds past means of control and usurpation of human intellectual creativity and innovation. These new ways of organising, and acting, infuse values like collaboration, sharing, exchange of knowledge and expertise, decentralisation and distribution, diversity and inclusion, and common goals, into the private sector in order to boost the production of value, which we know to be seriously undermined by the corrosive effects of competition. This strategy shows that our values are not only desirable but also effective, as long as we find ways to make them the operational core of our collective mobilisation, instead of being just part of our rhetoric.

We have to create new popular power if we want to bring about substantial change, or make ourselves resilient instead of just handling the remaining, seriously depleted, if not already exhausted, popular power inscribed in traditional institutions. The question is what does it look like, to do politics in order to produce popular power, without presupposing traditional democratic functioning - to restore it by transforming it anew? In other words, what are the modifications needed in our political practice for the constitution and expansion of NESPs?

These modifications may be classified in three categories: political imagination, methodology and organising principles. From my experience, the very same people who energetically claim that we need to be more innovative, better adapted and more efficient, when they actually do politics, reproduce priorities, mental pictures, methods and organisational habits that they already know are insufficient or inadequate. There are ingrained norms, in terms of methodological guidelines that decisively shape the range of our collective actions, rhetoric, decisions and ultimately strategy. In the same vein, we believe in and fight for the promotion of the logic of cooperation and democracy, against the logic of competition, but in practice our organisations suffer severely in terms of cooperation and

3 | Corallia. "Corallia's vision is "A Greek environment with the right framework conditions to allow sciences, innovation and entrepreneurship to flourish (again)". (http://www.corallia.org/en/). 
democracy on the operational/organisational level. We need to recognise these blind spots and set up a process of identifying best practices, methods and regulations - both from the experience of our collectivities and from expertise in management, leadership, organisational complexity and network systems theory etc. - in order to operationally upgrade our forces.

Furthermore, our actions and initiatives are not connected up properly, but are fragmented and isolated, destined to face the same difficulties again and again. We need to upgrade our operational capacities through appropriate nodes of connection, facilitating smooth flows of know-how and information, transferring best practices, building databases and accumulating knowledge and expertise in an easily retrievable and useful way. Actually, this is the advantage of multinational and large corporations in general, in comparison to others: they have a vast social network, and powerful databases, that give them the necessary tools to plan and pursue their goals, while their smaller competitors seem in disarray in a global environment of rapid changes. We need these qualities if we want to be really useful today.

\section{It's the implementation stupid ${ }^{4}$ !}

Having been in the Syriza leadership during the period of preparation for assuming governmental power, I came to the conclusion that Foucault was right when he argued that one major lacking of the Left is that it misses a mode of governmentality stemming from its own logic and values. We miss a modality of administrating populations and running basic social functions in a democratic, participatory and cooperative way. One aspect of this lacking today - based on the Syriza experience - is the total ignorance and indifference towards issues that are related to the implementation process. The prevailing rhetoric within Syriza was that the

4 | German Finance Minister Schäuble used this phrase in a public discussion with the Greek Prime Minister Tsipras in order to point out that the implementation of the agreement must move on, giving real results in terms of measurable fiscal aims and structural reforms. Seen differently, this phrase indicates why we ended up in a situation in which the neoliberals are the true 'revolutionaries', dramatically changing the basic coordinates of modern societies whilst the Left seems unstable and feeble. 
issues are political and not technical. ${ }^{5}$ So, all we had to do was to decide what we wanted to do, not to explore the ways in which we were going to implement them. The implicit premise was that the crucial point was to be in the government and the ministries, making political decisions, and subsequently, somehow, these decisions would be implemented by the 'technical' nature of State mechanisms.

Apart from the fact that this attitude contradicted what we wanted to say regarding the corrosive effect of the neoliberal transformation of the State and the complexity of being in the EU and the Eurozone, it also revealed a greatly superficial understanding by the traditional political Left of the notion of the "transformation of the State". The fact that we are talking about a current in the Left, which includes governmental power within its strategy, the low level of awareness regarding the importance of implementation processes reflects the degree of obsolescence of Leftist organisations. To me this justifies exactly why there is the need for a radical redesign of the "Operating System" of the Left.

The major problem is that a mentality like this ignores the obvious fact that the range of one's political potential in being in the government is determined by what one knows one can do with the State. The implementation process is not a 'technicality', but the material basis of political strategy. What the traditional Left takes to be the political essence, namely the general, strategic discussion and decision (what to do with the debt, privatisations etc.) is just the 'tip of the iceberg' of State-politics. The implementation process is the 'iceberg' of State-politics beneath the surface. Instead of just being a 'technicality', it is the biggest portion of State-politics. Actually, it is where the political struggle within the State becomes hard, and where class opponents battle to prevail over implementation, which is, after all, a battle over shaping reality. The tip is not going to move the iceberg by itself, as long as it is not supported by a multi-level and multi-personal implementation process with clear orientation, functional methods and high-level coordination. This is the integrated concept of State-politics that we have forgotten in practice and by doing so we tend to fail miserably whenever we approach the tip of the iceberg. So, the question is not whether we should fight for the tip or not,

5 | A similar rhetoric appeared publicly during the negotiation process with the lenders. 
but whether we have any clue what to do with the iceberg beneath it, or not.

One of the results, in the case of Syriza, was that the Programme Committee, the highest political organs, and the departments of the Central Committee, did not work deliberately on managerial issues regarding steps, methods and difficulties of implementing our own policies and organisational issues, like restructuring processes in the various State institutions we would have access to, but rather, they were sites of political argumentation in the most general and abstract terms. The quality of governmentality, and the capacity of transforming the State-politics of the Syriza government, is just the natural outcome of this kind of preparation.

It is a matter of debate whether the Syriza experience in this respect is generalisable or not for the Left today, on a global scale. But it seems to me that there is also a lack of literature on these issues as well. There is Leftoriented literature, regarding geopolitics, economics, social movements, political science (political representation, alliances etc.). There are also Left-oriented debates regarding strategic questions, the nature of rupture, modern subjectivities. But, what about management, leadership, organisational theories, complexity, system and network theories? I hope I am wrong and it is just me, the Greek Left, or the traditional political Left, that is not familiar with the debates regarding these issues, triggered by current scientific production or practical experiences of our collectivities. In any case, I am sure that there are plenty of useful materials in these domains that the Left should recognise as being extremely crucial for our cause. And for as long as we have not explored such important areas of human activity and creativity, we can be optimistic that we may well discover some truly powerful 'weapons' in giving us stronger operational capacities in the future. 


\title{
The commons as unifying political vision
}

\author{
Sophie Bloemen ${ }^{1}$
}

The crisis of the European Union begs for new, unifying and constructive narratives - alternatives to the right-wing populist and nationalist wave that is getting fiercer every day. A 'commons' approach holds the potential for a unified vision towards an alternative economy, a Europe from the bottom-up, and an ecological economy and way of life. The idea of jointly stewarding shared resources, community, and a generative economy can find resonance with a diverse range of citizens.

Major fault lines are starting to appear in the dominant world-view based on individualism, private ownership and an extractive relationship with nature. Although this view is still pervasive in economics, politics and law, a novel outlook based on networks, access and sustainability is emerging (Capra\&Mattei, 2015). The online environment, where knowledge is shared and co-produced on a large scale, has made a huge contribution to this shift in perspective (Benkler, 2006).

The predominant discourses that permeate political discussions at the European Union level are, however, those of economic growth, competitiveness and efficiency - considerations that tend to trump everything else. The lion's share of the European Union's policy focuses on macro-economic indicators and the promotion of large commercial interests. Citizens are often viewed simply as entrepreneurs or consumers.

This dominant outlook follows the logic of the 'homo economicus', the fictional abstract individual of standard economics, who maximises his personal material gain through rational calculation. The underlying Cartesian subject-object dualism, in which mind is divorced from nature, leads to the perception that the world is there for humans to dominate

1 | An earlier version of this article has been co-written with David Hammerstein. 
and use. In addition, these models do not take into account the limits of our cognitive capacities or the limits of natural resources. As a result, it rationalises a view in which agents, when presented with the possibility to extract value from nature for their personal benefit, should always do so.

An ensuing focus on markets and growth has blinded us from the loss of social cohesion, rampant inequality, and the destruction of the environment. In the perceived need to quantify everything, gross domestic product is used as a measure of social wealth. Modern property rights and the dominant concept of ownership as an individual right protected by the State, to allow short-term accumulation, are central to the materialistic orientation and extractive mentality that lie at the root of today's global ecological crisis. The commodification of our common resources, and even our online behaviour, seem limitless.

\section{The commons}

The commons perspective stands in stark contrast to the policy priorities that currently dominate in Europe. The commons refers to shared resources and frameworks for social relationships, managed by community. Commons also stands for a world-view and ethical perspective favouring stewardship, reciprocity and social and ecological sustainability. This outlook defines well-being and social wealth not just by narrow economic criteria like gross domestic product or a company's success. Instead, it looks to a richer, more qualitative set of criteria that are not easily measured - including moral legitimacy, social consensus and participation, equity, resilience, social cohesion and social justice (Ostrom\&Hess, 2007).

The commons discourse considers people as actors who are deeply embedded in social relationships, communities and local ecosystems, instead of regarding society as a collection of atomised individuals, principally living as consumers or entrepreneurs. Human motivation is more diverse than maximising material self-interest alone: we are social beings and human cooperation and reciprocity are at least as important in driving our actions (Bollier, 2014: 112). This more holistic perspective considers human activity as part of the larger, living biophysical world. Recognising the multiple domains of people's lives, bottom-up, decentralised and participatory approaches to our major social 
and environmental dilemmas provide functional solutions to the current environmental and social crises facing our continent.

The idea of the commons does not fit within the traditional ideological frameworks of Left and Right. However, it does provide a clear ethical perspective and helps us appreciate and understand the value of people collectively stewarding resources, without the dominant, centralised roles of the market or the State. The commons are not primarily a political theory, but first and foremost a practice emerging from the bottom-up. Everywhere, people are engaged in alternative practices as part of the struggle for ecological, social and cultural transition within their communities.

All over Europe, local initiatives are seeking to take care of their direct environment, are sharing and stewarding knowledge online and claiming natural resources as our commons. Examples include community wi-fi structures, providing access to the internet in remote areas, co-housing initiatives ensuring affordable housing, community land trusts that explore collective forms of property and urban commons initiatives working to regenerate the city for its citizens. The digital knowledge commons are a key element of an alternative economy and online commons projects have attained an impressive scale. Creative commons licenses for cultural works, for example, are now over one billion. There is Wikipedia, by far the world's largest and most used encyclopaedia, and Firefox, which offers a free and open source alternative to Apple's Safari and Microsoft's Internet Explorer. About half of all administrative bodies in the EU are as of now using open source-software. In all these areas, the commons approach offers a new vocabulary for collective action and social justice. It opens up ways of reshaping processes for the governance of resources by communities themselves.

\section{Cultural change and political struggle}

All this while European civil society, NGOs and social justice networks, up to now have not been able to unite around a broadly shared agenda. Hundreds of organisations united in the fight against the TTIP, a trade agreement driven by the interests of large corporations and negotiated in a highly un-transparent manner. However, in order to make progress towards another, fairer and ecological economy and society, a movement cannot be solely reactionary; it has to set the agenda. The emerging radical initiatives that have been proposing alternatives have mostly been 
engaged at a national or local level, rather than on the European level. Examples are '15M' in Spain, 'Nuit de Bout' in France and the University occupation in Amsterdam. Occupy was translocal, but did not succeed in really opening up the conversation in Europe. Local struggles, forwardlooking and emancipatory projects, will have to be connected in order to really be strong. The national and local levels are essential, but not enough. The fact is that a great deal of the laws and developments that shape our societies come from the European level and global markets. Civil society has to have translocal and transnational solidarity around a shared vision of an alternative society.

We see this vision of an alternative society emerging, both in theory and political beliefs, but even more so in practice. It is emerging in the way people choose to live their lives. Whilst societal changes we experience are often cast in terms of economy or technologies and are dependent on a favourable institutional environment, they are often rooted in cultural change. Our culture reflects and shapes our values and how we attribute meaning to our lives. Cultural change is therefore a key driver for social transformation. Many current community-led and social innovation initiatives and practices are enabling communities to be generative, instead of extractive, outside of the market and State. This is creating a new civic and cultural ethic that breaks with conventional notions of citizenship and participation. The regenerative activities of commoners showcase, above all, cultural manifestations of new ways of daily life.

At the same time, the perspective of the commons unites many different struggles; the struggle for managing water as a common good, of managing our energy locally and sustainably, of being able to share knowledge, from affordable medicines and limiting patents, to struggles around the urban environment and citizen participation and new forms of democracy. All of these concern the participatory and equitable management of common goods in a sustainable matter: goods that are fundamental to everyone's well-being and flourishing. 


\section{European commons assembly}

The European Commons Assembly ${ }^{2}$ that took place in Brussels in November has been a case in point for the unifying potential of the commons. The movement of commoners has been growing across Europe over the last decade, but with the Assembly it came together for the first time in a political transnational European constellation. The objectives of the meetings were multiple, but the foremost goal was to connect and form a stable but informal transnational commons movement in Europe. Over 150 Europeans came to Brussels, and in a symbolic move of reclaiming Europe, met for half a day in the European Parliament. They came to develop new synergies, express solidarity and to discuss European politics, as well as policy proposals. Europe's democratically elected Members of the European Parliament exchanged views with the 'Commons Assembly', made up of a myriad of commoners, activists and social innovators from many different corners of Europe.

The political energy generated by bringing all these people together in this context was exceptional. The Assembly included important discussions, about the relationship between 'the Left' and local commons movements, between practical examples of building alternatives on the ground and macro political and economic visions of Europe. These conversations have to be about philosophy and vision, yet also about whom we are addressing and what is to be included or excluded in our narrative. How to build broader coalitions on the ground, not bound to the Left or Right, how to prevent erecting walls with academic language and theory, and indeed, how to attract conservative commoners. The Assembly will continue as a political process and diverse platform that still needs to find its way, yet holds a great deal of potential.

\section{How to move forward}

People left behind by globalisation find themselves in a world where economic insecurity is the default and everything is for sale. Moreover, globalisation and the focus on the individual has led to the loss of familiar culture and community and the loss of a clear national identity. Instead of rejecting these sentiments, we need to acknowledge them, for they

2 | https://europeancommonsassembly.eu/ 
are real. The commons embrace predominantly progressive values, but they are not about de-localised cosmopolitanism. Instead, the commons depend on the local environment and resources, on community, traditions, care and trust. Rather than letting the political backlash lead to Europe's disintegration, we should turn our gaze to what is below, to what people are creating locally, what is happening on the ground. That is where there is hope and energy, that is where people are jointly stewarding their own resources, be it local energy cooperatives or online initiatives such as Wikipedia.

As we build this movement, we can do our best to improve networking, campaign tactics and alliances ${ }^{3}$. We have to ask ourselves however, how does a commons movement as a political force relate to conventional political power? There is a tension between conventional political advocacy and 'commoning'. If the building of an alternative economy is the primary task, is it then the main role of advocacy and politics in favour of the commons which will be able to facilitate the building of such an economy? And should we not focus first and foremost on the deepening of democracy, as the role of representative democratic structures are part of the problem? These are questions the commons movement, and the political advocates involved, have to keep asking themselves. The role of local initiatives in the political platform has to be addressed and developed in such a way that we find a functioning and satisfying configuration. Otherwise, the movement risks being neutralised and domesticated in the policy venues that are so crucial in protecting and facilitating the flourishing of the commons.

\section{BibliogRAPHY}

Benkler, Y. (2006): The Wealth of Networks: How Social Production Transforms Markets and Freedom. New Haven and London: Yale University Press.

Bollier, D. (2014): Think Like a Commoner: A short introduction to the life of the commons. Canada: New Society Publishers.

3 | The reflections in this paragraph are based on an exchange with David Bollier in September 2016. 
Capra, F.\&Mattei, U. (2015): The Ecology of Law. Oakland, CA: BerretKoehler Publishers.

Elinor, O.\&Hess, C. (2007): Understanding Knowledge as a Commons, MIT Press 


\section{Instructions for building a pan-European movement}

Interview with Pia Eberhardt, Corporate Europe Observatory ${ }^{1}$

The negotiations on the proposed Transatlantic Trade and Investment Partnership (TTIP) between the European Commission and the US government led to massive protests both in the US and in Europe over the last few years. While supporters argue that an increase in free trade would result in economic growth and more jobs, critics claim that TTIP endangers environmental and consumer standards and that it is an assault on democracy itself. Pia Eberhardt, works for the Corporate Europe Observatory and is one of the spokespersons of the anti-TTIP movement.

$$
* * *
$$

Would you say the anti-TTIP movement has been successful? And if so, in what way exactly?

Yes, absolutely. It has been successful in many ways: First, we have managed to put a highly complex issue on the public agenda in many EU countries. In countries where TTIP has been publicly debated for a while now - like Germany or Austria - the majority of the population is now opposed to TTIP according to polls. Second, this has put enormous pressure on policymakers and made the TTIP negotiations much more complicated, to the extent that they may never be concluded. Third, we have managed to build a relatively stable - and broad - pan-European network. That did not exist in Europe before.

1 This interview took place in 0ctober 2016. The last two questions were added in January 2017. 
The street protests were among the most successful in a long time (at least in some countries, such as Germany). Why do you think people were mobilised over what is actually a very complicated and technical international trade treaty?

I think the most important reason is TTIP itself, and the fact that it will have an impact on so many issues that people care about - from the environment to labour rights and democracy as a whole. Because of its scope, nearly every component of Europe's organised civil society - trade unions, environmental and consumer groups, digital rights activists and so on - has a reason to worry about TTIP. And they all campaigned on it. I cannot think of any other issue where this has been the case.

Was it different to other protests, like for example Heiligendamm 2007? If so, what was the difference?

First, I would say that the threats that TTIP poses are much more concrete: this will be a treaty that binds our societies indefinitely and has a very concrete impact for example on how much competition small farmers face and which standards prevail in the food sector. The threats of a G8 summit are far more diffuse. It may be clear to us activists what the problem is with the G8 and why it is an important link in the network of institutions that has driven neoliberal globalisation, but for ordinary people the implications are very abstract. Second, I think that the antiTTIP movement is much broader - and allows for many more different ways of people getting involved than, for example, the anti-G8 protests. During the "TTIP Game Over" action days in Brussels, for example, we saw the kind of direct actions and civil disobedience that played a key role in Heiligendamm. But at the same time people have also spent a lot of time discussing the issue with local politicians and working on anti-TTIP and CETA resolutions, which have now been passed by over 2000 cities and regions in Europe. And you also have the small and medium-sized businesses against TTIP. This context allows a topic to become an issue for groups far beyond the usual suspects and small left-wing circles.

What were the difficulties in building up a transnational protest? 
I would say it wasn't very difficult, but obviously you face the usual challenges: language barriers and resources are always an issue. It simply takes a lot of resources to translate studies and other information sources so that people can work with them on the ground in their countries. And obviously we do not have the means to translate our EU-wide meetings into lots of different languages, so effectively only people who speak English can attend. Another challenge is that you need some form of coordination of such a movement - but at the same time you need a lot of space and flexibility so that all the national campaigns can work in a way that makes most sense for their own countries. So, for example, deciding on European-wide action days is never easy because a day or week that might make perfect sense in the Spanish context might be completely out of context in Austria.

What role did social media play? Do you see a conflict between "clicktivism" and protest on the streets or long- term engagement?

Social media plays a very big role. If you have a new analysis on TTIP, it can reach people everywhere in no time. You can use it to build up pressure on policymakers, for example during twitter storms. But online campaign groups like Campact in Germany do much more than clicktivism. Thanks to Campact, for example, thousands of people have visited the offices of their MPs. They have put "door hangers" informing about the different party positions on TTIP on people's doors ahead of important elections. And research has shown that around a third of the people who attended the big demos against TTIP in Germany did so because they had learned about TTIP from Campact. So no, I do not see a conflict between these different forms of engagement - as long as we do not put out different messages.

Have you cooperated with organisations from the US? Do you see potential for transatlantic solidarity rather than the transatlantic spectatorship we see, for example, with the US presidential election?

Yes, of course. US (and Canadian) groups were involved in the struggle against TTIP and CETA right from the start. All the working groups we have on the different TTIP issues - for example on agriculture or regulatory cooperation - are transatlantic, so there are regular calls on 
these issues between people on both sides of the Atlantic. Email lists, too, are transatlantic. Anything else would not make sense because with TTIP the key line of conflict is not the US vs. the EU or the other way round - it is corporations and their profit interests vs. other societal interests.

What are the most important things other movements can learn from all this?

I would say two things: First, confront any differences between the different actors in the movement head on - but do not get lost in them; focus on your commonalities. For example, at the very first European meeting we had on TTIP it was clear that there were people who opposed free trade while others were in favour of free trade but were still critical of many parts of the TTIP, for example regulatory cooperation and investment protection. So we made these positions very clear from the outset, but then said: let us not lecture each other on our respective positions but rather focus on what we have in common, for example that we see TTIP as a threat to democracy and to regulation in the public interest. The same goes for different forms of activities - we have a coalition that brings together people who regularly lobby policymakers and people who consider this a waste of time and prefer to do direct actions. But both are respected; it is clear to everyone that our broad base is our strength.

The second lesson is related to this: you have to be able to get out of your comfort zone. To stop TTIP it is not enough to get grassroots groups, trade unions and left and Green parties on your side. You also need to convince significant sections of the conservative middle class and more centre-right parties and conservative media. So you need people and organisations that know how to speak to, say, conservative farmers in Bavaria, to judges, to medium-sized enterprises, and to regulators. That has an impact on your messaging and the way you act.

How do you deal with the increasing appropriation of traditional left-wing causes by nationalist groups?

It is a challenge, and I do not think we have a satisfying answer to that yet. In the German context, for example, nearly every speech at the big demos we staged made it clear that there was no space for racist, anti-Semitic or anti-American positions in these marches. People bearing big banners with messages to this effect marched in front of the rest. And we had 
anti-fascist monitoring groups at the demos to kick out people with racist messages. These initiatives are very important and must continue. But I am not sure that that will be enough.

For example, we face the concrete problem that the Social Democrats in the European Parliament do not want to vote with the far right. I can totally understand that. And for the Greens in the European Parliament it must be horrible to be constantly lumped together with UKIP, for example, which is also voting against TTIP in the Parliament. But the response of the democratic parties cannot be to start approving all kinds of neoliberal projects simply because nationalists are opposing them. However, I honestly have no idea how to deal with that situation. It is pretty disastrous.

Wallonia, a French-speaking region of Belgium with a population of about 3.5 million people, grabbed the world's attention when it vetoed CETA. How do you evaluate what happened in Wallonia?

What happened in Belgium was on the one hand very encouraging. The Walloon Parliament organised 70 hours of public consultation on CETA. So, it scrutinised the agreement vigorously. And it identified serious concerns - and did have the backbone to at least temporarily block the CETA ratification when it was clear that its concerns had not been addressed. So, what we saw was a rare glorious democratic moment, where a Parliament actually did its job, scrutinised a complicated agreement with serious consequences and stood up to defend the interests of the people who elected it.

But the episode was also disillusioning. In the end, the pressure on Wallonia was too strong and it had to clear the path for the Belgian federal government to sign CETA - even though none of CETA's flaws were fixed. Nonetheless, Wallonia achieved two important things: it forced the Belgian government to send CETA's investment chapter to the European Court of Justice so that the court can check if the chapter is in line with EU law. And Wallonia - and the three other sub-federal entities which shared its opposition to CETA - put down in writing that they will not ratify CETA in its current form when CETA reaches the third stage of ratification, in which all regional Belgian Parliaments will have to vote on CETA again. So, it is clear that CETA will have to be changed - or Belgium will not be able to fully ratify CETA. 
As TTIP has been put off the political agenda, CETA is still in negotiations. Do you foresee the future of the movement working against CETA?

CETA will face a long and difficult battle to get ratified in all EU member states. Because in the third phase of the ratification, around 40 Parliaments in all $28 \mathrm{EU}$ member states will have to ratify the agreement. This is likely to happen quickly in some countries like the Nordic states where CETA is not really an issue. But in others like Belgium, France, Austria and Germany, it might take years until CETA will be put to an actual vote. And that will mean that the agreement will only partially enter into forceand the controversial investment protection chapter, for example, will not. That in itself is already a major civil society victory - even if we might not manage to kill CETA for good in these votes.

For TTIP, we will have to see what the Trump administration will really do. At the moment, we do not know its position on TTIP. It could be that the US government buries the agreement. But I think it is likely that the TTIP negotiations will be picked up again in the second half of 2017. Many of the TTIP chapters - for example, on regulatory cooperation or financial deregulation - fit quite well with Trump's deregulatory big business agenda. So, we will definitely remain vigilant. 


\section{Together means Razem}

Interview with Marcelina Zawisza and Maciej Konieczny, Razem ${ }^{1}$

Something is moving in ultra-conservative Poland. Marcelina Zawisza and Maciej Konieczny are members of Razem (“Together”), a new political party emerging from social movements and strongly inspired by the experience of Podemos in Spain. They explain their project and the Polish political scenario: from the surprising social policies of the current authoritarian government to the liberal opposition defending freedom of information but forgetting about inequality. In this context, what does it mean to launch a new party from the bottom-up in Poland today?

$* * *$

Why a new party in Poland? Why did you make the shift from social movements to party politics?

There was no real left party in Poland. There is the so-called Socialist or post-Communist party, which is just bureaucrats of the late Communist government that became the new establishment after the transition basically neoliberal, socially conservative, not leftist at all, but they took the place of the left in the country and our objective was to re-open that space. Nobody trusts parties anymore here, and this is why we were very sceptical regarding the success of this operation. But if parties are in distress, social movements are not in a better situation: small, fragmented groups, incapable of having a strong impact, chronically divided.

1 | This interview took place in July 2016. 
And so you thought a solution would be to have all these forces come together to form a single political group?

We wrote an open letter to all movements. We received two thousand signatures in a few days, almost all of them - and this was the real surprise - from people we did not know and who never took part in organised mobilisations. We really wanted to know who they were! We met them, and to our surprise we learnt they were not interested in traditional leftwing organisations or movements. They reputed those political forms to be old and useless.

This is a story we have heard before. When talking with Podemos' founders they say that to launch a new political project they had to leave the world of organised movements, who at the beginning were even against them, in order to intercept the energy coming from the $15 \mathrm{M}$ and only after that, they could go back and include organised movements. Is it something like that?

Exactly. The organised left has been in conflict with us since the beginning. But now many have left the traditional movements or organisations and joined Razem instead, to come out of their small bubble. We decided to be part of the trail of the new European left, moving from the base. In this sense, Podemos is a big inspiration; they have proved that it is possible to bring a change.

At the elections last year there was a coalition of the United Left, postcommunists, Greens, left-liberal ... Why didn't you join this list, rather than running by yourself?

We have our own agenda and a new way of conceiving politics itself, together with its organisation. The old way of doing politics is dead and is represented by the same names and the same politicians and power groups that, election after election, try to found new coalitions, new alliances, just to win their seat in Parliament again. We are talking about the political class as a whole. It simply does not work anymore and it is not what we want to do. Moreover, these parties, when elected, passed laws permitting evictions, perfectly fitting the mainstream "there is no alternative" narrative. 
And they have been eclipsed. The post-communist party was at 40 per cent and now is not even in Parliament. But what makes your model work? What are your flagship methods or policies?

Our program is somehow not so radical, we could define it as social democratic. But this, in Poland, is something new. Nobody ever talked about progressive taxation, redistribution ... And now, when statements concerning workers or poverty are needed by the media, they come to us. The same happens with social issues: we are the ones asking for the decriminalisation of abortion, still an illegal practice in Poland. And when the government tried to pass an even more restrictive law, making abortion illegal even in the case of rape, we organised a rally in Warsaw, which over than ten thousand people attended. The biggest demonstration ever on this issue in Poland.

Talking about social policies, the current government-led by Kaczyński's party Law and Justice - is quite an interesting case. It is for sure an authoritarian, xenophobic, illiberal government, on a collision course with the EU. But it is, nevertheless, passing some measures that could be seen as traditionally leftist: reduction of the retirement age, maternity allowance, social housing. What do you think about it? Is this a new kind of national socialism?

We must say we are surprised as well. We thought the social agenda mentioned during the political campaign would be forgotten once elected, as had happened when the same party had the chance to govern previously. But now they are really doing it! They are way more nationalistic and authoritarian than the first time, but they are also way more social. For the first time we have assisted a growth, rather than to a reduction in welfare provisions. The new maternity law will drastically reduce child poverty from 28 per cent to 10 per cent, an issue closely linked to large families here in Poland. And for the first time, most public spending will go to the poorest: 6 billion złoty to the poorest 10 per cent of the country, only 300 million to the richest 10 per cent.

So, for the first time there are redistributive policies.

And we will not be the ones criticising them. A social housing program was launched, not giving resources to banks or big building companies, 
but giving resources for controlled rents. And there is more: the taxation system is undergoing a modification that will make it more progressive, the flat tax is being abandoned, along with regressive taxes for the richest. But at the same time, the government is extremely authoritarian. A militia with semi-automatic weapons is about to be created, mostly made up of components of far-right groups. A bill against terrorism is about to pass, creating a permanent state of emergency. Not to mention the gag that has been put on the press and attacks against the independence of the Constitutional Court. It is quite frightening.

And it is against this authoritarianism that we have seen so many demonstrations in Poland. But you have chosen not to join KOD, the organising platform. Why is that?

Well, the governing party is in fact terrible, but these demonstrations have been predominantly organised elites of the previous government [Civic Platform, the party of the current President of the European Council, Donald Tusk - Ed].

They demonstrate for freedom of speech, but then attack the government's social policies - refuting them as a way to "buy" votes. They do not understand that this money is incredibly important for many people. They tell the poor they should go out in the streets, fighting to save our constitutional system, while at the same time, by accepting 500 złoty per month for maternity benefit, they are selling themselves. And all this while a majority of the low-middle class only earns 2000 złoty per month. They are completely out of touch with reality. And this is how in Hungary Viktor Orbán obtained an absolute majority in Parliament, by having only one opposition party that represented only the elite.

We want to kick out this government, but to do it we believe that just to gather liberals in big cities is not enough. You have to reach out to those people who now vote for Law and Justice [the governing party - Ed]. If no one has the courage to create a social agenda, then the space is open for authoritarian forces

What is the social base of the governing party?

They have a cross-cutting base. Many vote for them as they are thought to be against the establishment and as the people have had enough of the 
previous government; a government that chose to ignore completely all social issues. Civic Platform talks about those Poles who had to emigrate as "lucky" people who had the opportunity to have work experience abroad. They did not realise how much suffering was brought by family separations or that two million people could not find a job in their own country. These opposition groups - KOD, Civic Platform - are part of the post-transition elites that now would love to just go back to business as usual. All without realising inequality levels are much higher in Poland than the European average.

You received considerable public funding because of your result in the last elections. You have two more years until the next one: what now? What will be your next steps?

We are trying to open 25 social spaces across Poland. They will not be just normal party offices, but community places where everyone can come and utilise the space, organise a dance lesson, classes for children, legal assistance and so on. This is something the socialist party of Poland used to do before WWII. We do have a strong tradition of political parties as social entities, working with cooperatives, unions, even sport clubs, much more than just an election to election machine. We did not call ourselves "something-left", as nobody here knows what left is anymore. We called ourselves Razem, “Together”. But our origins are clear, and we want to start anew from there. 


\title{
The birth of a new civic platform in Romania
}

\author{
Interview with Oana Băluță and Camil Pârvu, Demos ${ }^{1}$
}

Romania's political landscape has become increasingly problematic as a result of growing social inequality and economic instability. In this context, Demos has emerged as a growing citizens platform that aims to secure more political influence for the people. It offers open forums for the citizens to come together and reflect on common demands and the problems that the government is not solving. Oana Băluță and Camil Pârvu are members of the new initiative Demos. They reflect about the political situation, the social struggles and about how the new citizens' platform can influence the political agenda in the country. Oana Băluță is an associate professor at the University of Bucharest's Faculty of Journalism and Communication Studies and Camil Pârvu is an associate professor at the university's Faculty of Political Science.

$$
* * *
$$

Over the last few years, in certain European countries like Greece, Spain and Poland we have seen the formation of political parties that began as social movements or citizens' platforms. How was Demos formed, what does it mean to be a civic platform and how do you see the transition to a political party?

Many of the members of Demos as a civic platform have been directly involved in the waves of protest that Romania has seen since 2011. A particularity of these protests is that they have been rather effective in these last five years - forcing two resignations by prime ministers

1 | This interview took place in November 2016, before the parliamentary elections in Romania, where the Social Democrats won 46 per cent of the vote. 
and, in the 2013 protests over the Rosia Montana gold mining project, a policy change from what was a very broad parliamentary coalition on other issues. Part of the strength of the street protests derived from the de facto impossibility of forming new political parties and the increasing cartelisation of the existing ones. In the course of the last year the electoral legislation has changed, making it much easier to establish new political parties. Some of the newly formed political parties are, however, very neoliberal in their social and political outlook - as they insist on postpolitical expertise delivering a social conflict-free society. We, by contrast, are, focussing on the key issues of rising inequality (Romania has the highest level of income inequality in the EU), social and environmental policy, poverty, housing, and rebuilding the social state, which is in the process of being dismantled. Our political and social vision is driven by the lessons and vocabulary of the social protests.

How would you describe the political context in Romania today? And within this context, what are the main policies advocated by Demos?

Given that 2016 is an election year in Romania - local elections have already been held and parliamentary ones will take place in December - it makes sense to reflect on the political context in terms of both the political parties running for election and the public policies. The competition is fiercer in this year's elections because new political parties have been established that have the potential to displace the parties that traditionally win. There is also a mixture of ideologies, a reluctance to adopt any single ideology, confusion regarding the official ideology, the public policies and the rhetoric of the politicians, as well as opportunistic strategies that embrace nationalism, populism and moral conservatism.

Demos is not running in the elections because for now it still functions as a civic platform. It brings people together to debate and discuss solidarity, democracy and giving politics back to the people. Despite the growing competition among political parties, socio-economic and environmental issues are still being left aside despite the fact that they are creating inequality and a lack of opportunities for individuals and groups. Demos wants to play an active role in combating inequality in education, in the labour market, in healthcare, in the environment and in the social welfare system by promoting opportunities for individuals in a precarious 
situation/the disadvantaged. Demos also advocates gender-sensitive, antiracist and environmentally-friendly policies.

What are the main social issues in Romania today and how is the government dealing with them?

The main social issues are unemployment, workers' rights, access to decent healthcare and education, work-life balance policies, housing, and the protection of vulnerable individuals - for instance women who are victims of gender-based violence. Some social issues are being addressed by the government, while others are being ignored or "postponed". Take public kindergartens, for instance. Their number has decreased steadily since 1989 , and the statistics show that the shortage of public kindergarten places is having a negative impact on women's employment rates and children's access to public school education, particularly in rural areas. Developing and investing in public kindergartens yields positive results in terms of gender equality and children's access to primary school education, especially in the case of one-parent families and families that are struggling financially and desperately need a second income to stay above the poverty line. You cannot increase employment rates among women without investing in public kindergartens. We have to understand the cumulative impact the lack of kindergarten places has for instance on pensions and on poverty rates among elderly women.

Where is Demos operating at the moment? Do you have different groups at the national and regional levels? If so, how do the policies and methods differ from one level to the other?

We are starting to set up central and local party structures (the party will become an official entity in a couple of months) to prepare for the next elections in three years' time. Parallel to this process the civic platform is now present in many of the big cities and has national reach. We selected particular themes for the debates at each local event - labour laws, the reconstruction of the social welfare state, the creation of new anti-corruption policies etc. We are very pleased with the attention and feedback that these local debates have generated and we continue to develop this network. 
When we talk to the founders and members of new political parties in Europe, they point to the challenges of maintaining a productive, enduring and healthy relationship between the social movement that produced them and the institutions. What are the expectations of Demos in this respect?

Because Demos is still a civic platform at present we have not yet actively confronted that challenge, although there is an internal process of negotiating our own identity as we make the transition from civic activists to members of a political party. For the moment our organisational structure remains rather horizontal and we are setting up working groups and subgroups in which we can harmonise our expertise for several key policy areas, such as social policy, environmental policy, administrative reform etc. This means that when the political party is finally established it will inherit the style and political culture of the civic platform. It will, however, be a political party with specific decision-making procedures. We have included several groups in a process of consultation in order to ensure a better integration and coverage of various policy areas. We have already consulted green NGOs, LGBT groups and newly formed trade unions, and we plan to have consultations with women's rights groups and other such organisations. Many members of the Demos Initiative Group come from social movements and NGOs themselves, and we can build up a healthy relationship with these groups if there is mutual trust and if we understand and accept each other's limitations, as well as the importance of working together in order to respond more effectively to the needs of special groups and better represent their interests. It will be a learning process for both the agents of social movements and Demos. We need to create trust, advocate specific policies and dialogue, and embrace an approach based on common sense. 


\title{
The Rojava Revolution and the model of democracy without a state
}

\author{
Sheruan Hassan and Jonas Staal ${ }^{1}$
}

At the start of the Syrian Civil War in 2011, Kurdish revolutionaries reclaimed the northern part of Syria, known as Rojava, which means "West" in Kurdish and refers to the western part of Kurdistan. In 2012, the peoples of the region declared a Democratic Self-Administration of Rojava, aimed at bringing about a new political model known as democratic confederalism. This model was described by Kurdish revolutionary Abdullah Öcalan as "democracy without the state," an ideal based on local self-governance, gender equality, communal economy, secularism, and cultural and religious diversity.

The Rojava Revolution is widely known for its effective resistance against the brutal violence of the Islamic State. The Women's Protection Units (YPJ) and People's Protection Units (YPG) - the self-organised people's armies of Rojava - have proved most successful in liberating land that was under the control of the Islamic State, and subsequently securing the rights and protection of religious and ethnic minorities in the region.

However, the revolution of Rojava is not just a military struggle. It is also a cultural struggle, a struggle to "change mentalities," as Amina Osse, Deputy Chair of the Committee of Foreign Affairs of Canton Cizîrê in Rojava, puts it. With this change of mentality, Osse refers to the ideological awakening of Rojava through the practice of stateless democracy. The old model of the nation-state, Osse explains, is not capable of representing a diversity of peoples, due to its centralised and homogeneous identitarian

1 This text was first published in New Worlds, The Democratic Self-Administration of Rojava \& New World Summit (Studio Jonas Staal), KORO / URO, 2016. 
politics. The nation-state further operates as a vehicle for global capital, privileges, and patriarchal relationships, and stands in conflict with ideals of a sustainable ecological society. In that light, the ultrafundamentalist and hyperpatriarchal Islamic State, which emerged from a history of violent imperialist politics in the region, stands in epic contrast to Rojava's ideal of a non-state democracy, championing women's rights and cultural diversity.

The Rojava Revolution is thus important for reasons that go beyond the enormous sacrifices at the frontlines against the Islamic State. It is also a struggle for a new society and a new democratic ideal. The Rojava Revolution brought about local parliaments, councils, and communes, which form the heart of the project of political self-governance - the heart of the Democratic Self-Administration. The revolution brought about new academies, such as the Women's Star Academy in Rimelan, which developed a new scientific paradigm based on women's perspectives, known as "Jineology." The Movement for Culture and Arts, Tev-Çand, established cultural centres in all of Rojava's villages and cities and organises exhibitions, music events, theatre, film screenings, and the cultural education of children and young adults. Moreover, it brought about the Rojava Film Commune, which is producing the first films by and for Rojavans on their history and revolution.

\section{The democratic self-administration of Rojava and the new world summit}

It is the intersection between culture and politics in the Rojava Revolution that brought about the collaboration between the Democratic SelfAdministration and the New World Summit, an artistic and political organisation founded in 2012. The New World Summit aims to create temporary parliaments in theatres and art spaces all over the world, where it invites representatives of stateless and blacklisted organisations to speak. The organisation aims to explore the space of art and culture to create new models of democracy that aim for equality between state and non-state actors. Six summits have been organised so far, including in Berlin (2012) and Brussels (2014), and have involved more than forty stateless and blacklisted organisations from around the world.

In 2014, the Democratic Self-Administration invited the New World Summit team to travel to Rojava and witness the development of their 
new civil society. It was during this visit that Amina Osse proposed to the New World Summit to contribute to the Rojava Revolution with a project: the creation of a new public parliament in the city of Dêrik in Canton Cezîrê, Rojava. A parliament as a public artwork, a sculpture, and symbol inspired by the Rojava Revolution, which at the same time would operate as a political space for the communes of Rojava to gather. This invitation resulted in a series of different collaborations. The construction of the public parliament began in August 2015, and an international delegation of representatives of stateless political organisations, politicians, academics, journalists, artists, and students travelled to Rojava in October 2015 to witness the achievements of the Rojava Revolution and celebrate the start of construction on the new parliament, which is aimed to be inaugurated early 2017. In January 2016, the Democratic Self-Administration of Rojava and New World Summit collaborated on a temporary parliament in Utrecht, inspired by the ideal of stateless democracy. Currently, a new project is underway in the form of a temporary embassy of Rojava in the City Hall of Oslo - the New World Embassy: Rojava.

To us, this collaboration between the realms of revolutionary politics and art emphasises the importance of cultural struggle within political struggle. Rojava inspires new political movements and artists all over the world to re-imagine the world differently, to confront the major crises in our politics, economy and ecology, to change mentality, and embrace a democratic paradigm that allows for power and resources to be shared by a diversity of peoples. It is not just one new world that Rojava is making possible; Rojava inspires many new worlds in the making, and invites artists and thinkers to contribute their imagination to make these many new worlds a reality, in the same way that the Rojava Revolution has made their new world of stateless democracy a reality for its peoples.

\section{New world summit-Rojava}

In 2014, the New World Summit was commissioned by Amina Osse, Deputy Chair of the Committee of Foreign Affairs of Canton Cizîrê, to develop a new parliament for the autonomous region of Rojava.

Amina Osse, Democratic Union Party (PYD) representative Sheruan Hassan, and artist Jonas Staal conceptualised the design as a public parliament - a parliament as a public space surrounded by a newly developed park, symbolising the Rojavan ideal of politics as common 
property. The location of the parliament was decided to be the city of Dêrik. The circular space of the parliament can accommodate about two hundred and fifty people, the average size of a local commune in Rojava. The centre of power remains purposely unoccupied, emphasising the egalitarian ideal of stateless democracy as collective self-governance. Around the circular space, arches are constructed on which key concepts of Rojava's Social Contract are written. The roof consists of hand painted fragments of flags representing local political organisations. On October 16-17, 2015, a two-day summit was organised in the local cultural center of Tev-Çand in Dêrik to celebrate the start of construction, where Rojavan representatives spoke side by side with representatives of other state-less movements and progressive political parties from all over the world. 


\section{Works by Democratic Self-Administration of Rojava and Studio Jonas Staal}

New World Summit Rojava (2015-2017)

Figure 1: New World Summit - Rojava.

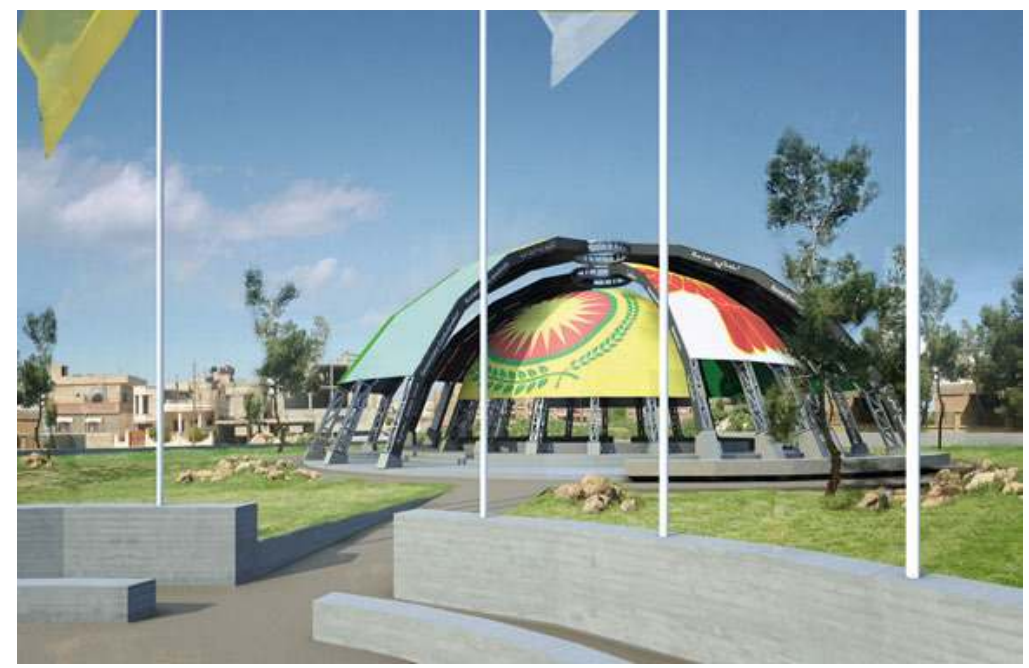

Description: Design of the new public parliament and surrounding park in the city of Derik, commissioned by the Democratic Self-Administration of Rojava (northern-Syria). Artist: Democratic Self-Administration of Rojava and Studio Jonas Staal, 2015-16. 
Figure 2: New World Summit - Rojava.

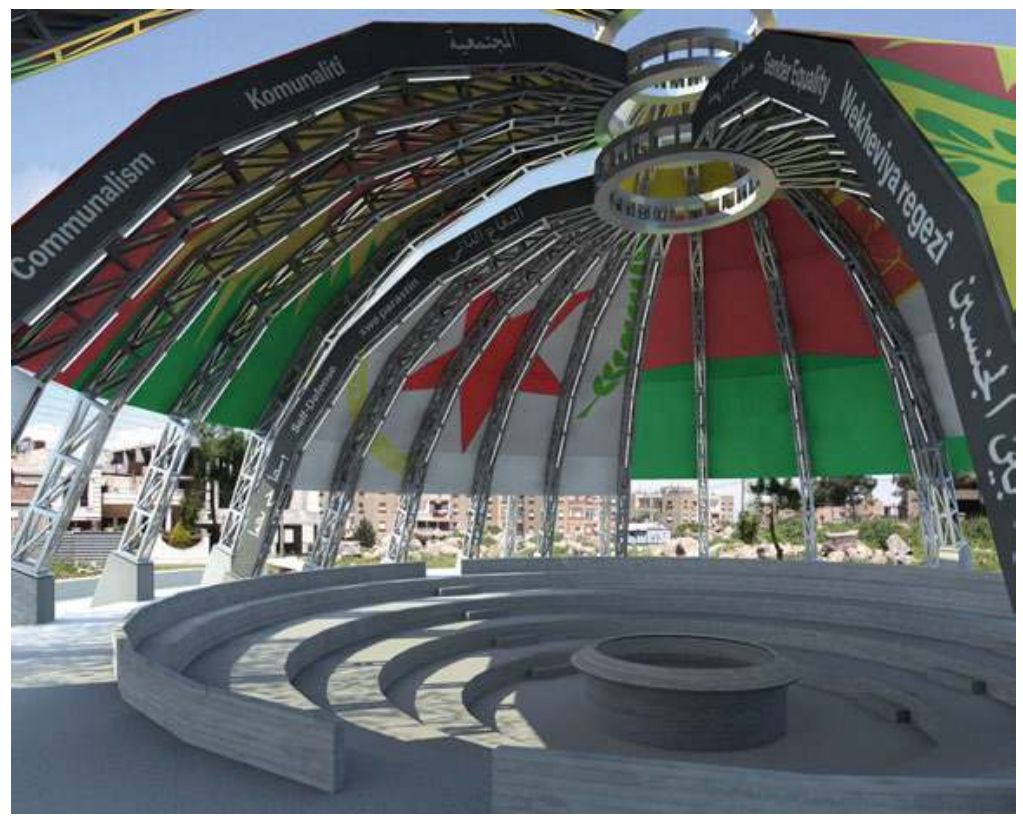

Description: Interior design of the new public parliament in the city of Derik, commissioned by the Democratic Self-Administration of Rojava (northernSyria). Artist: Democratic Self-Administration of Rojava and Studio Jonas Staal, 2015-16. 
Figure 3: New World Summit-Rojava.

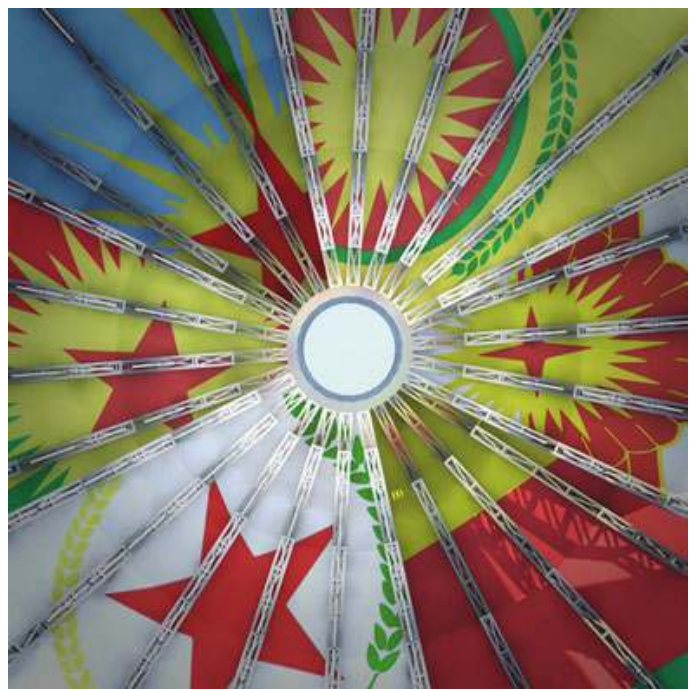

Description: Design of the inside of the roof of the new public parliament in the autonomous Rojava region: clockwise from top-center these depict the flags of the autonomous Rojava region, the Syriac Union Party (SUP), the Movement for a Democratic Society (Tev-Dem), the Democratic Union Party (PYD), the Rojava Democratic Youth Union (YCR) and the Star Union of Women (Yekitiya Star). Artist: Democratic Self-Administration of Rojava and Studio Jonas Staal, 2015-16. 
Figure 4: New World Summit - Rojava.

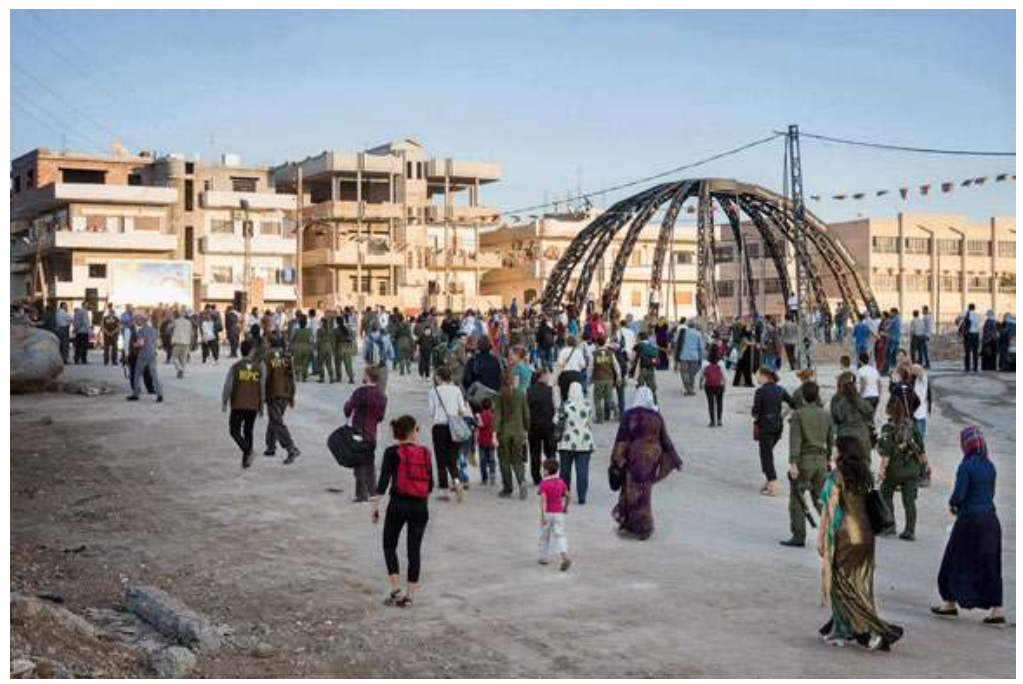

Description: Public arriving for the celebration of the construction of the new public parliament and surrounding park in the city of Derik, commissioned by the Democratic Self-Administration of Rojava (northern-Syria). Artist: Democratic Self-Administration of Rojava and Studio Jonas Staal, 2015-16. Photo: Ernie Buts.

Figure 5: New World Summit - Rojava.

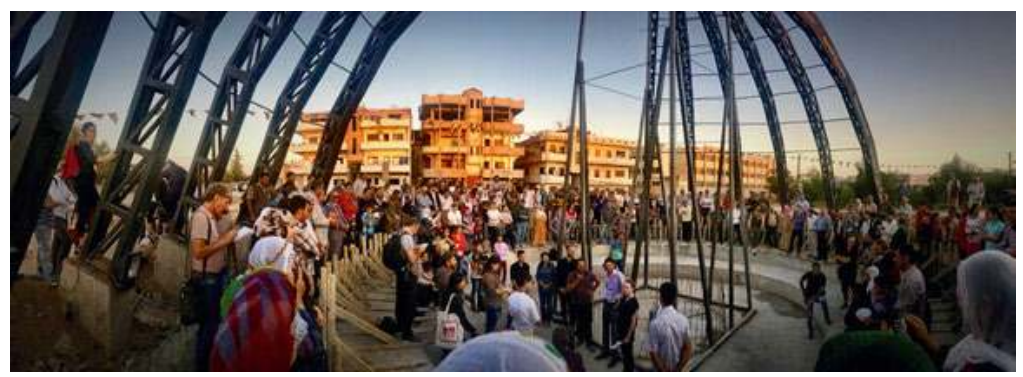

Description: Public celebration of the construction of the new public parliament and surrounding park in the city of Derik, commissioned by the Democratic Self-Administration of Rojava (northern-Syria). Artist: Democratic Self-Administration of Rojava and Studio Jonas Staal, 2015-16. Photo: Ruben Hamelink. 
Figure 6: New World Embassy: Rojava.

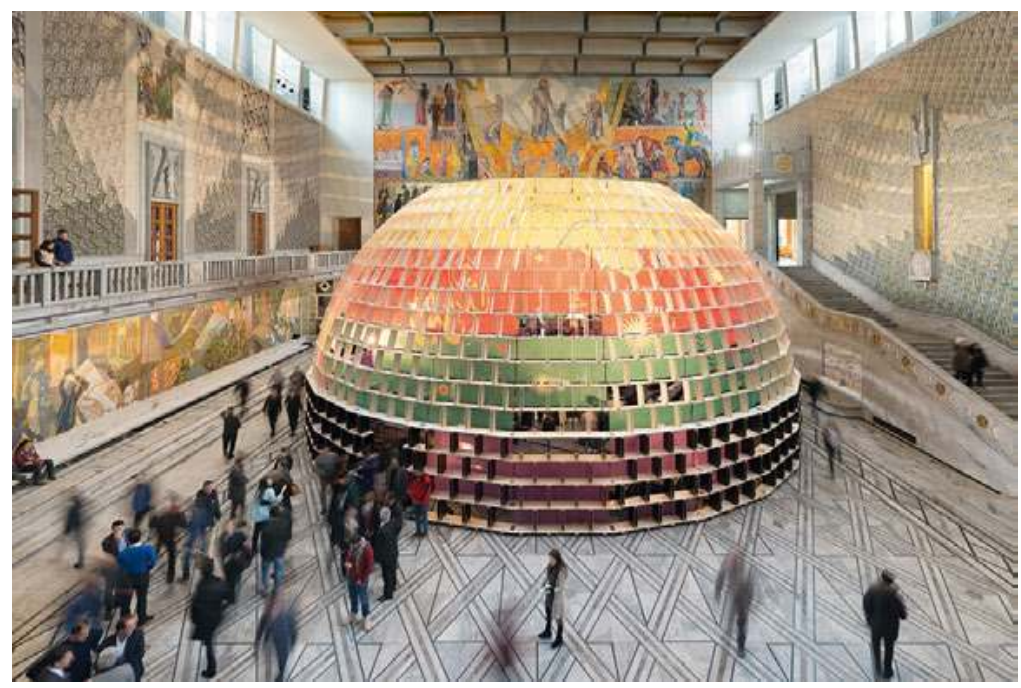

Description: Overview of the New World Embassy: Rojava in the Oslo City Hall. Artist: Democratic Self-Administration of Rojava and Studio Jonas Staal, 2016. Commissioned by: Oslo Architecture Triennial: After Belonging, After Belonging Agency and KORO Public Art Agency Norway / URO. Photo: Istvan Virag. 
Figure 7: New World Embassy: Rojava.

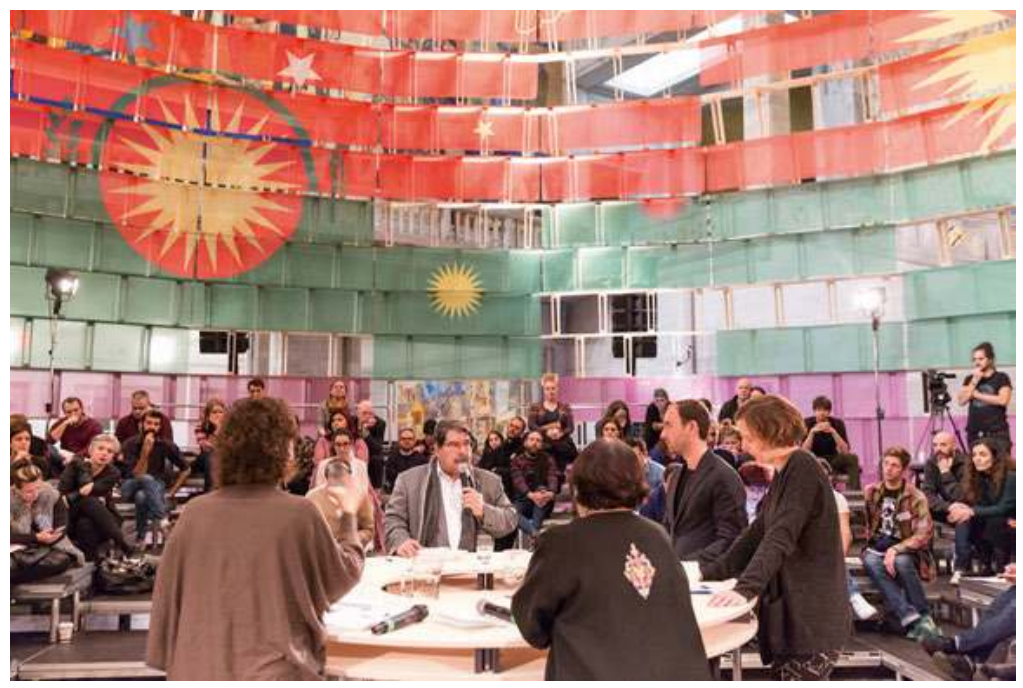

Description: Ambassador Salih Muslim (Co-chair Democratic Union Party, PYD) debates with Katerin Mendez (Feminist Initiative!), Lorenzo Marsili (European Alternatives), Despina Koutsoumba (Antarsya) and Kate Shea Baird (Barcelona en Comú), chaired by Radha d'Souza (University of Westminster). Artist: Democratic Self-Administration of Rojava and Studio Jonas Staal, 2016. Commissioned by: Oslo Architecture Triennial: After Belonging, After Belonging Agency and KORO Public Art Agency Norway / URO. Photo: Ernie Buts. 
Figure 8: New World Embassy: Rojava.

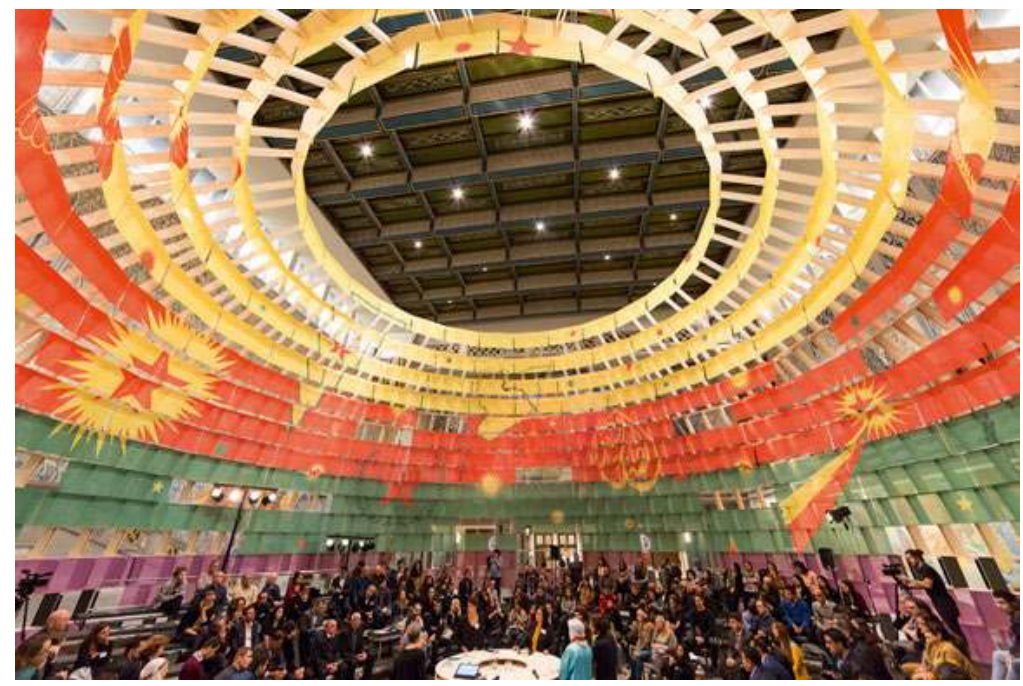

Description: Ambassador Sînam Mohammed (Democratic SelfAdministration of Rojava) debates with Laura Raicovich (Queens Museum, New York), Moussa Ag Assarid (Free Azawad) and Shela Sheikh (Goldsmiths University, London), chaired by Maria Hlavajova (BAK, basis voor actuele kunst, Utrecht) in the New World Embassy: Rojava. Artist: Democratic Self-Administration of Rojava and Studio Jonas Staal, 2016. Commissioned by: Oslo Architecture Triennial: After Belonging, After Belonging Agency and KORO Public Art Agency Norway / URO. Photo: Ernie Buts. 


\title{
A revolution of life
}

\author{
Jonas Staal in conversation with Salih Muslim ${ }^{1}$
}

In your lecture today you made clear that the battle in Rojava is not just about fighting against the Islamic State; it is also a fight for a specific political idea: the model of democratic autonomy. What exactly is this model of democratic autonomy that lies at the heart of the Rojava Revolution?

The reason we are under attack is because of the democratic model we are establishing in our region. Many local forces and governments do not like to see these alternative democratic models being developed in Rojava. They are afraid of our system. We have created, in the middle of the civil war in Syria, three autonomous cantons in the Rojava region that function by democratic rule. Together with the ethnic and religious minorities of the region - Arabs, Turkmen, Assyrians, Armenians, Christians and Kurds - we have written a collective political structure for these autonomous cantons: our Social Contract ${ }^{2}$. We have established a people's council with 101 representatives from all cooperatives, committees, and assemblies running each of our cantons. And we have established a model of copresidency - each political entity always has both a female and a male chair - and a quota of a minimum of forty percent gender representation of each gender, in order to enforce gender equality throughout all forms of public life and political representation. We have, in essence, developed

1 This interview took place after a lecture by Muslim in Amsterdam, on November 10, 2014. It was first published on Tenk.cc.

2 | The Social Contract was republished in Dilar Dirik, Renée In der Maur and Jonas Staal (eds.). Stateless Democracy. Utrecht: BAK, basis voor actuele kunst, 2015. The Social Contract can be found at: https://civiroglu.net/ the-constitution-of-the-rojava-cantons/ 
a democracy without the state. That is a unique alternative in a region plagued by the internally conflicted Free Syrian Army, the Assad regime and the self-proclaimed Islamic State.

Another way of referring to this concept of democratic confederalism, or democratic autonomy, is radical democracy, where people are mobilised to organise themselves and to defend themselves by means of people's armies like the People's Protection Units (YPG) and Women's Protection Units (YPJ). ${ }^{3}$ We are practicing this model of self-rule and self-organisation without the state as we speak. Other people will speak of self-rule in theory, but for us, this search for self-rule is our daily revolution. Women, men, all strands of our society are now organised. The reason why Kobanî still stands is because we have built these structures ${ }^{4}$.

In your lecture, the words "democracy," "freedom," and "humanity" came up very often. Could you explain what you regard as the fundamental difference between capitalist democracy and what you have just described as democratic autonomy?

Everyone knows how capitalist democracy plays for the votes; it is a play of elections. In many places, parliamentary elections are just about propaganda; they only address the direct self-interest of a voter. Democratic autonomy is about the long term. It is about people understanding and exercising their rights. To get society to become politicised is the core of building democratic autonomy. In Europe, you will find a society that is not politicised. Political parties are only about persuasion and individual benefits, not about actual emancipation and politicisation. Real democracy is based on a politicised society. If you go now to Kobanî, and you meet the fighters of the YPG and the YPJ, you will find that they know exactly why they are fighting and what they are fighting for. They are not there

3 | The model of democratic confederalism is explained by Abdullah Öcalan in, among others, Abdullah Öcalan. Democratic Confederalism. London: International Initiative "Freedom for Abdullah Ocalan-Peace in Kurdistan," 2011.

4 | At the time of this interview, the Women's and People's Protection Units (YPJ and YPG) were defending Kobanî against the invasion by IS that started in September 2014. At the end of October, only 20 percent of the city was under the control of the YPJ and YPG, yet in November, they slowly started to gain more terrain. Kobanî was liberated by the YPJ and YPG on January 27, 2015. 
for money or interests. They are there for elementary values, which they practice at the same time. There is no difference between what they do and what they represent.

So how does one politicise a society to that level of political consciousness?

You have to educate - twenty-four hours a day - to learn how to discuss, to learn how to decide collectively. You have to reject the idea that you have to wait for some leader to come and tell the people what to do and instead learn to exercise self-rule as a collective practice. When dealing with daily matters that concern us all, they have to be explained, criticised and shared collectively. From the geopolitics of the region to basic humanitarian values, these matters are discussed communally. There has to be collective education so we know who we are, why we are facing certain enemies and what it is we are fighting for.

In a community that is at war and facing humanitarian crisis, who is the educator?

The peoples themselves educate each other. When you put ten people together and ask them for a solution to a problem or propose to them a question, they collectively look for an answer. I believe, in this way, they will find the right one. This collective discussion will make them politicised.

What you are describing as the heart of democratic autonomy is in essence the model of the assembly.

Yes, we have assemblies, committees; we have every possible structure to exercise self-rule throughout all strands of our society.

What do you consider the conditions for such a democratic experiment to be able to take place?

It is a long-term process. I myself have been involved in this movement for decades, in this fight - I have been in jail; I have been tortured. So the people of my community also know why I do what I do. I am not there to collect money or to benefit personally. At the time, the reason the 
Syrian government captured and tortured me was that I was educating the people. And I am just one person; so many friends have gone through the same. Many have become martyrs as they died as a result of the torture of the regime. Democratic autonomy is not an idea to be realised in one day; it is an approach, a process that takes explaining, education - it is a revolution that takes a lifelong commitment.

There are many students, intellectuals and artists who are looking to Rojava, who are looking to Kobanî, and who recognise that, in a way, the promise of stateless internationalism has found its way back in our time. What do you say to these people who are not in Rojava but who see its revolution as a horizon. What can they do?

Well, go to Kobanî. Meet the people and listen to them, understand how they have brought their political model about. Speak to the YPG, the YPJ, and learn what they are doing - ask them questions, meet their society. In the near future, the conditions will allow you to go, and you can learn about the model of democratic autonomy that was defended in the worst imaginable conditions, with threats to life, with a lack of food and water. Go and speak to the people and you will understand how and why they did it. And what our society looks like as a result of it.

Do you believe that democratic autonomy could be a model enacted on a global level?

I believe that the democratic administration that we have established is one that everyone feels they are sharing in, so yes, that is a model for the world. There were many prejudices about our revolution, but when people from outside visited and sat down with our communities, they started to believe that democratic autonomy was the right thing. We had people joining our revolution even from Damascus. Everyone can come and see for themselves that our revolution is being fought and realised every day. It is a revolution of life, and as such, our struggle is a struggle for humanity. 

Annex 



\section{List of organisations in order of appearance}

European Alternatives is a non-profit organisation that works to promote democracy, equality and culture beyond the nation-state. https://euroalter. com

European Democracy Lab is a Berlin based think-tank working towards a more social, politically equal and democratic European future. http:// www.european-republic.eu/de/

Barcelona en Comú is a citizens platform and political coalition in the city of Barcelona. https://barcelonaencomu.cat

Marea Atlántica is a citizens platform and political coalition in the city of A Coruña. http://mareatlantica.org

P2P Foundation is an organisation with the aim of studying the impact of peer to peer technology and thought on society. https://p2pfoundation.net

Ahora Madrid is a citizens platform and political coalition in the city of Madrid. https://conoce.ahoramadrid.org

Cambiamo Messina dal Basso is a grass roots movements and citizens platform in the city of Messina. http://www.cambiamomessinadalbasso.it

Ne davimo Beograd (Don't let Belgrade d(r)own) is a right-to-the-city initiative in Serbia resisting massive redevelopment plans in the centre of Belgrade as well as government corruption https://www.facebook.com/ nedavimobeograd/ 
Human Rights Institute Bratislava, Slovakia is a NGO fighting for civil liberties and rights in Slovakia and the region http://www.ludskeprava.sk/

openDemocracy is an independent global media platform covering world affairs, ideas and culture which seeks to challenge power and encourage democratic debate across the world. https://www.opendemocracy.net

Krytyka Polityczna is a network of Polish left-wing institutions and intellectuals that works on the fields of social sciences, culture and politics to have an impact against economic and social exclusion. http://krytykapolityczna.pl

Eldiario.es is a member financed Spanish online newspaper founded in 2012. http://www.eldiario.es Abwab is the first Arabic newspaper in Germany launched in 2015. http://
www.abwab.eu

DiEM25 is a pan-European, cross-border movement of democrats that works as an infrastructure to democratise Europe before 2025. https:// diem25.org/home-de/

Syriza is left-wing political party in Greece, founded in 2004

The Commons Network is a civil society initiative and think-tank working on a local, national and European level promoting access to knowledge and other social and ecological causes from the perspective of the commons. http://commonsnetwork.eu

European Commons Assembly is a process that started in in May 2016 gathering diverse commons activists from 21 countries across Europe participating to develop a shared agenda for the commons. https://europeancommonsassembly.eu

Stop TTIP is an alliance of more than 500 European organisations running campaigns and actions against TTIP and CETA. https://stop-ttip.org 
Razem is a left-wing political party in Poland formed in May 2015. http:// partiarazem.pl

Demos is a civic platform formed in Romania that works bringing people together to debate and organise around the values of democracy and solidarity. https://www.facebook.com/Platforma.Demos/

New World Summit is an artistic and political organisation dedicated to providing alternative parliaments to host organisations that currently find themselves excluded from democracy. http://newworldsummit.org

Democratic Union Party Syria (PYD) is a left-wing Kurdish political party established in 2003 by Kurdish activists in northern Syria. It is the leading political party in the Federation of Northern Syria - Rojava and its cantons. http://pydrojava.com 


\section{List of contributors}

Renato Accorinti is the Mayor of Messina.

Ramy Al-Asheq is a poet, writer and journalist from Syria, Palestine. He is the editor in chief of Abwab

Esther Alonso is the Marketing and Development Director at the Spanish online newspaper eldiario.es

Victoria Anderica is Head of Transparency in the City Council of Madrid

Miguel Arana is Director of Citizen Participation in the City Council of Madrid

Renata Avila is an international human rights lawyer and a scholar on surveillance and digital rights

Etienne Balibar is a philosopher and a Distinguished Professor of French \& Italian and Comparative Literature at the University of California, Irvine. He is member of the Advisory Board of European Alternatives

Oana Băluță and Camil Pârvu are members of the new Initiative Group Demos in Romania

Sophie Bloemen is a policy advisor based in Berlin and co-founder of Commons Network

Daphne Büllesbach is Director of European Alternatives and coordinator of Transeuropa Festival 
Giuseppe Caccia is a scholar in History of Political Thought and member of the Board of European Alternatives

Marta Cillero is responsible for Communications at European Alternatives

Claudia Delso is Councillor for Participation and Democratic Innovation in the city of A Coruña

Jakub Dymek is a journalist and analyst of Krytyka Polityczna, Poland

Pia Eberhardt is the spokesperson of the anti-TTIP movement

Laia Forné is Responsible for Active Democracy and Decentralisation in the city of Barcelona

Ulrike Guérot is a political thinker, Founder and Director of the European Democracy Lab. She is professor for European Studies at DonauUniversity Krems, Austria and member of the Advisory Board of European Alternatives

Sheruan Hassan is a member of the Kurdish Democratic Union Party (PYD)

Andreas Karitzis is a former SYRIZA member and former member of its Central Committee and Political Secretariat

Alena Krempaska is Programme Director Inštitút liudských práv - Human Rights Institute Bratislava

Luigi de Magistris is the Mayor of Naples

Robin Mansell is Professor of New Media and the Internet and Head of the Department of Media and Communications at the London

Lorenzo Marsili is the co-founder of European Alternatives. He was founding editor of Naked Punch Magazine

Salih Muslim is Co-Chair of the Kurdish Democratic Union Party (PYD) 
Dieter Plehwe is a senior Research Fellow at the Berlin Social Science Center (WZB)

Adam Ramsay is Co-Editor of openDemocracyUK

Jan Rohgalf is post-doc Researcher at the University of Rostock, Germany

Gesine Schwan is Political Science Professor, a member of the Social Democratic Party of Germany and former presidential candidate

Barbara Spinelli is an author, journalist, and Member of the European Parliament for the GUE/NGL group

Jonas Staal is a visual artist and scholar. He established the artistic and political organisation New World Summit in 2012

Lukas Stolz is a special projects collaborator at European Alternatives

Stacco Troncoso is is the strategic direction steward of the P2P Foundation

Dobrica Veselnovic and Ksenija Radovanović are activists from the $\mathrm{Ne}$ davimo Beograde initiative, Belgrade

Peter Weisenbacher is Executive Director Inštitút l'udských práv - Human Rights Institute Bratislava

Marcelina Zawisza and Maciej Konieczny are members of the Polish political party Razem 


\section{Social Sciences and Cultural Studies}

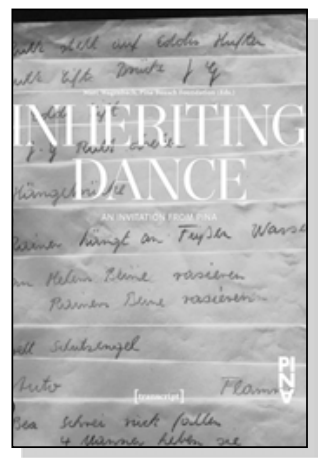

Marc Wagenbach, Pina Bausch Foundation (eds.) Inheriting Dance

An Invitation from Pina

2014, 192 p., 29,99 € (DE),

ISBN 978-3-8376-2785-5

E-Book: $26,99 €(\mathrm{DE})$, ISBN 978-3-8394-2785-9

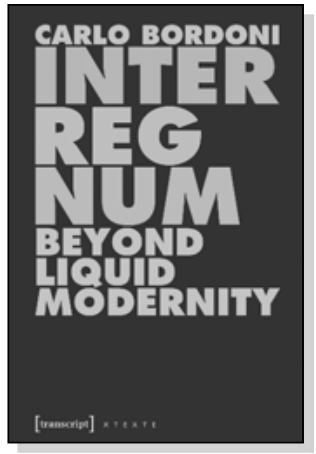

Carlo Bordoni

\section{Interregnum}

Beyond Liquid Modernity

2016, 136 p., 19,99 $€(\mathrm{DE})$,

ISBN 978-3-8376-3515-7

E-Book: $17,99 €(\mathrm{DE})$, ISBN 978-3-8394-3515-1

EPUB: $17,99 €(\mathrm{DE})$, ISBN 978-3-8394-3515-1

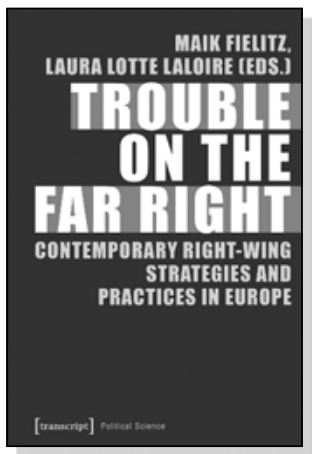

Maik Fielitz, Laura Lotte Laloire (eds.)

Trouble on the Far Right

Contemporary Right-Wing Strategies

and Practices in Europe

2016, 208 p., 19,99€ (DE),

ISBN 978-3-8376-3720-5

E-Book: $17,99 €(D E)$, ISBN 978-3-8394-3720-9

EPUB: $17,99 €(D E)$, ISBN 978-3-3728-3720-9

All print, e-book and open access versions of the titels in our entire list are available in our online shop www.transcript-verlag.de/en! 


\section{Social Sciences and Cultural Studies}
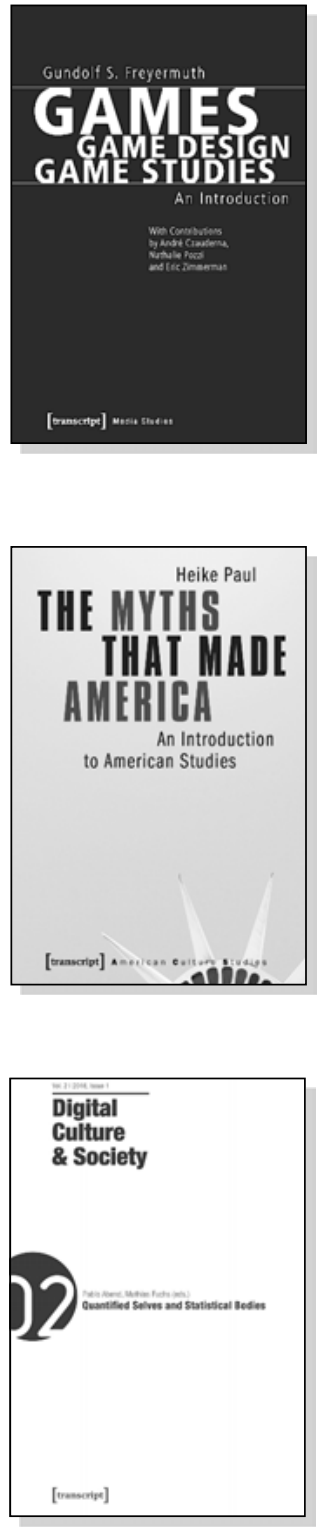

Gundolf S. Freyermuth

Games | Game Design | Game Studies

An Introduction

(With Contributions by André Czauderna,

Nathalie Pozzi and Eric Zimmerman)

2015, 296 p., 19,99€ (DE),

ISBN 978-3-8376-2983-5

E-Book: $17,99 €(D E)$, ISBN 978-3-8394-2983-9

\section{Heike Paul}

The Myths That Made America

An Introduction to American Studies

2014, 456 p., 24,99€ (DE),

ISBN 978-3-8376-1485-5

available as free open access publication

E-Book: ISBN 978-3-8394-1485-9

Pablo Abend, Mathias Fuchs, Ramón Reichert, Annika Richterich, Karin Wenz (eds.)

Digital Culture \& Society

Vol. 2, Issue 1/2016 -

Quantified Selves and Statistical Bodies

2016, 196 p., 29,99€ (DE),

ISBN 978-3-8376-3210-1

E-Book: 29,99€ (DE), ISBN 978-3-8394-3210-5

All print, e-book and open access versions of the titels in our entire list are available in our online shop www.transcript-verlag.de/en! 